\title{
Professional Development School Support of the Elementary GLOBE Curriculum A Facilitated Adaptation of Inquiry Science
}

Vance D. High

West Virginia University

Follow this and additional works at: https://researchrepository.wvu.edu/etd

\section{Recommended Citation}

High, Vance D., "Professional Development School Support of the Elementary GLOBE Curriculum A Facilitated Adaptation of Inquiry Science" (2012). Graduate Theses, Dissertations, and Problem Reports. 3586.

https://researchrepository.wvu.edu/etd/3586

This Dissertation is protected by copyright and/or related rights. It has been brought to you by the The Research Repository @ WVU with permission from the rights-holder(s). You are free to use this Dissertation in any way that is permitted by the copyright and related rights legislation that applies to your use. For other uses you must obtain permission from the rights-holder(s) directly, unless additional rights are indicated by a Creative Commons license in the record and/ or on the work itself. This Dissertation has been accepted for inclusion in WVU Graduate Theses, Dissertations, and Problem Reports collection by an authorized administrator of The Research Repository @ WVU.

For more information, please contact researchrepository@mail.wvu.edu. 
Professional Development School Support of the Elementary GLOBE Curriculum A Facilitated Adaptation of Inquiry Science

\author{
Vance D. High \\ Dissertation Submitted to the \\ College of Human Resources and Education \\ at West Virginia University \\ in partial fulfillment of the requirements \\ for the degree of
}

Doctor of Education in

Curriculum and Instruction

James Rye, Ph.D., Chair

Patricia Obenauf, Ed.D.

Joy Faini Saab, Ed.D.

Jeffrey Carver, Ed.D.

Sebastian R. Diaz, Ph.D.

College of Human Resources and Education

Morgantown, West Virginia

2012

Keywords: Integration, Barriers, Science Inquiry, Elementary Education, Collaboration, Earth System Science

Copyright 2012 Vance D. High 


\section{DEDICATION}

This dissertation evolved from the inspiration of former students, friends, and faculty, especially James Rye and Constinia Charbonnette. Jim provided unwavering support with unlimited coffee to spur ideas. From my students, I thank the following: Laura, Sherri, Jeff, Elizabeth, Alyssa, Terry, Robert, and Alex. The latter was of exceptional talent who would lose his life to falling between the cracks and needs beyond the support that a school system could provide. I wish that he had sought me out. Special dedication is given to my pillow (枕頭), and my former dear furry friends, Strider and Sterling. Strider enjoyed sitting on the lectern and visiting students to cheer up an otherwise melancholy young face, which he succeeded in doing innumerous times. Lastly, I wish to dedicate this effort to the time that my parents, Luther and Velma High, provided in the way of a safe and loving home, which encouraged taking risks and a love of reading. Book 1, line 203 of Virgil's Aeneid, is Haec olim meminisse invabit - roughly translated, "In the future it will be pleasing to remember these things.” I am pleased with the thought of memories of the things included within this body of work and the inspiration of those who filled my sails with wind and friends like Arian whose humor lifted the tedious endeavor of editing the final draft. Also, I am indebted to Connie for her stalwart assistance. 


\section{ACKNOWLEDGEMENTS}

I wish to acknowledge the support of the West Virginia University College of Education and Human Resources for support in completing this effort to further science education in the elementary grades. The college's support was unequivocal in promoting the objective of opening doors for young learners and tackling the many issues facing the students living in the $21^{\text {st }}$ Century, paramount among these concerns are the challenges of Global Climate Change.

This research could not have succeeded without the enthusiastic support of the participating teachers who contributed their efforts in addressing the research questions which eventually amounted to a year and half of data collected in a most gracious and supportive environment. Of special note, I wish to acknowledge the exceptional cooperation of North and Suncrest Elementary Schools. Visiting these schools was a simple matter without undue barriers. This allowed for collecting data in a timely and productive fashion.

I wish to pay special tribute to those who served unselfishly on my dissertation committee. Your special support on keeping me on task is hereby highlighted; nonetheless, it seems abysmally miniscule to make just an acknowledgement in just how big a role that the each of you provided. James Rye provided the glue to keep the research moving. It is fitting in this time where there is actual evidence for the Higg's Boson (the God particle) that Jim was the glue to hold the effort together. The Higg's Boson is theoretically why all matter sticks together as part of the standard model in physics. 


\title{
Professional Development School Support of the Elementary GLOBE Curriculum \\ A Facilitated Adaptation of Inquiry Science
}

\begin{abstract}
This qualitative study focused on identifying barriers and remedies to those barriers found when teaching elementary school science. The Elementary GLOBE Program (2006) was the curriculum selected when doing the 18 month study. The researcher asked what made Elementary GLOBE (EG) easy and/or difficult to use. The researcher also wished to ascertain what impact did the adoption of EG have on the delivery of science instruction in the K-4 grade classrooms participating in this study. Two professional developments schools (PDS), located in a Mid Atlantic state were the sites for the study. Both schools are in an urban setting and affiliated with a nearby land grant university.

The main purpose of this study was to investigate how elementary teachers integrate inquiry-based science in their classrooms. This was accomplished by providing an inservice workshop on an elementary science curriculum (EG) to six teachers. Then teachers were observed instructing with the newly learned curriculum. During the course of the study, teachers kept journals about their experiences teaching science. Later, they gave interviews about their classroom and school environments while teaching science.

To ascertain trustworthiness, a member check in the form of a questionnaire was given to the participating teachers to determine the reliability of the findings at the conclusion of the study. Seven out of seven teachers agreed that EG changed the way their students experienced science. Five out of seven participants felt EG increased their confidence to teach science. Time management was identified as the major barrier to teaching science with six out seven teachers
\end{abstract}


agreeing with this finding. Although accommodation was identified as a barrier, four out of seven agreed to this finding even though there was a high prevalence of diversity in the studied schools and EG was not presented in the any language other than English. Five of the seven participants preferred teaching science with EG over the approved textbook used by the schools. There is a dearth of primary level earth system science materials, so the findings from this study provide evidence for an engaging curriculum promoting science and literacy. 


\section{TABLE OF CONTENTS}

$\begin{array}{llll}\text { Page } & \text { Pas }\end{array}$

Chapter 1 Introduction..................................................................... 1

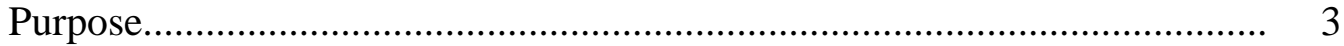

Significance of Study........................................................................... 4

Theoretical Foundations.......................................................................... 4

Problem Statement (background) ..................................................... 7

Research Questions........................................................................... 9

Limitations of Research....................................................................... 10

Chapter 2 Literature Review....................................................................... 13

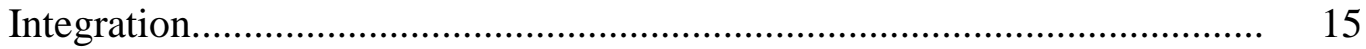

Elementary Science Teaching Barriers.......................................................... 23

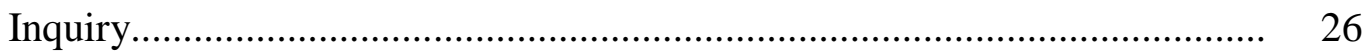

Chapter 3 Methodology ........................................................................ 36

Review of Purpose............................................................................. 36

Research Questions.............................................................................. 37

Rationale for Research Questions......................................................... 37

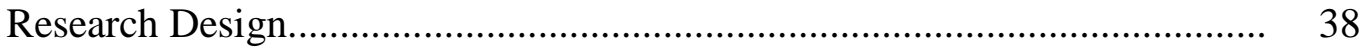

Data Collection......................................................................................... 41

Sequence of Data Collection ............................................................ 41

Figure 3.1 Research Design Timeline .................................................. 42

Figure 3.2 Participant Profiles..................................................................... 43

Observations.................................................................................... 43

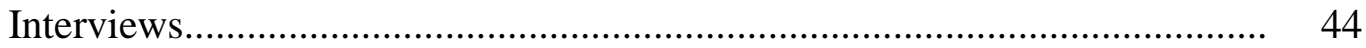

Development of Interview Questions...................................................... 45 
Participant Journals............................................................................. 45

Artifacts of Student Work..................................................................... 46

Analysis of Qualitative Data.............................................................. 46

Summary analysis of Data................................................................ 47

Classroom Observations........................................................................ 49

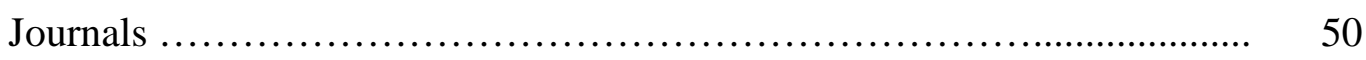

Sequence of Analysis Followed......................................................... 51

Member Check............................................................................... 51

Chapter 4 Findings and Discussion................................................... 54

Review of Rationale for Research Questions......................................... 54

Review of Data Collection and Analysis................................................ 55

Participant Involvement and Attrition................................................. 57

Organizations of Findings................................................................ 58

Research Question One...................................................................... 58

Table 1-Barrier Categories Found in Science Teaching
From the Majority of Interviews RQ1... 59

Classroom Observations.................................................................... 66

Table 2- Barrier Categories Found in the Classroom Observations.................. 67

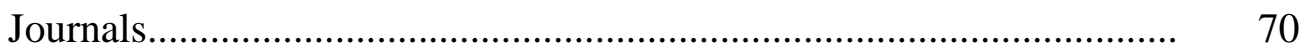

Table 3- Barrier Categories Found in the Teachers' Journals RQ1.................. 71

Change Over Time RQ1................................................................... 72

Triangulation Data from Observation, Journals, Interviews, and Artifacts RQ1 72

Research Question Two....................................................................... 73

Interviews......................................................................... $\quad 74$

Table 4-Impact on Barrier Categories Found in Interviews for RQ2 ................ 75 
Classroom Observations..................................................................... 93

Table 5-Impact on Barrier Categories Found in the Classroom Observations ... 94

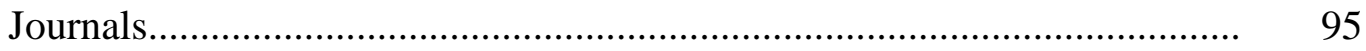

Table 6-Impact on Barrier Categories Found in the Teachers’ Journals........... 96

Change over Time for RQ2

Triangulation of Data from Observations, Journals, Interviews, and Student Artifacts for RQ2 ............... 100

Research Question Three.............................................................................. 100

Table 7-Factors/conditions Categories Found in Interviews for RQ3................ 101

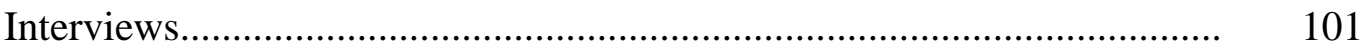

Classroom Observations............................................................................... 109

Table 8-Factors Found in the Classroom

Observations Making EG Difficult/easy to Use.............. 109

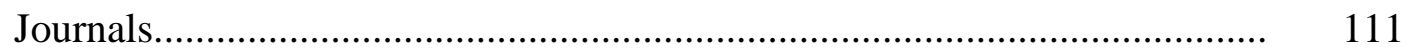

Table 9-Factors Found in the Teacher Journals Making EG Difficult/easy to Use.. 112

Change over Time for RQ3................................................................... 113

Triangulation of Data from Observations Journals, Interviews, and Student Artifacts for RQ3....................... 115

Research Question Four ............................................................................. 117

Interview .......................................................................... 117

Table 10-Impact and Delivery Categories Found in Interviews for RQ4............ 118

Classroom Observations............................................................................. 129

Table 11-Factors Found in the Classroom Observations on Delivery and Approach.......... 129

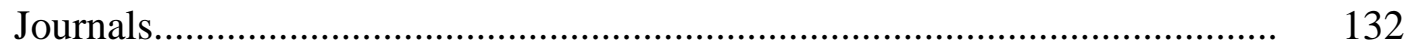

Table 12-Factors Found in Teachers' Journals on Delivery and Approach........ 132 
Triangulation of Data from Observations Journals, Interviews,

Research Question 5

Table 13-EG Influence on the School's Function/Capability as a Professional Development School within WVU PK20 Collaborative.

Interviews.

Classroom Observations

Table 14-Factors Affecting Function/capability as a Professional Development School within WVU PK20 Collaborative From Observations.

Journals

Table 15-Factors Found Journals Affecting Function/Capability of Teaching in PDS w/in PK20.. 148

Change over Time for RQ5.

Triangulation of Data from Observations Journals, Interviews, and Student Artifacts for RQ5... 152

Member Check.

153

Table 16-Member check.

Chapter 5 Summary

157

Conclusions.

Implications of Practice.

Recommendations for Research.

References...

Appendix A-Interview Script

185

Appendix B- Questions for Interview \# 1........................................... 186

Appendix C- Questions for Interview \# 2.......................................... 187 
Appendix D- Questions for Interview \# 3............................................. 188

Appendix E- Recruitment Letter for Member Check...................................... 189

Appendix F- Participant Follow-up Questionnaire for Member Check............... 190

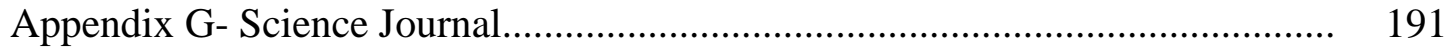

Appendix H- Teacher Artifact, Park used by Jane Doe Students........................ 192

Appendix I- Teacher Artifact, Jane Doe Playground........................................ 193

Appendix J- Teacher Artifact, Jack \& Jill Green Space................................... 194

Appendix K- Teacher Artifact, Jack \& Jill Playground.................................... 195

Appendix L- Student Artifact- Cloud System Displayed in Hall......................... 196

Appendix M- Student Artifacts-Three Cloud Systems Displayed in Hall............ 197

Appendix N- Soil Treasure Hunt Student Activity Sheet 2.............................. 198

Appendix O- Student Artifact, the Color of the Seasons................................... 199

Appendix P- Student Artifact- Measure up Activity Sheet 1............................ 200

Appendix Q- Student Artifact- Measure up Activity Sheet 2........................... 201

Appendix R- Student Artifact- Getting to Know Soil Activity Sheet 2............... 202

Appendix S- Student Artifact- Honing in on Hummingbirds............................ 203

Appendix T- Student Artifact- All Year Long Student Activities Sheet 2........... 204

Appendix U- Student Artifact- All Year long Student activities sheet 3................. 205

Appendix V- Student Artifact Hummingbird Cutout......................................... 206

Appendix W- Example of Teacher Interview............................................... 207

Appendix X- Coding Used for RQ1-RQ5, Journals, and Observations............... 210

Appendix Y- Initial Codes Used in Classroom Observations.............................. 233 


\section{LIST OF TABLES}

Table 1-Barrier Categories Found in Science Teaching from the Majority of Interviews for RQ1....... 59

Table 2- Barrier Categories Found in the Teachers' Journals............................. 67

Table 3- Barrier Categories Found in the Classroom Observations..................... 71

Table 4- Impact on Barrier Categories Found in Interviews for RQ2 ................. 75

Table 5- Impact on Barrier Categories Found in the Classroom Observations...... 94

Table 6- Impact on Barrier Categories Found in the Teachers’ Journals.............. 96

Table 7- Factors/conditions Categories found in Interviews for RQ3................. 101

Table 8- Factors Found in the Classroom Observations Making EG difficult/easy to Use...... 109

Table 9- Factors Found in Teacher Journals making EG difficult/easy to Use...... 112

Table 10- Impact and Delivery Categories Found in Interviews for RQ4............ 118

Table 11- Factors Found in the Classroom Observations on Delivery and Approach.. 129

Table 12- Factors Found in teachers’ Journals on Delivery and Approach........... 132

Table 13- EG Influence on the School's function/capability as a Professional Development School within WVU PK20 Collaborative.... 136

Table 14- Factors affecting function/capability as a Professional Development School within WVU PK20 Collaborative... 145

Table 15- Factors Found in Journals Affecting Function/capability of Teaching in PDS w/in PK20.... 148

Table 16- Member Check findings.............................................................. 154

\section{LIST OF FIGURES}

Figure 3.1 Research Design Timeline.

Figure 3.2 Participant Profiles. 


\section{CHAPTER ONE}

\section{Introduction}

At both a personal and societal level, science is significant in contemporary life (Osborne, Simon, \& Collins, 2003). Unfortunately, research has indicated that the general population holds negative views of science (Osborne, Simon, \& Collins, 2003). This negative perception often begins to develop at an early age and by $7^{\text {th }}$ grade, $70 \%$ of Americans are turned off by science (Fisher, 1997). One way to generate positive feelings toward science is to create lessons in which children enjoy being active participants. Attempting to make inquiry-based science enjoyable, curriculum developers created The Elementary Global Learning and Observations to Benefit the Environment program (GLOBE, 2006). This was followed with the more recent, Picture-Perfect Science Lessons (2010). Having motivated students pursue activities through self-cognizance should be a goal for educators (Hidi \& Harackiewicz, 2000).

The ease of implementing curriculum should make using it as seamless as possible. This promotes the learning objectives, and builds self-esteem both for students and educators alike. Science curriculum projects of the 60's used materials such as lab blocks, films and filmstrips, and other media. In the 90s advances in technology and real world application were prevalent (Blosser, 1990). Teacher involvement permeates throughout the inquiry processes incorporated in Elementary GLOBE (EG), so its use becomes a learning experience for all the participants no matter what age. The elementary school years offer many opportunities for teaching science to young minds. Success in the primary grades often determines how students later perceive science (Novak, 1997). These early school years are crucial for nurturing a child's sense of curiosity of the world. The development of the EG (GLOBE, 2006) curriculum provided the investigator a venue for exploring the barriers faced in encouraging curiosity, inquiry, and teaching science in 
the kindergarten to fourth grade classrooms. Lessons fostered at this age guide and build foundations for later learning, so scaffolding extends the transfer of knowledge (Smith, Wise, Anderson, Krajick, \& Coppola, 2004). Developing a foundation of inquiry, in science and other endeavors, leads to many other opportunities, not only in school, but in life and its many venues for exploration. This thinking is based on an increased understanding of how students learn and on instructional approaches incorporated to build on the ideas that learners construct knowledge based on their observations and experiences (Blosser, 1990).

Since 2001, the amount of time spent on science in the K-6 classroom has declined by an average of 33\% nationally (California Council, 2010). One California study found even lower totals, with only $50 \%$ of teachers spending at least an hour a week, and $16 \%$ using no time on science (California Council, 2010). "Time” has been identified as a major factor influencing the planning of lessons for students in the elementary classroom (CEP, 2008). It would seem contradictory to emphasize foundations for math and language arts without including science instruction in the lower grades, but elementary science is often deemphasized in many school district curriculums (Vasquez, 2005) even though learning science and language has been found to be reciprocal (Ackerson, 2001). Math and language arts receive the lion's share of resource priorities.

The EG curriculum was designed realizing this limitation (Henderson, Hatheway, Gardiner, \& Zarlengo, 2006). The curriculum includes many opportunities for literacy and math development by keeping journals, writing poems, drawing and writing observations. EG provides learning activities that are "kid friendly" and incentivized for use specifically by the K-2 student (Henderson et al., 2006; High \& Rye, 2011). 
Students in the grades K-2 vary in cognitive abilities, so EG includes a section called "Adaptations for Younger and Older Students," to give the teacher a useful range of activities for application (Henderson et al., 2006). The GLOBE Kids provide written adventures for the K-2 students, where they can empower young children to imitate scientists. These characters are found in five modules, each with an environmental theme, encouraging students to question, make observations, and conduct scientific research.

Investigations occur in children's lives on a daily basis, so focusing them can add to discovery of learning for the basis of science concepts and thoughts. Sadly, this does not appear to be the case due to time restraints created by preparations for national assessments. There is an alternative to this scenario. This alternative is the subject of this investigation and hence offers enough information for a doctoral dissertation to be covered in breadth over the ensuing pages. The use of curriculum tailored for the early grade school years provided an opportunity to investigate the K-4 primary school teaching environment.

\section{Purpose}

It was the purpose of this study to investigate how elementary teachers integrate inquiry science in their classrooms. This was accomplished by providing an inservice workshop on an elementary science curriculum (EG) to teachers. The teachers were then observed instructing with the newly learned curriculum. During the course of the study, teachers kept journals about their experiences teaching science. Later, they gave interviews about their classroom and school environments while teaching science. 


\section{Significance of the Study}

The findings of this study have the potential to validate and promote the expanded use of EG to teach inquiry-based science in the lower grades. Given the reduced time for instruction, this is highly significant, as EG includes lessons that integrate language arts, math, and social studies. It promotes the sharing of knowledge on a global venue. This is especially important when science attempts to address issues on large scale, and this begins with informed citizenry asking questions learned while attending school. EG teaches lessons where collaborative learning is emphasized and utilized in the classroom. In this way, learning acquires a community awareness and insight incorporating student opinions and decisions facilitated by the teacher. Bruner found: "Intellectual development depends upon a systematic and contingent interaction between a tutor and a learner” (Brunner, 1974, p. 6). By using storybooks, EG provides a system to learn inquiry based science in the early grades, where the students have fun and are excited about their investigations.

\section{Theoretical Foundations}

This research targets the identification of barriers when teaching elementary school science. Once noted, ways to overcome these barriers are suggested based on the study's findings. In this qualitative study, the investigator interviewed participants using open ended questions, observed the participants' teaching, and examined journals. He also examined student artifacts as were relevant. Phenomenological analysis attempts to elucidate the meaning of lived experience by thematic interpretation of materials, which are listed in the preceding sentence. "In short, in real-world practice, methods can be separated from epistemology out which they emerged" (Patton, 2002, p.136). 
The naturalistic paradigm is relevant to this study as the researcher was the interviewer and principal accouterment in this study (Pidgeon, Turner, \& Blockley, 1991). The researcher was the "lens" through which the data was collected and interpreted (Erlandson, Harris, Skipper, \& Allen, 1993), which needs to be considered when doing the analysis and weighed as a confounding variable when examining the conclusion(s) for validity. The researcher attempted to minimize this whenever possible.

EG is inquiry-based in format and meets the inquiry criteria found in the national standards (NRC, 1996). These include the abilities to do "scientific inquiry, employ simple equipment for gathering data, using the data to construct explanations, and communication of explanations” (NRC, 1996, pp. 122-123). Scientific inquiry in the K-4 grades extends beyond regular process skills so as to incorporate knowledge using critical reasoning (NRC, 2000). The five essential features of inquiry are 1) questions, 2) evidence, 3) explanations, 4) connections, and 5) communication. They provide an outline to move through all stages of scientific reasoning while doing an EG investigation (NRC, 2000).

Studies have shown that elementary students grasp the meaning of variables and testing vis-a-vis hypothesis (Lin, Chien, \& Thier, 1977). Ten to twelve year old students perform experiments from written directions and using scientific apparatus to learn about variables. Lin et al., (1977) showed that children clearly fall within the expectations of Piaget (1971) and Bruner (1974). However, recent research has disproved Piagetian tenets on the metacognition limitations of young children (Vygotsky, 1997; Keen, 2003). Elementary students enjoy working in a free choice environment supplemented with supervision and written direction. EG provides opportunities for free choice. This instruction requires teachers to function as facilitators. 
While the instruction is very basic, it does require teachers to develop an understanding of inquiry-based pedagogy. Rye (1997) did that with his development of a math-science, integrated approach to secondary science instruction using grapes to learn about experimental design through density investigations. This lesson has been adapted and used extensively in a learning cycle format for elementary preservice teacher preparation. It can be scaled down and modified to introduce elementary students to density of matter.

In an earlier attempt, Renner, Stafford, Coffia, Kellogg, and Weber (1973) addressed the need of inquiry-based science in elementary school with the Science Curriculum Improvement Study (SCIS) curriculum. Renner et al., (1973) found that first graders had greater gains in reasoning skills, as measured by Piagetian conservation tasks, than first graders using a textbook. Although SCIS proved effective in teaching process skill, the curriculum required extensive management of resources to be used effectively and faded from use, even with a high national saturation (Kratochvil \& Crawford, 1971). Additionally, SCIS required the teacher to go beyond their traditional role and was more adapted to those with a science major or graduate degree (Kratochvil \& Crawford, 1971; Renner et al., 1973).

Due to the present dearth of primary school (K-2) science curricula, curriculum developers created a more simplified inquiry-based pedagogy. It originated through NASA and the University of Colorado (GLOBE, 2006). The program uses storybooks to teach lessons involving the seasons, soil, clouds, water, and earth as a system. This is categorized as Earth System Science (ESS), and it identified an area needing applicable curriculum development given Global Climate Change (Henderson et al., 2006). These storybooks emphasize science process skills through activities where the characters (GLOBE Kids) lead investigations from the 
storybooks, and students follow along as active participants, mirroring the investigations of the GLOBE Kids as they posit questions and seek answers.

\section{Problem Statement}

State standards often fail to fully address the preparation of elementary teachers in science (Bolyard \& Moyer-Packerham, 2008). Thus, there is a need to address the continued preparation of elementary teachers to improve and enhance their confidence to teach science. Science teacher education for elementary teachers presents challenges for science educators (Carrier, 2009). Studies have found that teachers do not think they have the knowledge to teach environmental sciences (Smith-Sebasto \& Smith, 1997).

This was evident in the need for teacher training when using the Science Curriculum Improvement Study (Kratochvil \& Crawford, 71) for educators to learn to assist students explore. Bethel (1982) reported that in-service training was one way to help improve the quality of U.S. education, especially elementary science teaching. Rubio, Barley, and Jenness (1993) found that teachers increased their science knowledge $54 \%$ by using kits to teach science, but the research failed to address elementary teachers. Bethel (1982) reported teachers using kits showed the time allotted to elementary science in classes went to 100 minutes per school week in a Texas study. In-service training is an effective way to address the needs of teachers especially when addressing content area when $68 \%$ of teachers in one study felt inadequate teaching science (Bethel, 1982). According to Darling-Hammond et al., (2009), teachers identify their top priorities for further professional development as learning more about the content they teach (23\%), followed by classroom management (18\%), and teaching students with special needs (15\%). 
With the continued restraints on teaching time, curriculum must be tailored to available time and still cover $21^{\text {st }}$ Century Learning Objectives especially those relevant to science like critical thinking. Today, students need to address global climate change, famine, the world's population explosion, and the interconnectedness of environmental issues. These issues project a need for students to be able to create change personally, socially, economically and politically on all levels.

This makes teaching inquiry science pervasive though specific use of process skills in early childhood aged children (Gallenstein, 2005). This is very important when considering that first and second grade instruction sets the ground work for later success in school (Novak, 1997). The development of learning to do inquiry-based science builds a foundation for learning to ask questions in other courses. The art of teaching inquiry begins when a child asks the proverbial "why" to satisfy their curiosity. Learning to focus this curiosity is the directive in early science education. Limited time in elementary school often pervades the decision to nurture inquiry-based science, and curriculum often becomes the ease of last resort (e.g. doing handouts).

Edwards (1997) and the National Science Teachers Association (1998) promoted engaging students in the application of thinking skills for inquiry-based instruction. The process of inquiry allows for exploration by student and teacher. When connected, the science content and process skills (e.g. observing, classifying, measuring, predicting, inferring, and experimenting), show meaningful student understanding (Llewellyn, 2002). The teacher becomes the facilitator guiding students in developing context, for solving problems as meaningful experiences relate to the real world. This builds on connections made between experiences permitting the linkage of knowledge, skills, and attitudes from one context to the next. 
This study examined the barriers that teachers encountered with a recently learned curriculum. EG was developed to specifically include inquiry lessons. It offers an integrated approach covering many areas of instruction especially geology, weather, hydrology, and social studies. It also provides a methodology for teaching students with special needs, different ages, and cultures (GLOBE, 2006). Because time has been identified as limited, the developers designed it to be used with minimum effort. Rowan, Correnti, and Miller (2002) suggests relevant causal agents produce student learning by how teachers use instructional time. The EG curriculum scripts in time allotment for activities, so these science investigations have supporting research for the methodology and time planned for instruction. It offers kid friendly story books for implementation of inquiry activities for K-4. The science content covered in EG provides an introduction to GLOBE's scientific protocols. Therefore, it produces a springboard to technology and basic methods of inquiry (NRC, 2000). The curriculum designers wished to introduce young learners to thinking of Earth as an interactive system in the amalgam of learning basic investigative skills (Henderson et al., 2006). The study of Earth cannot be understood in isolation, but as an interconnected system (Barstow \& Geary, 2002; NASA, 2004). EG promotes the understanding of this interconnectivity through lessons designed for students in grades K-4 and taught in a manner to address investigations in a collaborative atmosphere of teamwork.

\section{Research Questions}

The researcher developed five research questions to guide this study. These questions facilitated the investigation and derivation of categories and themes salient to the purpose. These research questions (RQ) are listed as follows:

RQ1: What kinds of barriers do the teachers encounter when teaching science in elementary school? 
RQ2: What impact if any, has the use of Elementary GLOBE had on these barriers?

RQ3: What actions/conditions made Elementary GLOBE difficult for the teachers to use and what factors/conditions made Elementary GLOBE easy for them to use?

RQ4: How has the adoption of Elementary GLOBE impacted the teachers, including their approach to and delivery of science instruction?

RQ5: How has the adoption of Elementary GLOBE influenced the school's function/capability as a Professional Development School within the WVU PK 20 Collaborative?

The ease of implementing curriculum should make using it as seamless as possible. This promotes the learning objectives, and builds self-esteem both for students and educators alike. Teacher involvement permeates throughout the inquiry processes incorporated in EG, so its use becomes a learning experience for all the participants no matter what age. As the author of this paper can attest, the observed elementary students enthusiastically engaged the five EG modules which addressed the interrelated subjects of weather, hydrology, phenology, and soils (ESS). This is a manuscript written as a dissertation, but ultimately, it is a collection of vignettes of six elementary teachers, and their travails encountered when introducing inquiry science with a new curriculum. A seventh teacher, and one with the most experience, had used EG for one year before participating in the study. His case is one used for comparative analysis and will be discussed further in findings and conclusions sections.

\section{Limitations of Research}

The study population recruited for this investigation consists of seven teachers, so any conclusions derived from the analysis of the collected data may not be applicable to other populations of teachers. Though effort was done to recruit teachers who had not used the EG curriculum, that was not entirely possible in one case with a new teacher, who had limited exposure to EG in a methods class while completing her master's degree. Nonetheless, the group 
of teachers serving as the non-experienced for study provided phenomena for the interested questions (RQ1 - RQ5). Phenomenological analysis seeks to provide insight into the meaning, structure, and lived experience of studied group of people (Patton, 2002).

The research questions may not have reflected the purpose that they were derived to answer, even though triangulation and review of results by participants attempted to assess the trustworthiness of the findings. While reducing the data for summarizing into categories and themes, the researcher may unconsciously have overlooked a meaning, even though there is an attempt to "horizontalize" and spread out the data (Patton, 2002, p.486). In this manner, all the elements should be given equal weight, but being a human endeavor, personalities, emotions, and even health could implicate a change in guidance for an effect. Phenomenological analysis attempts to contain the "bones" of the experience for a group of people being studied "in a way of understanding how researchers as a group experience what they experience” (Moustakas, 1994, p. 142).

Since this study deals with the interpretation of experience examined through observations, journals, interviews, and teaching artifacts, it is subjective in nature. It is a collection of experiences refined to give meaning to for ultimately "a refinement of all these results for oneself” (Craig, 1978, p. 52). Therefore, one limitation is the interpretation of the researcher's personal lens and bias he brings to the investigation.

The researcher had to enter classrooms and follow students to outside green space, so the students knew he was someone other than a parent or student intern. This may have affected their normal behavior. There was one instance while he was observing Alicia’s students doing an investigation in the back of Jack and Jill Elementary, where he stood at the periphery and took notes discretely, but then the wind blew at a higher velocity (gusted). The teacher was trying to 
keep the students on-task as they were attempting to complete the Zoomed in View activity, but they started to lose their papers to the wind gusts (Alicia observation, 10/12/10. The researcher walked up to the seated students and procured a fist sized rock, which he handed to a boy to place on top of his papers, so they would not blow away. When the other students witnessed this act, several of them wanted their own rock to keep their papers from blowing away. The researcher's presence obviously altered the male student's and other students' behaviors in the outdoor classroom setting. In the same observation, the students observed the remains of tent caterpillar nests, which they thought were spiders’ webs.

While the students returned to class, the researcher broke off a branch with the caterpillar nest remains and brought with when returning to the classroom. As it was near the end of instruction, he showed it to the teacher, explaining what it was. She asked him to explain to the class that it was not a spider web but the remains of a caterpillar nest that many of them had drawn in their EG activity sheets. This altered the observer-participant relationship in this particular class in two instances. 


\section{CHAPTER TWO}

\section{Literature Review}

The major areas covered by this literature review are curriculum integration, barriers to elementary science teaching, and inquiry. Integration of curriculum had long been identified as way to make instruction more inclusive and applicable to society’s needs and even more so in the elementary grades where language arts and math are core subjects. Since childhood obesity is a major concern in public education as it impacts student performance and causes diabetes, it was included in the review because it is easily integrated into instruction of science and math using pedometers and calculating calories burned through exercise. Science, Technology, and Sociology (STS) deals with the interrelationship of three areas in an understanding of the relationship in an effort to bring attention to the whole problem without emphasis on a specific area, in hopes that student choice will allow for a collaborative way to address the issue (Yager, 1996). STS focuses on encapsulating curriculum in an interdisciplinary context of personal and social perspectives, and addresses curriculum in an integrative manner.

Elementary aged children explore and create imaginary worlds, but the structure of their introduction to science is left for scaffolding by adults. Teachers are the usual models for facilitators and scaffolding, as they are the ones encountered in elementary school. Where a child once could create an imaginary world, he is no longer left to develop independently due to the marketing of large corporations that promote high caloric food (e.g. 850 calorie hamburgers). This means that teachers need to focus on development of many skills, inclusive of these are an appreciation of nature and the investigation of phenomena that can counter the effect of modern culture with its many consumer driven messages. Notwithstanding, there is an absence of 
determination to encourage self-exploration and development of science in elementary school. This absence of support, its causes, and impediments are the focus of this review.

Our consumer driven culture and dearth of primary level science curriculum contribute to children's imaginary worlds being less self-generated. Science is a natural way of exploring the environment. In the past, the school playground (Pretty et al., 2009) was a place to learn about the best trees for climbing and where to avoid hornet's nests. When absorbed in play, children achieve mastery and become self-assured (Eliot, 2010). Children need to explore the world by using tools whereby they achieve mastery of sensory-motor play. Jean Piaget and Maria Montessori taught the need of exposure to hands on things. Eliot (2010) suggests that books, plants, pets, sand, water, soil, and most anything beyond a computer mouse and TV remote control can assist in development of sensory-motor play. Nonetheless, U.S. schools continue to reduce recess time to “cram in extra computer, language, and math lessons” (Eliot, p. 151). This is not restricted to American students. In the United Kingdom, time outdoors for children has fallen from 86 to 42 minutes per day since the 1980's (Orr, 2002). This is free time to explore and should be viewed as a general trend not inclusive of time at a recess during the school day. Advances in science, technology, and changes in society have placed different demands on science education. According to Bybee and Landes (1990), these demands are such that they cannot be met through revision of the 1960s curriculum or current textbook programs and major reform was needed, which lead to the need for a better integration of curriculum, especially at the often neglected elementary level. 


\section{Integration}

The case for integration remains paramount for reform in science and math curriculum at all educational levels, especially in the elementary K-4 grades. The current needs of society demand the integration of disciplines to tackle issues confronting students and citizens on global scale. Technological change overshadows much of the present, outdated constructivist learning concepts. For example, global climate change is a much cited area where integration can utilize math and science concepts. Knowledge is more than what is gained in a social context; it is a collaborative enterprise to further the welfare of a group much like the bees in a hive or ants in a colony.

Recent documents highlight a long standing recommendation for integration of science and mathematics in secondary education. Beginning with Science for All Americans (Rutherford \& Ahlgren, 1990) and Reshaping School Mathematics: A Philosophy and Framework for Curriculum (NRC, 1990), these have morphed into Principles and Standards for School Mathematics (National Council of Teachers of Mathematics, 2000) and evolved further with the current state mandated high stakes testing like No Child Left Behind (NCLB).

This trend for integration grew substantially from 1901 to 2001 with 401 citations found on the subject in that time period, to where 449 citations were found for the 1990 to 2001 time frame, a span of 11 years (Berlin \& Lee, 2005). Those first 89 years of integrated science and mathematics literature showed a profound lack of research articles. Out of 401 citations, only 44 or $11 \%$ of the documents are associated with research over a period of 89 years. There was a marked difference in the $1990-2001$ periods. This time frame showed an increase to 86 or $19 \%$ devoted to research, nearly double the number of articles devoted to research in a mere 11 years (Berlin \& Lee, 2005). These papers covered curriculum, instruction, research, and evaluation, so 
the numbers do not add specifically for curriculum, but should be noted because it shows the momentum for change beyond the status quo. This well accepted goal needs to develop integrated science and mathematics curriculum to match the ever increasing demands technology places on our society. With the rapid pace of change in society, this integration theme is screaming for a ground spring of topical integrated subject matter. This integration needs a core of knowledge beginning at the earliest grades and continuing throughout life. This theme should begin when core subjects are begun and woven with interdisciplinary subjects through the educators functioning as facilitators. There should be a lessoning of boundaries of subjects (e.g. history, sociology, biology, economics, etc.) and guided integration towards current societal technological trend issues.

Mathematics at its core is the manipulating of variables to solve problems and reference our environments. Science uses math to record and investigate hypotheses, research, and record data for interpretation. One current teaching model for science is Science, Technology, and Society (STS). This paradigm can integrate science and math for application to issues in the environment, culture, medicine, and engineering. Berlin and Lee (2010) found the percentage of documents focusing on curriculum and instruction dropped from 11\% (1901-1989) to 5\% (19902001). Journals published for elementary mathematics teachers accounted for $10.3 \%$ of the integrated instructional articles in the 1900-2001 time period compared to the present $6.7 \%$ and $6.2 \%$ of the integrated documents found in journals for elementary science teachers and middle school mathematics teachers, respectively (Berlin and Lee, 2005). One has to couch this with the change from one room multi-age classroom to the modern school. Technology changes, alters, and evolves so rapidly that there is a preponderous need for better curriculum at all levels. This should be referenced beyond dictated standardized testing requirements. 
The integration dilemma ranks high among the issues of curriculum development. For proper integration to occur, teachers need to be able to not only teach well in their discipline but also to know how to insert principles interchangeably. They need to have curriculum to use math when teaching science and vice versa. For example, teaching astronomy needs an appreciation of vast distances in space and time. Obviously, mathematics should be used to teach, compare, and compute distances on global and galactic scales. If one were to address the needs of U.S. primary and secondary education, the metric system requires utilizing in all curriculum and problems addressing real life issues. The often present Tylerian rationale (McNeil, 1976) should be banned and replaced with real life simulations to advance learning. Integration would lead to this by creating greater proficiency whereby you need math as a tool and language. In real life situations, no one stops and assigns problems based on subject categories. Problems become addressed through unified approaches. The separate subject approach is a legacy of Eurocentric classical humanism (Pinar, Reynolds, Slattery, \& Taubman, 2004) and long ago dated in our digital age.

Over the past two decades, a plethora of evidence converged in the fields of cognitive science and educational research to show it is important how people learn complex bodies of knowledge (Service, 2008). Teaching has to be a profession of facilitating and not telling. Integration does this and more to face the challenges of change, both at present and into the future. People learn by doing with their hands. The left hand would not have evolved unless the right hand assisted it. Computer keyboards do not assist with the valuable leaning directed by hands-on outdoor activities; including playing in the backyard and changing a bicycle tire (Louv, 2006). Outdoor activities integrate learning in ways still being researched, but it may be integration at a level needing research to validate the positive effect of learning in an outdoor 
environment and how it influences educational outcomes (Rickinson, Dillon, Teamey, Morris, Choi, Sanders, \& Benefield, 2004).

The separate subject approach is one of folklore, so how does integration play a part? How does one use the separate disciplines of knowledge into organizing themes applicable to the present? These themes need to address present needs. That is tall order given the pace of cell phone innovation and the degradation of the environment. The themes should address conflict; living in the future; cultures and identities; jobs, money and careers; and the environment (Beane, 1995). This can be made to tailor fit recommendations in the local communities in areas like population, health, recreation, transportation, and conservation. Knowledge needs to be applied when it is pertinent and not taught as a convenience. That is what textbook curriculum design has allowed. Integration directs the learner to apply knowledge via thematic application. It engages and creates new experiences. The developers of the EG curriculum designed a K-4 program of study that integrates math, language arts, social studies, and practice of inquiry skills (GLOBE, 2006).

Science, Technology, and Society (STS) frames science within technology, and societal issues, so students get a broad view of an issue. STS attempts to link the science and technology in an actual, authentic situation. This leads to problem solving and communication within a curriculum format vis-a-vis integration. STS makes curriculum personal by indicating what learners need to appreciate and applying knowledge in an action based manner (Penick \& Bonnstetter, 1996). Students might examine global climate change and ways to combat local contributions to greenhouse gases. The situativity goes beyond the gross memorization of facts.

Proper integration negotiates constructions within a social context and provides explanations to make sense of the world (Frykhom \& Glasson, 2005). Integration emphasizes 
the importance of situated uses of mathematics in daily life. This is apparent with the food pyramid developed and formerly publicized by the USDA. The incorporation of dietary needs and the negative and positive energy balance extrapolates the use of integration. It can extend to calculating caloric balance, energy needs, and optimal dietary intake by using metabolic equivalent (MET) rates referenced in The Compendium of Physical Activities Tracking Guide (Ainsworth et al., 2000). This application extends the learning of science by making it personal. You are what you eat has often been the mantra in school cafeterias. Now you can calculate the energy that you eat by using MET scores. The energy is easily studied through science or health courses. The mathematics is initially limited to elementary concepts of division and multiplication, but is easily extended to pedometer studies. This can be further extended to topography related activities including Global Positioning System (GPS) tracking. Teachers learn these skills along with their students, so the attributes become fundamentally linked to the contexts. This develops student experts, so they can in turn, be mentors. The situation in which the student learns becomes a principled part of what is learned.

The call for research on integration of mathematics and science continues today as it applied to the lack of authentic practice data in the early 1990's (Goode, 1991). The ultimate goal is for students to work collaboratively to frame problems, then design their own questions and seek solutions. This obviously incorporates the tools of science and understanding of applied mathematics. This integration is further engaged with the use of graphs, charts, and equations which are deemed relative to the topic of investigation (Barnett \& Hudson, 2001). Augmenting the need for integration is the need for more research on how to make teachers more comfortable instructing outside of their content area. Mathematics is a language to apply with different subjects whether it is biology, chemistry, physics, or environmental study. Curriculum needs to 
be developed to bridge this discomfort, so the teacher can become the onsite expert as a facilitator. Many states urge teachers to obtain additional endorsements to address the need for integration, but little research has been done to investigate whether this has affected the problem. How the development of methods courses can provide the context for promoting the connections of math and science is an ongoing issue without adequate redress (Frykholm \& Glasson, 2005).

Higher levels of learning are achieved by integrating math and science (Friend, 1985). It is thought that the two areas complement each other to reinforce the experience making problem solving more comprehensible by students. The use of integration makes the phenomena of science more comprehensible so the relevance to everyday life becomes more readily apparent (Lawson \& Bealer, 1984). Integration is widespread in contextual application. All grades and ages of development benefit from bringing math, a language, in kind with science, an exploration based on method. This especially holds true with the elementary aged children.

Sadly, this integration has gone lacking in the K-4 grade population. Mathematical and science inquiry share much pedagogical methodology. These are investigation, conjecture, evidence, reasoning, and testing (McBride \& Silverman, 1991). The lack of integration stems from a lack of development of curriculum and trained elementary teachers who feel comfortable using it. By using curricula that seamlessly inserts inquiry-based teaching, integration can allow for better use of time by covering more material. Some schools have addressed the issue by merging their math and science departments. They made arrangements for the transfer of subject matter and experiments of science and mathematics to be taught by science personnel. It also has implication of practice as teachers benefit when they collaborate. They become facilitators of change for teachers to learn content and pedagogical content knowledge (Briscoe \& Peters, 1998). 
Teachers need to utilize hands-on science activities to teach math concepts and this includes getting better access to curriculum designed with integration in mind. Many are just unaware of the existence of materials. Nevertheless, all integrated classrooms should have organized inventoried materials for science based activities and a teacher committed to hands-on activities. The teacher should value the power of integrating the fields. These characteristics are ultimately prerequisites for success to integration and learning.

As integration becomes essential to learning, it moves down the curriculum into the lower grades such as in elementary K-4. Science is still often taught as a memorization of facts (Harty, Kloosterman \& Matkin, 1991). There continues to be advocates to move the curriculum towards more integration. Certainly there have been milestones towards teaching the integration as inquiry. This is evident in the textbook, Teaching Science as Inquiry by Joel Bass, Terry Contant, and Arthur Carin (2009) which uses inquiry methodology. This text moves beyond the catch all phrase of "hands-on" to "teaching inquiry." This is more appropriate since many children have not experienced hide and seek moments in academics, nor been pushed into their backyards beyond computer games and television (Louv, 2008). Integrated math and science is not a passive activity. Truly integrated concepts require thinking beyond a linear framework. It becomes an active, even physical, way of approaching learning at the elementary (primary school) level. Teachers typically refer to this kind of curriculum as "hands-on." This moniker can refer to any activity that involves the manipulation of something in a learning environment. "Hands-on" is not a curriculum, but just a descriptor for an activity. "Inquiry-based" is a curriculum emphasizing asking questions in a guided manner. In this manner, the teacher acts as a facilitator of the activity while providing students choices and learning opportunities. 
The EG curriculum (Henderson et al., 2006) is an interdisciplinary science program designed to teach reading and writing while learning about the earth. Through a series of units involving clouds, soil, seasons, water, and the earth, EG bridges mathematics with science. Students investigate by recording, magnifying, journaling, and measuring (Owens, 1999). Student dramatizations personalize the units, so all participants become involved at an experiential level. NASA (1990) became the moving force in the development of the GLOBE program which now connects with student groups worldwide. Students connect at all grade levels, but it is believed that EG is the first integrated curriculum that does this at this at grades K-4. These activities do not require special training and introduce students to the environment which many have foresworn for other activities, such as computer gaming or watching television. Furthermore, urbanization has taken the nature from the block and often turned green space into commercially viable property by paving it over for a strip mall or parking lot. Joni Mitchell wrote a song on the topic, “Don't it always seems to go that you don't know what you got till it's gone. They've paved paradise and put up a parking lot (Mitchell, 1970).” Louv (2008) and McKibben (1989) argue that our society has shifted away from how we view nature, a position that EG attempts to address by introducing elementary children to investigations that explore the world.

EG exposes students to green space, environmental issues, and collaboration with other students globally. Effort is made to draw connections between concepts deepening the literacy component of the GLOBE materials. The materials have been correlated with the National Science Education Standards, National Geography Standards, and the Principles and Standards for School Mathematics (NRC, 1996; NSES, 2000; NGS, 1994; GLOBE, 2006). Great Britain, Canada, France, Spain, and the Netherlands utilize the GLOBE materials. This makes it possible 
for elementary students to work collaboratively with foreign students enhancing their understanding of other cultures. Through a network of participating schools worldwide (http://classic.globe.gov/fsl/html/templ.cgi?elemGLOBE\&lang=en), GLOBE provides collaborative opportunities for inquiry-based science in 111 countries.

\section{Elementary Science Teaching Barriers}

The dearth of material to teach inquiry science in the K-4 grades continues to receive attention from curriculum specialists (Henderson et al., 2006). The National Science Teachers Association (NSTA) acknowledged the paucity of resources for this aged student, and supported efforts to develop more inquiry based curriculum with Ansberry and Morgan's Picture-Perfect

Science Lessons being one result. Ansberry and Morgan (2010) created lessons involving animals that help engage students with science inquiry with the focus being grades 3-6. Ansberry and Morgan (2010) used the BSCS 5E Model--Engage, Explore, Explain, Elaborate, and Evaluate--to build a template for inquiry lessons (Bybee et al., 2006; Biological Science Curriculum Study \& International Business Machines, 1989). EG taught concepts related to Earth science and integrated these with life, physical and earth science areas for the elementary grades K-4. Math and science integration becomes a language for exchange between cultures with lessons about the natural world. This outcome is a well integrated development of age appropriate lessons that needs additional study from the teacher's perspective, especially in an environment pressed for time and cultural diversity. Pressing modern issues make integration a decided choice for addressing concerns such as those with the environment.

Due to reduced time and resources, many teachers state an inability to include any inquiry-based science in their K-6 curriculum (California Council, 2010). Hands-on activities 
serve many applications in inquiry based sciences, so reduced time affects development of sensory motor skills, and the promotion of learning the art of investigation in the elementary grades. Science is about "asking questions and the process of generating answers to those questions” (NSES, 1996, p. 122).

Mathematics and science concepts easily apply to the pressing need for curriculum addressing the child and adolescent health crisis. Overweight students are absent more often and have a higher incident of cardiovascular pathologies (Daniels, 1999). There are higher comorbidities associated with being obese. The most commonly cited example is Type II diabetes, but cardiovascular abnormalities often lead to cardiovascular disease in children. This includes sleep apnea and depression. Designing appropriate intervention strategies for childhood obesity must use integrated curriculum since so much of a child's life is spent at school.

The Eat Well and Keep Moving Program (Gortmaker et al., 1999) is an intervention that focuses on decreasing the consumption of foods high in saturated fat and increasing fruit and vegetable intake. It attempts to reduce the amount of television viewing and increase physical activity. The participating student and parents monitor their activity and consumption of food to record energy equilibrium based on MET scores. Teachers in Baltimore have successfully been trained with this program and are incorporating it with the district's curriculum (Gortmaker et al., 1999). This integration can be easily adapted for use elsewhere, but is not isolated in its application to the obesity epidemic. Pedometers are being used to self-monitor and collect data for graphing at the elementary level.

Curriculum has been developed for pedometer use in the science and mathematics classroom. Its integrative approach ties in math, health, science, and physical education. Pedometer usage requires the student to convert pedometer counts and stride length, so a useful 
number can approximate the distance traveled. Tallies can be made from various groups and compared. Students can calculate their energy usage using MET scores to measure energy equilibrium. This data can be easily graphed at most grade levels. The students of the Health Sciences and Technology Academy incorporate pedometers to measure energy expenditure (Rye et al., 2008). This is a West Virginia club initiated to steer promising secondary students towards careers in medicine and science. They have used pedometers in school settings to measure walking, jumping rope, and daily activities. These activities can integrate math in many ways besides taking averages (means) and graphing. Competitions between classes can be compared to stimulate learning and burning calories. The phrase ‘energy equilibrium’ can be defined by class statistics. Most importantly, food can be described by energy content even at the elementary level. Most food packages have the stated USDA ingredients that can be compared for energy content for ALL level of students. This alone can become a thematic curriculum to integrate math and science just on dietary subjects (Bass, Contant, and Carin, 2005 Section III, A-195). Obesity results from a discrepancy between calories consumed and those used. This is called the energy equilibrium (Liberatore, 2008). Too many calories and weight is gained (stored). Bears and bats do this before hibernation. What makes humans different is the lifestyle that they have adapted with watching television and consuming high sucrose drinks and foods high in saturated fats. Integrated curriculum addresses the understanding of the cause and applies an action through exercise such as pedometer use. Obesity can also be a barrier for learning as the students often have early onset Type II Diabetes which may need medical attention while in school.

The K-4 grades need curriculum that integrates language arts with science, so it brings the joy of nature back to the student (Rickinson et al., 2004). Where students historically played 
outside, swam outside, shot basketball and/ or rode their bicycles, now they are staying indoors to do other activities such as computer gaming. Because science, math, and environmental education are coalescing disciplines, the integration of subjects is highly needed to address the alarm of Global Climate Change. This argument holds for the integration of the subjects if students are to be prepared for the real world (Wiebe, Ecklund, \& Hillen, 1986). Science provides principles for exploration and mathematics has a language which incorporates the tools for investigations leading to conclusions while investigating the backyard or nearby park (Louv, 2006). It is not passive and builds on experience, so action can be taken when addressing issues such as the environment. Getting children to explore their environment is a barrier in this media saturated society, so involving them with forecasting the weather can combine math and writing but only when it is applied and not through visiting the internet for a weather forecast.

Inquiry

Storybooks (GLOBE, 2006) are one way to teach inquiry skills for the K-4 grade student. By its definition, inquiry is a set of interrelated processes where scientists and students ask questions about the natural world (NRC, 1996). Renner, Stafford, Coffia, Kellogg, and Weber (1973) attempted to address the need of inquiry-based science in elementary school in the 1970’s. Renner et al., (1973) found that first graders who used the Science Curriculum Improvement Study (SCIS) materials had greater gains in reasoning skills, as measured by Piagetian conservation tasks, than first graders using a textbook. Unfortunately, SCIS required substantial teacher training and extra resources making it prohibitive, which lead to its discontinuance (Kratochvil \& Crawford, 1971). Another highly taunted curriculum of the post Sputnik era was Science: A Process Approach (SAPA). It remained in use from 1960-1974 and 
received funding from the NSF. Even though SAPA was more effective than traditional teaching methods (http://archives.aaas.org/about/index.php?c_id=5), the program never achieved market penetration. SAPA included kits of materials for children from kindergarten to sixth grade and covered inquiry process skills. Research consistently supported that SAPA had an effect on student process skills (Wideen, 1975), and additionally enhanced teacher understanding of science processes.

Inquiry is done to investigate phenomena and is critical to developing content, teaching, and assessment. In the process, students and educators gain knowledge through understanding of concepts, models, and theories. "Inquiry is a critical component in all modes of learning and at all grade levels, and in every domain of science” (NRC, 1996, p.214). Enhancement occurs when inquiry learning is coordinated through integration with other courses including math, social studies, language arts, and technology. Such coordination "can make maximal use of time in a crowded school schedule” (NRC, 1996, p.214).

This inquiry skill requires practice, and EG provides opportunities to incorporate practice with the investigations explained and followed in the storybooks. Students may practice the inquiry skills of observing, questioning, sequencing, measuring, predicting, and recording while involved with a EG activity (Owens, 1999). The story books make the process of practicing these skills entertaining to the students at the K-4 grade level. High and Rye (2011) found that "fun" was a major reason preservice teachers enjoyed practice with EG and looked forward to using it in their practice. These follow the essential features of classroom inquiry found in the National Science Education Standards which include "asking questions, conducting experiments, using tools, constructing explanations, and communicating findings” (NRC, 1996, p.122-123). 
While students need to think globally, they can act locally. Students learn to take ownership of current environmental issues with an integrated curriculum dealing with the changing world, as are the demands of $21^{\text {st }}$ Century learning. It also provides an opportunity to increase the pedagogical content knowledge (PCK) of teachers through the easily followed instructions that describe allotted time for activities. Elementary teaching has limitations with the available time for instruction, so teachers rarely have the resource to build their PCK. The National Academy of Sciences addressed the need for elementary science curriculum with the publication of Ready, Set, Science (Micheals, Shouse, \& Schweingruber, 2007). This book offered suggestions for teaching elementary science through stories about animals. EG is designed to facilitate teaching to diverse student populations and is available in the five United Nation languages of English, French, Spanish, Arabic, and Chinese (Mandarin). Inquiry science can assist students learn to understand scientists' approach to discovering solutions to problems, which has been supported with evidence in every culture (Bass et al., 2005).

The problems are in evidence of the overwhelming gap between the world people experience and their capacity to thrive, World Wildlife (2010); Global Footprint Network (2010); Service, R.E. (2008). “The dwindling health of the world's species is no surprise considering how much of nature's services humanity is taking for its own use," said Mathis Wackernagel, President of Global Footprint Network (Living Planet Report, 2010, p.1) Humans are now using nature's services 50 percent faster than what the Earth renews, reports the 2010 edition of the Living Planet Report (World Wildlife Fund, 2010).

An inquiry-based science curriculum provides students with tools which they use in their exploration and understanding of the world. This is a historical challenge far surpassing the Scope’s Monkey trial (Linder, 2008) and debates on teaching evolution. It requires leadership for 
creating students with proper accouterments for success. STS is one recommendation and GLOBE is another, but these need to be emphasized over the priorities of current mandated federal and state assessments. The focus needs shifting towards new technologies and the problems ensuing from them. It is so easy to "Google” when researching and using new phone applications when engaging a question, but there needs to be a cohesive effort on mastering the process skills. These skills include asking questions to address Global Climate Change and other pressing problems confronting the $21^{\text {st }}$ Century student.

Hands-on play allows children to explore, manipulate, touch, and talk about their exploration. Play is recognized as essential to child development (Ginsburg, 2007). Hands-on play is not limited to the playground and can be included in planed elementary school curriculum. Research shows that young children learn through play (Colker, 2002). The related pedagogical content knowledge (PCK) should be a strong component of preservice teacher preparation and in-service training (Lubchenco, 1998). Play can and should be used to educate kindergarten to third grade elementary students. It becomes a motivator for learning and teaches inquiry as being “fun” (High \& Rye, 2011).

The skill of learning to do "scientific inquiry" is a requirement for learning and is included in the National Science Education Standards (NSES, 1996, p. 121). From the beginning of school, students should experience science that engages them. This process builds on the personal development of each child and is especially important in founding inquiry skills. While developing inquiry skills, "students should learn to communicate findings and justify their explanations” (NSES, 1996, p.121). In the kindergarten to second grade years, the mystery of the world, its communications, and explorations are important to building foundations for later success in school (Novak, 1997). Numerous reports have highlighted the importance of early 
experiences in science, so that students develop problem-solving skills that empower them to participate in an increasingly scientific and technological world (NSTA, 2002). John Dewey recognized this major tenet with these words:

But the basic material of study cannot be picked in a cursory manner. Occasions which are not and cannot be foreseen are bound to arise wherever there is intellectual freedom. They should be utilized. But there is a decided difference between using them in the development of a continuing line of activity and trusting to them to provide the chief material of learning. Unless a given experience leads out into a field previously unfamiliar no problems arise, while problems are the stimulus to thinking (Dewey, 1938, p. 79).

The world has become a tipping point of levels of carbon dioxide never observed during modern man or in the history of the earth (Balog, 2009). This is due to changes produced on a human dominated planet (Lubchenco, 1998). In view of the over-whelming importance of environmental issues, our teachers should be learning to be more environmental literate, and to teach related issues by using inquiry methods. Nearly 10 years ago, this became recognized by the American Geological Institute (AGI, 2000). It would be several more years before Elementary science curriculum was developed to meet the stated need (GLOBE, 2006). Unfortunately, elementary students often go fully challenged to their full potential even though they can be impacted greatly from time invested with teaching inquiry skills. This is due to many reasons, foremost being that many elementary educators feel uncomfortable teaching science (National Survey, 2000). Less than one third of elementary teachers felt comfortable teaching science in a 2000 study (National Survey, 2000). Least it be forgotten, mankind's effort to understand the natural world initiated the beginning of scientific endeavor. 
A child's interest in the natural world begins, when they looked up at the night sky and wondered how far the nearest star is. This same curiosity leads to great discoveries like Michael Puppin’s invention of inductance coils permitting long distance telephony. His thoughts from tending sheep as a boy in Bosnia built on later education to make a major contribution to science (Burlingame, 1960). By being relatively new to the world, children are usually not as prejudiced with preconceived ideas, so they are more open minded to possibilities. With time being limited for instruction, it is surprising that the core subjects (e.g. reading and math) do not get integrated more often with teaching science lessons. Reading and language arts can be taught with the proper curriculum highlighting inquiry skills. Jaeger (2007) recognized the overwhelming demands placed on educators to teach to assessments, at the exclusion of work for other courses.

Because language arts and mathematics are seen as prerequisites for later learning, the teaching of science has not been prioritized in the elementary grades. Teaching within one's specialty makes the subject more comfortable for instructional purposes. Hawkins, Stancavage, and Dossey (1998) found that fourth graders, who had a teacher with a college major in mathematics or mathematics education, outperformed students whose teacher had other nonmath related degrees. The elementary grades have frequently not attracted teachers with science backgrounds. As a comparison, Chaney (1995) found the same effect for teaching middle school science as Hawkins et al., (1998) did with elementary mathematics. Students with teachers who held a degree in the discipline outperformed students with teachers not having related college degrees. For the primary grades, this results in most elementary teachers becoming generalists. Given the reduced time, schools should support teaching science in the elementary grades, and thus the goals of inquiry as established in national standards. The National Science Teachers' Association lists this objective in its position statement on the subject (NSTA, 2002). 
The elementary science program must provide opportunities for students to develop understandings and skills necessary to function productively as problem-solvers in a scientific and technological world (NSTA, 2002).

Teacher preparation and professional development must provide for experiences that will enable teachers to use hands-on activities to promote skill development, selecting content and methods appropriate for their students, and for design of classroom environments that promote positive attitudes toward science and technology (NSTA, 2002).

The reaction from teacher colleges was to emphasize an umbrella of courses beginning with Total Integrated Math and Science (TIMS, 1999) leading to the present model of Science Technology Engineering and Math (STEM) curriculum originating with the American Competitive Initiative (2006) to address shortfalls in all academic levels of related fields. It has since been replaced with the America Competes Act (2008) which has as one its tenets to strengthen the skills of teachers through additional training in science, math, and technology. Because of the increasing need to understand technology and science, the elementary generalists often fail in their attempts to educate about science. This is due in part because of the increasing competition for time during the school day (California Council, 2010). There are additional constraints created by preparing for state assessments such as No Child Left Behind's Adequate Yearly Progress (AYP). In order to teach a subject area, the school day has to have built in elements of time for instruction. This has become narrower given the emphasis on scores created by AYP. The result is less time to explore the playground for nature. Due to insufficient time and resources, many educators report an inability to include any inquiry-based science in their K-6 curriculum (California Council, 2010). 
Elementary teachers rarely have a strong background in science (Smith-Sebasto \& Smith, 1997), so science curriculum is often limited in availability, even though research has shown there are many ways to improve elementary science teaching. NASA, the U.S. State Department, and University of Colorado developed EG to address this need (GLOBE, 2006). Given the interim, elementary education graduates still use textbooks as they often did year's earlier (Stepans, McClung, \& Beiswenger, 1995). Inquiry methods fail to be used when textbooks supplant activities by the less trained teacher. This may seem counter intuitive when realizing elementary students have the ability to think in the abstract, test variables, and construct models (Keen, 2003). Introducing inquiry-based methodology to science teachers became a issue and warranted a response from curriculum developers. This was an impetus in the development of the EG curriculum (Henderson et al., 2006). Elementary science curriculum must teach the instructor and student alike. Research supports these findings with the consequence that many elementary teachers fail to teach to the student's level of optimal learning (Rohrkemper \& Corno, 1988).

When children learn science through an inquiry-based approach, using classroom investigations, the context of language can be taught (Lapp, 2001). These experiences promote the growth of literacy and verbal fluency. EG promotes science and literacy with one study showing similarities between inquiry-based learning and building literacy (Their, 2002). The lists describe skills which are desired for students to develop in science and language arts. The lists categorize abilities that students should learn including to "note details, compare and contrast, predict, distinguish fact from opinions, make inferences, and draw conclusions” (GLOBE, 2006, p.2). The developers of EG desired to assist K-4 teachers as they integrated earth science in their curriculum and taught literacy skills (GLOBE, 2006). Being a nature based curriculum, EG also 
supports enhancing the development of academics, social, and health related domains (Ozer, 2007).

In this way, learning generates excitement and love of the outdoors. Having motivated students pursue activities through self-cognizance should be a goal for educators (Hidi \& Harackiewicz, 2000). The ease of implementing curriculum should make using it as seamless as possible. This promotes the objectives and builds self-esteem both for students and educators alike. Teacher involvement permeates throughout the inquiry processes found in EG. Its use becomes a learning experience for all the participants no matter what age. For teachers, one consequence is self-efficacy (Bandura, 1997), which promotes confidence to teach science and lay the foundations for future behaviors (Gunning \& Mensah, 2011). Bandura (1997) stated that, “perceived self-efficacy refers to beliefs in one’s capabilities to organize and execute the courses of action required producing given attainments” (p.3), which contributes to the teacher feeling, empowered to make a positive change.

High and Rye (2011) found that “fun” was major component when using EG to instruct science methods to preservice teachers. Vicarious experiences motivated by "fun" are powerful because they provide opportunities for others to visualize a peer's experience in similar situations and "promote encouragement and success” (Bandura, 1997, p. 101). This should have significant professional implications for the practice of teaching science in elementary school. EG promotes collaborative play among students and teachers. Subsequently, teachers enhance their knowledge of practice. They play a central role in generating knowledge by making their schools and classrooms places of inquiry; ergo, a connection between their school and broader issues (e.g. global climate change). The teacher becomes a researcher in conjunction with her students and colleagues in an effort to interpret findings (Cochran-Smith \& Lytle, 
1999). The ease of use of EG reduces the time for preparing lessons. Inquiry-based curriculum should reinforce interdisciplinary instruction as it mitigates the challenges many teachers have when reinforcing the skill; therefore, lessening traditional forms of dissemination (e.g. journals, conferences, and web sites). The "knowledge-of-practice" conception has potential to effect positive change in teachers and students, especially when teachers become more proactive for their own learning (Capobianco \& Feldman, 2006). EG supports knowledge-of-practice so the teacher and student learn from each other through participating in inquiry, as opposed to the ineffective use of number of college science courses taken to change the attitude toward teaching science (Stevens \& Wenner, 1996; Wenner, 1993).

Educating through inquiry is easily learned with the storybooks included with EG. The storybooks model inquiry and foster questions which the teacher uses and facilitates with investigations integrated through journaling, social studies, language arts, and math. It provides opportunities for refection and collaborative interpretation, so the learning experience is fun and students are enthusiastic, which are qualities implicated for acquiring the knowledge (Spector, Burkett, \& Leard, 2007). 


\section{CHAPTER THREE}

\section{Methodology}

The research questions dictated a qualitative design be adopted for collecting data and then triangulating the information. The research protocol for this study was approved as an expedited study (H-22366) by the WVU Office of Research Compliance. The protocol consisted of making three observations of inservice teachers at an elementary level, and called for interviewing each teacher after an observation, eventually composing three observations and three interviews over the duration of the protocol. Once coded, the researcher used interview transcriptions, observation notes, teacher journals, and student artifacts (Appendices G, L, M, N, $\mathrm{O}, \mathrm{P}, \mathrm{Q}, \mathrm{R}, \mathrm{S}, \mathrm{T}, \mathrm{U}$, and V) to triangulate themes. He also kept a personal journal detailing thoughts and reflections while conducting the investigation. From the analysis of the collected data emerged categories, themes, and possible assertions regarding the population of teacher cases studied.

\section{Review of Purpose}

The purpose of this study was to investigate how elementary teachers integrate inquiry science in their classrooms. This was accomplished by:

(1) providing teachers with an in-service workshop on an inquiry-based curriculum (Elementary GLOBE);

(2) completing classroom observations of the curriculum in use;

(3) examining journals kept by teachers relevant to the curriculum;

(4) interviewing teachers after they had taught from the curriculum;

(5) reviewing student artifacts that emerged from the instruction. 
The research questions for this study addressed topics which teachers encountered in everyday instruction.

\section{Research Questions}

RQ1: What kinds of barriers do the teachers encounter when teaching science in elementary school?

RQ2: What impact if any, has the use of Elementary GLOBE had on these barriers?

RQ3: What actions/conditions made Elementary GLOBE difficult for the teachers to use and what factors/conditions made Elementary GLOBE easy for them to use?

RQ4: How has the adoption of Elementary GLOBE impacted the teachers, including their approach to and delivery of science instruction?

RQ5: How has the adoption of Elementary GLOBE influenced the school's function/capability as a Professional Development School within the WVU PK 20 Collaborative?

\section{Rationale for Research Questions}

RQ1: This question addresses concerns with teaching science when the core subjects of elementary school are language arts, mathematics, reading, and writing. Many elementary teachers are generalist and have a limited background in science, so this question attempts to learn more about barriers to teach science and inquiry to the K-4 grades. If barriers can be identified, then strategies may be found to improve teaching science to elementary students.

RQ2: Before an impact can be determined, the barriers to teaching have to be identified. To ascertain these barriers, they first must be identified from RQ1 through interviews, observations, journals, and change over time from use. The developers of EG attempted to identify potential barriers for its use and provided instruction to address time 
management, accommodation for special populations, and integration with other subjects including how EG fulfills educational standards (GLOBE Teacher Implementation Guide Appendix 1, 2006). The impact to barriers should be considered as remedies to promote and facilitate instruction of inquiry-based science at the elementary level. It is important to ask about impact because this is how the curriculum is ultimately utilized and assessed, and EG has not been studied beyond the developers' initial trials.

RQ3: Given the structured day that elementary teacher's encounter, this question provides information on ways to best teach science given limited instruction time.

RQ4: Elementary GLOBE allows the teacher to integrate many subject areas and still teach science and the format of investigations, an area listed in the West Virginia Standard Core Objectives (WVSCO’s) and National Science Education Standards (NRC, 1996). This question encourages the teacher to develop the curiosity of students and learn how to facilitate the lesson while learning with the students.

RQ5: All participating teachers are employed at a professional development school (PDS) affiliated with a nearby university. This relationship creates an environment that is conducive to the development of a teacher's pedagogy. In this study, teachers were given instruction through an inservice training taught by faculty from the university. This relationship provides a continuing support for the teachers' efforts and questions, but little research has been found to document the changes stemming from that support, so this question provides information for continued research in this area.

Research Design 
Stake (1995) defined the primary methodology for collecting and analyzing data used in this study. A defined case is used to draw from naturalistic, holistic, ethnographic, phenomenological, and biographic dimensions of a particular group. This case is defined to study the research questions through interviews, observations, journal entries, and student artifacts. The defined cases were used to make generalizations from triangulation of data.

This study dealt with two major groups (cases). One group consisted of a teacher with experience using the Elementary GLOBE (EG) curriculum while teaching in a regular classroom (Appendix Y). The other group consisted of teachers who had not used EG in a regular school classroom. This group consisted of four teachers who had been trained in using EG through inservice training in the spring 2010; one former middle school science teacher who was teaching third grade for the first time; and two new elementary teachers Patton (2002) characterizes the case control design as an efficient way of studying processes between groups. It is an effective way to make a program evaluation. The methodology can be used to focus on the program and outcomes, aggregate data, make goal-based decisions, and draw conclusions intended for decision makers. In this study, it was used to aggregate, examine, and explore the collected data.

Elementary school teachers were the participants in this study. All are affiliated with the Benedum Collaborative Five Year Teacher Education program affiliated with West Virginia University. Collectively, they represent four different levels of professional experience and familiarity with the Elementary GLOBE curriculum: (a) Four in-service teachers spanning grades K-4 in one elementary school who participated in an Elementary GLOBE workshop (Winter, 2010) and had not yet implemented the curriculum (but planned to initiate implementation in Spring 2010); (b) one grade two former middle school teacher who learned Elementary GLOBE (EG) as she taught in the fall 2010; (c) one former middle school science 
teacher who was teaching third grade for the first time, and one kindergarten teacher who had learned how to use the EG while completing coursework for her master's degree in 2009; and (d) one grade three teacher who had been trained on and used EG the previous year. Participants in (a) through (c) were all located in the same elementary school (Jack and Jill Elementary) and the participant in (d) was at a different elementary school (Jane Doe Elementary). Specific definition of the preservice teacher will be defined during the translating raw data into transcribed data phase.

In order to triangulate data, all the participants were asked to keep a journal about their use of the Elementary GLOBE curriculum, and observed in their classrooms while teaching EG. The teachers sat for interviews three times over the duration of the study, from April 7, 2010 through April 6, 2011. Three sets of interview questions were used, and an attempt was made to interview teachers as close to teaching with EG as possible. The time between use of EG and interview varied from a week to one month.

The cases provided a lens to view the research. When examining the literature, the researcher could not locate any information dealing with elementary teachers learning and implementing the Elementary GLOBE curriculum. The nascent research on the subject provided an opportunity to make a lens to build on interviews, classroom observations, teacher journals, and student produced artifacts. The participants made up two distinct cases:

Case one: This case consisted of a male $3^{\text {rd }}$ grade teacher who had experience using EG. Case two: This case consisted of seven teachers at a different elementary school than the teacher in case one. This group of participants, who had not previously used EG, consisted of (a) four teachers who had had an in-service training on the use of Elementary GLOBE in the winter of 2010; (b) one new elementary teacher who 
had formerly taught middle school science and was teaching second grade; (c) one new kindergarten teacher who had recently completed her master's in elementary education; and (d) one new elementary teacher who taught third grade.

Two participants were lost due to attrition. One, the third grade ex-middle school teacher dropped out after one interview and observation. She had been recruited to replace a participant who dropped out over the summer. To replace the participant who joined the study and later dropped, an opportunity arose to recruit another teacher. This kindergarten teacher joined the study in the fall of 2010.

\section{Data Collection}

Data collection took four forms: observation notes, teacher interviews, teacher journals, and student artifacts. The researcher attempted to observe the participating teachers at least three times during the duration of this study.

\section{Sequence of Data Collection}

The data was collected over 18 months as is shown in (Figure 3.1). The participant profiles (Figure 3.2) describes attrition and experience levels of the teachers. This is summarized in Figure 3.2 to show the grade levels taught and experience.

The researcher made a classroom observation before conducting the interview with five out seven participants. It was felt that the observation would encourage thinking by the teacher and then produce a more valid response to the interview questions. In realizing this factor, the time between observation and interview was kept at a minimum. Because the interview questions 
reflected the insight of the teachers, interviews were given priority when time became a limiting factor (i.e. the school term was concluding).

Figure 3.1 Research Design Timeline

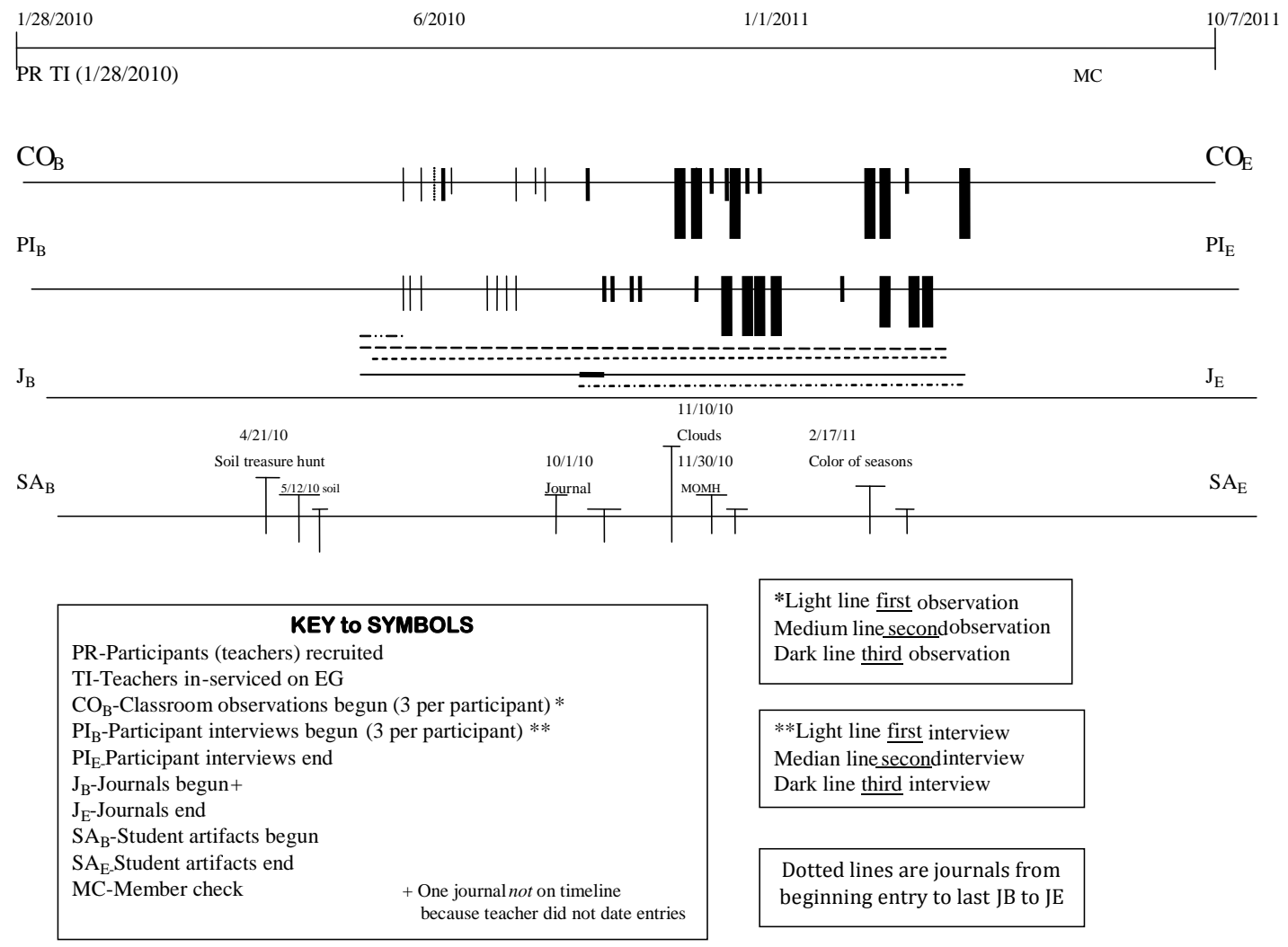

The researcher made a classroom observation in five out seven participants, before conducting their interview. It was felt that the observation would encourage thinking by the teacher and then produce a more valid response to the interview questions. In realizing this factor, the time between observation and interview was kept at a minimum. Because the interview questions reflected the insight of the teachers, interviews were given priority when time became a limiting factor dictated by scheduling of the school term. 
Figure 3.2 Participant Profiles

\begin{tabular}{|c|c|c|c|c|}
\hline Name $^{*}$ & Experience & Grade taught & $\underline{\text { Started }}$ & Completed \\
\hline Peter & (32 yr) & $3^{\text {rd }}$ grade & $4 / / 9 / 10$ & 3/23/11 \\
\hline Mary & $(5 \mathrm{yr})$ & $1^{\text {st }}$ grade & $4 / 13 / 10$ & $4 / 9 / 11$ \\
\hline Amy & (7 yr) & $3^{\text {rd }}$ grade & $4 / 13 / 10$ & 4/13/11 \\
\hline Sterling & (5 yr) & $4^{\text {th }}$ grade & $4 / 13 / 10^{`}$ & $3 / 30 / 11$ \\
\hline Linda & $(23 \mathrm{yr})^{* *}$ & Kindergarten & $4 / 13 / 10$ & 3/30/11 \\
\hline Kelly & (unknown) & $2^{\text {nd }}$ grade & $4 / 13 / 10$ & withdrew 2010 \\
\hline Mandy & (unknown) & $3^{r d}$ grade & $9 / 2 / 10$ & withdrew1/31/11 \\
\hline Alicia & $(<1 \mathrm{yr})$ & Kindergarten & $9 / 24 / 10$ & $3 / 30 / 11$ \\
\hline Allison & $(5 \mathrm{yr})$ & $2^{\text {nd }}$ grade & $9 / 1 / 10$ & $4 / 4 / 11$ \\
\hline
\end{tabular}

\section{Observations}

The observation duration varied if the lesson carried over for more than one class period. If an observation began with EG, the researcher followed it until the teacher ended the investigation. This occurred on several occasions, but the researcher felt it best represented the opportunity to record the complete experience of investigation while witnessing the interplay between teacher and students. Since the sample size was small $(n=7)$ grades K-4 were used as a representative sample for the breadth of grades. Once the observation was made, the notes were transferred into cooked notes, and then typed for analysis later. If clarification was needed, the researcher contacted the observed teacher for a member check (Erlandson et al., 1993).

Observing teachers instruct using EG provided a specific lens to examine the overall application of the curriculum. It led to significant understanding, reorganizing relevant experiences, and robustness of interpretations of actions (Stake, 1995). 


\section{Interviews}

Once observed, a participating teacher was scheduled for an interview as soon as possible. This time frame varied from one week to a month. Questions were developed to pursue three interviews. These interviews occurred at the teacher's school in the morning, during the planning period, or afternoon depending on the teacher's available time. Every effort was made to be as unobtrusive to the participant as possible. One teacher met with the researcher in his office for a second interview. He was the only teacher in his case, and occasionally works with the university as a grader of preservice teacher portfolios.

The interview questions (Appendices B-D) for each of the three sessions were designed to measure the changes encountered by teachers as they incorporated the EG curriculum. While conducting the interviews, the researcher took notes of the interviewee's responses to keep his place while conducting the interview. He also recorded a backup if the recorder failed in any way. Each transcription was checked against the respective audio-tape. Hard copies of the transcripts were printed to refer to when analyzing the data. The researcher used a code to identify the transcripts in hard copy form. At the beginning of each of the three interviews, a script was read to the teacher interviewee (Appendix A). Interview one consisted of eleven questions (Appendix B). For interview two, there were fifteen questions. For interview three, there were ten questions. In the third interview, one question was added to investigate how teachers would use a garden in their EG assignments if it were available. The script for interview one is listed in Appendix B. For interview two, the script is listed in Appendix C. The script is listed in Appendix D for interview three. 


\section{Development of Interview Questions}

The teaching of science in elementary school has been impacted by the demands of national assessment testing leaving very little time to teach inquiry based science investigation (Jaeger, 2007). Reading and math have been traditionally the fundamental core courses emphasized in the K-3 curriculum. The development of questions for interviews addressed teacher training, barriers to teaching science, integration of science with other subjects, role of school in teaching science, how to teach about the environment, and use of a school garden in teaching science.

In realizing the limited time that elementary teachers have, an attempt was made to minimize the impact on the teacher's day, so interviews were conducted before and after school, and during teacher planning periods. They were limited to a maximum of 20 minutes. Responses to any questions from the interviews were fact checked within 48 hours. The researcher took notes as he interviewed the teacher, so he was able to notate the context for clarification and elaboration of questions. This allowed for ease of fact checking.

\section{Participant Journals}

Collection of the participant journals occurred at the conclusion of the study. These journals were sequentially numbered by page for later referencing in the analysis and conclusions. Three of the journals were collected before the school district's summer break to examine. This was to insure that participants were keeping relevant entries. To promote regular 
journal use, the investigator sent two emails to remind participants about it. The researcher also left a card with a brief note for each teacher during their Christmas break.

Artifacts of Student Work (Appendices $G, L, M . N, O, P, Q, R, S, T, U$, and V)

When relevant, the researcher obtained artifacts of student work. The researcher requested the artifacts, and removed any means of identifying the creator of the artifact before making a photo copy or photographing the artifact. If the student artifact was on display, any identifying names were masked before photo documentation. At the conclusion of study, there were twelve artifacts used and included with the dissertation in the Appendices ( $G, L, M, N, O$, $P, Q, R, S, T, U$, and V).

\section{Analysis of Qualitative Data}

The field notes of the observations were transcribed as soon as possible. These notes were then typed into Microsoft Word. Every effort was made to use emphatic notation in original observations. When a noted event occurred, the researcher would highlight the notes to indicate a peculiar event had occurred. The typed observation notes were printed into hard copies to examine and read for coding. This was a simple way to initially examine the data for possible convergence (Guba, 1978; Patton, 2002). Recurring regularities in the data were sought. These regularities were defined into patterns labeled categories. After sorting for categories, they were judged for internal homogeneity and external heterogeneity (Patton, 2002). These examinations verified the classification system for accuracy and meaningfulness of the categories. The researcher used open coding with the interview transcripts to determine repeating phrases and 
themes. These transcribed interviews provided an opportunity to review the data from the coding which was used for examining the transcriptions. Once coding was made for repeating themes, the teacher journals were then examined for congruity or dissimilarity of themes. This permitted the analysis of changes regarding teacher encounters with barriers, collegial support, and accommodation of the curriculum for specific reasons. This also allowed the researcher to examine the time of year as a factor in teaching science, since getting outside for science investigations is a major thrust of EG.

After the completion of the third interview, the interview questions (from all combined interviews) were collated with the interviewee responses and open coded. This allowed for a comparison with coding used in a study by High and Rye (2011). The interview questions were catalogued by date (sequence: interview 1, interview 2, and interview 3). This allowed for the participant responses to be easily examined for changes over the duration of the study. This was from April 27, 2010 to April 5, 2011. Coding made possible the creation of themes and categories. Examining this data was for the expressed purpose of identifying categories and themes. This was done by tallying words and open coding for phrases.

Summary Analysis of Data Interview questions

1) Once an interview was completed, the researcher had the tapes transcribed within 24-48 hours and in the duration checked his interview notes; all interviews were transcribed in Microsoft Word 2007

2) Once the researcher received the transcript via internet (GroupWise), he checked it with his notes and printed a hard copy which he filed away for later analysis; he retrieved and 
listened to the tape to check the transcript and then labeled and placed it in locked desk drawer in Allen 807-C per compliance with IRB procedures; the tape would be listened to one more time to check the accuracy of the transcription and for any nuances (e.g. tremor in voice, excitement in answering certain questions).

3) I $f$ there was a question about the interview the researcher contacted the interviewee.

4) The researcher waited until there was a full set of interview transcripts in hard copy (interviews one, two, and three). Then, he read and noted repeating words by bracketing (Denzin, 1989) these words and compared with the grade level taught, class composite (e.g. SPED students, percentage of ESL students, number of class aides). He wrote notes in the margin which he kept on file; he reread these paper copies several times for interpretation and reflection. By the conclusion of the study, these class sets of RQ1-RQ 5 were read five times.

5) When this was done, the researcher analyzed for repeating words, phrases for unique perspectives (Patton, 2002); he kept RQ1-RQ5 in five separate files which he viewed on the desk top of his computer. In this way, he could look at each RQ again, and compare the responses with other participants' responses. He could also compare journal entries and classroom observations made around the same time by having all the data in Word and available on his computer's desktop. This made for ease of compiling table data for RQ1-RQ5 beginning with interview responses, class room observations, journals, and change over time, student artifacts, and triangulation of findings for each RQ, so each RQ had five levels of analysis before triangulating.

6) The researcher recorded repeating words and phrases as open coding in the interview responses. 
7) The researcher used open coding to create categories which he then used to place the actual words/phrases from the 20 interview transcripts to form categories and possible themes.

8) The researcher created tables for each RQ with the categories identified and frequency of words/phrases to substantiate categories (again) and built a case for themes, which he determined would be a frequency of six or seven out of the sample $n=7$.

\section{Classroom observations}

The researcher kept all classroom observation notes in black Moleskin ruled Recorder Notebook 192 lines per page and used two of these notebooks, which he kept on his desk or on his person until the conclusion of the study. He used $0.5 \mathrm{~mm}$ lead Pentel mechanical pencil to take notes as it also afforded the advantage of making sketches of the classrooms and students doing investigations inside and outside. These sketches help him place the notes in a better context when transcribing them in Microsoft Word. The sketches were suitable for use as data to support his observations and notes but were not scanned for that purpose.

After observing a classroom, he returned to his car and wrote notes in the notebook margins to cement the events and for possible use in referencing questions of the participants if they should arise. After several observations (three or four) he transcribed his notes into Microsoft Word. As he transcribed his notes, the researcher would make notation on certain behavior (e.g. best practice, on-task behavior, how teacher dealt accommodation issues). He used these notes to identify repeating behaviors for categories (e.g. accommodation of students, teacher confidence, student excitement, ease/difficulty using EG). 
After two school terms, the researcher transcribed the collection of 25 classroom observations into a composite copy of all notes and examined them for possible categories (e.g. repeating comments, noted behaviors). Having collected the transcribed observations, the notes were coded and examined for repeating words to form categories. The researcher kept counts of this data when doing closed coding of this analysis since the sample $(n=7)$ was small. He did keep a journal when analyzing this data to record it for creating tables. Then, he later used the transcribed notes in Word to bracket the notes with other observations and examination of phenomena present (e.g. high incidence of English Second Language (ESL) students/classroom).

Since the observations were transcribed in Word, it was convenient to save the file for review and examination. Once transcribed, the researcher called the observation notes "cooked notes” as had been suggested by his qualitative research instructor and been done by him. The researcher concluded the study with 30 pages of single spaced notes without the sketches from each observation. Much of these notes were in short phrases and not written in complete sentences because the researcher decided it was more important to record the observed events and create as accurate a vignette as possible. While transcribing the observation notes, the researcher began to include bold face type in the transcription indicating a behavior (e.g. teacher conscious of time, teacher lacked resources, best practice, good use of inquiry).

\section{Journals}

The journals were collected at beginning of the summer break. Only three of the journals were obtained for review. These were returned to the participants at the beginning of the fall semester. All seven journals were collected at the end of the study. The last one was collected on $4 / 18 / 11$. 
The journals were read from front to back and notes were written in them to indicate significant entries. Since the journals were not standardized with regard to later referencing the entries, the researcher numbered each page of the journals from the first page until the last. Given the journal entries were relatively short (ranging from 5-41 pages), the researcher decided to transcribe the journals into Word for ease of analysis. In this manner he created a composite of all the journals and maintained annotation to identify each participant and date (when presentone participant did not date her entries). This composite journal was read and reread three times for entries to capture the phenomena of teacher experiences they recorded in their entries. From the reading, he captured repeating words, phrases, and events to establish categories and possible themes.

Ortlipp (2008) believes journals are a rich source of individual experiences and collection of phenomena as it relates to the writer. Since the journal entries varied in length and quality, they were read for relevance noting when and where the teachers were when teaching while doing the observations. They provided a rich collection of insights into the processes of why certain teachers taught and how they were impacted by using EG. Categories and themes found in the journal were used to analyze RQ1-RQ5.

\section{Sequence of analysis followed}

Because there were five research questions, each question was examined from the perspective of interview questions, classroom observations, journals, and change over time, student artifacts, and finally triangulating the data for reliability of findings. These findings were summarized in separate tables for each of the research questions (RQ1-RQ5). 


\section{Member Check}

This study is qualitative in design, so it is an attempt to understand phenomena in a specific context. Qualitative research by definition is any research that "produces findings without the use of statistical quantification” (Strauss \& Corbin, 1990, p.17); hence, “the interested phenomenon occurs or unfolds naturally” (Patton, 2002, p. 39) such that the researcher has no predetermined course as would occur in a controlled (laboratory) setting. When a quantitative researcher considers research validity and reliability, he is typically referring to research which is credible, while "the qualitative researcher speaks of research that depends on the ability and effort of the researcher” (Golafshani, 2003, p.600).

According to Patton (2002), validity and reliability should be considered when designing qualitative research. This is of particular significance when judging the analysis and quality of the study. In qualitative paradigms, the terms Credibility, Conformability, Consistency, Dependability, and Transferability are to be the essential criteria determining quality of research and analysis (Lincoln \& Guba, 1985). More specifically, they use the term dependability in qualitative research because it corresponds to idea of reliability (Lincoln \& Guba, 1985).

For reliability to be insured, examination of trustworthiness is crucial. Seale (1999) states, "Trustworthiness is paramount to the issues conventionally discussed as validity and reliability” (p.266). In order to address the meaning of rigor in qualitative research, Davis \& Dodd (2002) found that the term rigor often appears in discussions of reliability and validity. Lincoln and Guba (1985) posit that to sustain the trustworthiness of a research report depends on dealing with validity and reliability. This establishes the confidence in the findings (Lincoln \& Lincoln \& Guba, 1985). While attempting to briefly define the concepts of reliability and validity 
in qualitative research, one question is paramount. How one test for reliability of a qualitative study is the pertinent question?

Since the quality of a study is related to generalizability (Polit \& Hungler, 1991), this requires generalizability of a study to have a method to ascertain reliability and testing for trustworthiness of research. Patton (2002) recommends the use of triangulation to strengthen a study by combining methods and provide trustworthiness for generalizability. One type of “analytical triangulation is to have the participants of the study review the findings" (Patton, 2002, p.560). The reactions of the participants of a study can offer insight about the accuracy, completeness, fairness, and perceived validity of the findings.

In order to test for reliability for this study’s findings, a member check (Appendix F) was given to the participants. This member check consisted of five questions asked in a manner that would have the participant "agree” or "disagree” with the finding, and then space was provided for explanation of the participant's rationale for their answer. A letter (Appendix E) explaining that the member check was a method of getting feedback on the study's findings accompanied each questionnaire. The member check questionnaire (Appendix F) was distributed by leaving them at each of the participant schools and through email. With each questionnaire, a selfaddressed, stamped envelope was left. It was thought that this mode of distributing the questionnaire would provide the participants with choices which would minimally impact their time. 


\section{CHAPTER FOUR}

\section{FINDINGS AND DISCUSSION}

\section{Review of Rationale for Research Questions}

RQ1: What kinds of barriers do the teachers encounter when teaching science in elementary school?

This question addresses concerns with teaching science when the core subjects of elementary school are language arts, social studies, mathematics, reading, and writing. Many elementary teachers are generalist and have a limited background in science, so this question attempts to learn more about barriers to teach science and inquiry to the K-4 grades. If barriers can be identified, then strategies may be found to improve teaching science to elementary students.

RQ2: What impact if any, has the use of Elementary GLOBE had on these barriers?

Before an impact can be determined, the barriers have to be identified. To ascertain these barriers, they first must be ascertained from RQ1 through interviews, observations, journals, and change over time from use. The developers of EG attempted to identify potential barriers for its use and provided instruction to address time management, accommodation for special populations, and integration with other subjects including how EG fulfills educational standards (GLOBE Teacher Implementation Guide Appendix One, 2006). The identified barriers have the potential to determine how science is taught and perceived by students, subsequently encouraging or discouraging their curiosity and perception of science. 
RQ3: What actions/conditions made Elementary GLOBE difficult for the teachers to use and what factors/conditions made Elementary GLOBE easy for them to use?

Given the structured day that elementary teacher’s encounter, this question provides information on ways to best teach science given limited instruction time.

RQ4: How has the adoption of Elementary GLOBE impacted the teachers, including their approach to and delivery of science instruction?

Elementary GLOBE allows the teacher to integrate many subjects and still teach science and the format of inquiry investigations, an area listed in the WVCSOs and National Science Education Standards (1996). This question examines the degree to which teachers developed the curiosity of their students and learned how to facilitate instruction to learn with the students.

RQ5: How has the adoption of Elementary GLOBE influenced the school's function/capability as a Professional Development School within the WVU PK20 Collaborative?

This question investigates the corroboration developed between the Professional Development School (PDS) and West Virginia University, as influenced by the implementation and use of Elementary GLOBE. Particular focus is on the assistance provided by West Virginia University in strengthening the enhancement of instruction for elementary science for students and teachers.

\section{Review of Data Collection and Analysis}

After each taped interview, the questions were transcribed and checked with written notes. The interviews were then arranged in order from beginning of the study to its termination. This made for ease of comparison and analysis. The first interview was on June 3, 2010, and the last interview occurred on April 5, 2011. The researcher was able to conduct 20 interviews. The transcribed interviews were analyzed by the researcher to generate categories. From these categories, the researcher developed the emerging themes (Patton, 2002). 
The interviewer took notes during the interviews and he checked responses to each question when initially listening to the tapes. These responses were helpful to remember specific comments of interest. When analyzing the data, he again listened to the tapes and compared the interviews with the transcriptions. He made corrections where needed. This did not change the interview data in any way.

Each participating teacher kept a journal for the duration of the study. The researcher collected them at the conclusion of the study and examined them for their contents. Three of the teachers' journals were collected over the summer and read for relevance and then returned to the teacher. Additionally, this was done for compliance. All journals were in the possession of the researcher by 4/18/2011. These journals were read and the examined for categories. After determining categories, these were coded (Appendix X). The ascertained entries were typed into Microsoft Word for later analysis. The seven journals had a range of entries from 7-47 pages in them.

There were a total of 24 teacher observations done during the time period of this study. The researcher attempted to lessen any bias of an observation created by his presence; nevertheless, he became aware that students were cognizant of his presence. This may have influenced student behavior. The researcher attempted to take notes in a non-descript manner by hiding his notebook in his hand and staying in a least travelled place in the room, which was usually the corner the furthest distance from the door. Notwithstanding, the students knew of his presence and some asked if he was a parent helper. He never engaged students in conversation, and if asked a question, smiled in response to discourage further interest in him. 


\section{Participant Involvement and Attrition}

Seven teachers initially volunteered to participate in this study. One teacher withdrew over the summer to accept a different position within the school district. Her replacement was recruited, and then later withdrew citing lack of time even though she had completed one interview and observation. Because there was a concern for future attrition, an additional recruit was accepted in the study. This participant was familiar with Elementary GLOBE through her coursework in an elementary science methods class at a nearby university. This made the recruitment advantageous and limited the impact on the validity of the data collection.

The study concluded with seven teachers participating in 20 interviews out of 21 proposed. There were a total of 20 out of 21 observations made in each of the final study participant classrooms with two teachers receiving two more observations to conclude the lesson because additional time was needed to complete the activity, so 24 observations were completed. Each of the participants kept journals during the study. The experience of the seven teachers varied from less than one year to 32 years of teaching. The mean teaching experience was 11 years; the mode was 5; and median was 5.5. One teacher with 23 years of teaching experience held National Board certification. Of the seven participants, only one was male with 32 years of experience.

The participating teachers taught grades ranging from kindergarten to fourth grade. The classes observed included two of kindergarten, one first grade, one second grade, two third grades, and one fourth grade. The teacher with 32 years of experience taught third grade, and the teacher with 23 years of experience taught kindergarten. 


\section{Organization of Finding}

The findings for each research question are organized by reporting the data from the interviews first, followed by the other data sources (journals, observations, student artifacts). The principal categories that emerged from the interviews for each research question are set forth in tables at the beginning of each section of the findings that answers each research question. The code lists that correspond to the emergent categories are found in Appendix X. Supporting interview transcript excerpts and discussion follow each table. The findings for each research question conclude with subsections that discuss "change over time" and "triangulation of the data sources."

\section{Research Question One}

RQ 1: What kinds of barriers do the teachers encounter when teaching science in elementary school?

\section{Interviews}

Six interview questions were posed to participants to identify barriers when teaching elementary school science.

1) How do you deal with the barriers of teaching science in elementary school? This question was used in interviews one and two.

2) When using the Elementary GLOBE, how did using the GLOBE Kids affect the learning environment in the classroom? This question was asked in interviews one, two, and three.

3) What are the teacher's limitations in getting their students to understand science in elementary school? This question was used in interviews one, two, and three.

4) How could you improve the effectiveness of Elementary GLOBE when teaching about global warming and related issues? This question was asked in interviews one and two.

5) What were your thoughts about using Elementary GLOBE in the classroom? This question was asked in interviews one and two. 
6) Describe the changes that you observed in your classroom while using Elementary GLOBE? This question was asked in interviews one and two.

Each of the six interview questions provided insights for identifying barriers when establishing categories and themes. For research question one (RQ1), several categories emerged from inductive analysis: time management, a dislike of textbooks, accommodation, and outdoors (lack of available green space). The themes that emerged were time management and teacher training (includes learning how to accommodate special needs students).

\section{Table 1 Barrier Categories Found in Science Teaching from the Majority of Interviews for RQ1}

\begin{tabular}{lll} 
Category & \multicolumn{3}{l}{$\begin{array}{l}\text { Number and percent of teachers } \\
(\mathrm{n}=7)\end{array}$} & \\
\hline Time (including prep for hands-on activities) & $7 / 7$ & $100 \%$ \\
Lack of outdoor resource & $5 / 7$ & $71 \%$ \\
Teacher training & $5 / 7$ & $71 \%$ \\
Textbook dislike & $4 / 7$ & $57 \%$ \\
Accommodations & $2 / 7$ & $29 \%$ \\
& & \\
\hline
\end{tabular}

Of the six interview questions used to investigate RQ1, interview question one provided the most substantive information. Presumably, this was due to the focus on the word "barriers" in the question. There was internal homogeneity (Patton, 2002) with the other interview questions. There was agreement among the participant responses for each interview question. The findings dovetailed and helped establish priority regarding utility, salience, credibility, uniqueness, heuristic value, and use of classification scheme (Patton, 2002).

Seven of the seven teachers cited the lack of time as a barrier in teaching science in elementary school. There is a focus on reading and math in the early grades and this affects the 
ability to teach science. There is a pervasive pressure to focus on language arts (reading, writing, vocabulary) and math. Managing time was so pervasive (86 percent or six out of seven) in the participants' answers that it is listed as both a category and also a theme. One teacher stated it as a dichotomy of trying to teach within the limitation of time and need to address the State Content Standards and Objectives (CSO). Linda expressed the difficulties saying, "I think a lot of people would say time. It is time management for the teacher how to balance the science CSO's. There is such pressure to do the core reading and math because that is what is tested...” (Linda, interview two, 9/29/10).

The barrier of time showed up repeatedly. As the aforementioned teacher mentioned, the feeling of being pressured to adhere to coursework on which the students would be tested. These tested courses are reading and math.

I would say time is one of the barriers is that I can't find time to do it [science] because we have all these other pressures on us like reading and math and writing. I try to do something science related once a week.

(Alicia, interview two, 12/2/10)

Four of the seven teachers cited the lack of having a place to go outside for investigations was a barrier. Outside is defined as a large green space with trees. One of the participating teachers used a nearby park because it was safe to access (Appendix H). This teacher was aware of the space restraints in teaching science both in and outside the classroom. The school playground was a place devoid of trees and covered in unnaturally occurring sawdust (Appendix I).

With the GLOBE you need to have an area that you can safely get to be able to do these outdoor observations. We were actually very lucky we are 
in a very low traffic area and all the areas we walk to were very safe with sidewalks. We just have to adapt (Peter, interview one, 6/10/10).

This was not the case in the other studied school. This school had some accessible woods (Appendix J), but this teacher, Allison, expressed her frustration by telling the interviewer the following:

...It is hard to find places to take them outside. Part [referring to part of school property] is like a nature walk but no one has ever shown me and I don't know where it is. Maybe it used to be (Allison, interview one, 10/10/10).

As a comparison, the school playground was similar to the other school. It was devoid of trees and sawdust covered the ground. The area had playground equipment scattered among the field of woodchips (Appendix K). Both playgrounds appeared sterile and unnatural for activities promoting environmental exploration.

Textbooks were not the preferred curricula to instruct science. In the studied sample, five of the seven teachers searched for hands-on activities other than those in the textbook. All seven participants liked the fact that EG is a hands-on curriculum. This was apparent in the thinking of one teacher with 32 years of experience, who said, “...I thought it would be a good opportunity to give the kids a little bit more of hands on using the outdoors a little bit and we were excited about it” (Peter, interview one, 6/10/10).

This paralleled the recorded responses from the other six teachers. Though the teachers were assigned district approved science textbooks, they were not inclined to use them. When asked specifically about using EG, the teachers endorsed the opportunity to get away from the textbook. Mary welcomed the chance to teach with an alternative curriculum. She explained, "It 
has been great. It gives me another way to get away from just our regular textbook. It lets me do more hands-on projects with them; I would say” (Mary, interview two, 10/15/10).

The act of creating a fun lesson was considered a barrier. The textbook is two dimensional in its projected use for teaching science. It was left to the teachers, mostly generalists without science teaching endorsements, to incentivize science lessons. Sterling spoke to the importance of making the subject enjoyable.

I was hesitant at first to [be] quite honest because it seemed like a lot of materials that I did not necessarily have but after we got the supplies it ended up being a lot of fun. The kids really, really enjoyed it. They got more out of it than they [sic] have the regular text book work... (Sterling, interview one, 10/19/10).

Mary echoed similar thoughts regarding fun in the EG lesson.

My kids were more engaged and more excited. They couldn't wait until the next day and they would come in and go outside. They couldn't wait until the next day to explore and do the soil. I just think they were really excited to see me. They knew that I talked it up so much they were excited to do it (Mary, interview one, 6/3/10).

While the EG curriculum materials provide hands-on lessons, the teacher had to implement and execute the instruction. Amy endorsed the hands-on lessons even with the realization of needing to plan for going outside and providing materials for investigations.

I think it has to do with being outside again and then coming back in and transferring into the hands-on and you could [see] this in their faces they could see more than just this one type of cloud, then them [sic] back in and 
creating clouds (Appendix M). They were taping it together and that it is difficult for several of my students. I think so just being able to see some of them [sic] that really did connect right away (Amy, interview one, 10/19/10).

Accommodation surfaced as a category in the interview responses though less frequent than expected given the diversity found at Jack and Jill Elementary School (Nedeff, 2010). The EG developers addressed accommodation issues with guidance on how to implement the curriculum for special needs populations. This infrequently surfaced in the interview responses but was noticeable in the adaptations that teachers made when presenting a lesson especially with reading and incorporating teacher's aides when present in the classroom. There were only two out of seven teachers making an interview response which could specifically address accommodations, so even though this barrier was not found in the majority of interview responses, it was listed as one. In one example, Sterling had to deal with accommodation issues in one of her classes.

I have the collaborative room so a third of the kids are special needs and learning disabled in reading is a trick thing so it was nice to have the read aloud even though I didn't do as well as I think I should have. What didn’t require them to read and get frustrated which was nice. [I] was able to present it in a more interesting way than the text book (Sterling, interview one, 10/19/10).

Amy commented on accommodations by seeing a change in her students once they had been outside and then returned after completing an EG activity. 
I think because it had multi steps to the task so the kids were seated for awhile and they were focused in their classroom and then they were outside and they go to get up and go outside. When we came back in it was hands on so I think because of meeting all the different senses and all the different learning styles it was really beneficial for them and for myself (Amy, interview one, 10/19/10).

Time management and teacher training are the themes for RQ1. Time management should be considered a theme because it involves all aspects of barriers for science teaching. Seven out of seven teachers cited it as a barrier. It affected how the teacher utilized curriculum, the learning environment, and what is learned by students, especially science. Teaching science usually encompasses class room management involving learning stations, hands-on activities, reporting results, and investigating phenomena. Any teaching strategy that results in more effective use and management of time promotes a higher quality learning environment. There is nothing that more efficient use of time does not affect when teaching elementary science. This is especially relevant when integrating science with reading, math, and social studies.

Teacher training is also a theme due to the teachers mentioning they would like additional instruction on how to use hands-on lessons. Using time outdoors for hands-on instruction requires the teacher to receive additional training to manage the students in an environmental setting. Gaining practice of hands-on activities ameliorates the learning curve of knowing how to teach science investigations especially inquiry activities, such as EG is tailored for use.

The reluctance to ask for assistance when teaching science was one barrier indentified. This was coded under teacher training. This was surprising, given how well the participating teachers worked collaboratively. One teacher responded to the interviewer's question on dealing with 
barriers by saying assistance was available if it was sought. She was in her second year of teaching, but when probed with the question, "Are there other teachers who are reluctant to ask for help?” She responded by saying there were others who did not ask for assistance: “Oh, yes $\operatorname{lot}[\mathrm{s}]$ of them. I think it is easier not to. I think that is what they think. It is easier to say no and move along and not deal with it” (Amy, interview two, 3/31/11).

Because many elementary teachers are trained as generalist, their knowledge of science can be lacking. When teaching inquiry-based science to elementary children this can be a barrier for a teacher trained as a generalist. This can be ameliorated by having mentors (Gunning \& Mensah, 2011) on the school staff with the desired knowledge. This barrier was addressed by one teacher seeking advice from colleagues:

This is only my second year of being in the classroom full time ...so I am running around to all my colleagues and asking them what did you do when you came up [to] this lesson? Can I have some help? Can I have some ideas? You guys have done this before. My third grade team is wonderful. They all have given me help and now with GLOBE I have other teachers in other grades that have ideas too so I can just adapt it to my third grade classroom (Amy, interview one, 10/19/19).

Of the six interview questions used to probe barriers for RQ1 'Describe the changes that you observed in your classroom while using Elementary GLOBE, provided the most insight on the issue of barriers. Alicia stated, "Going outside first of all they loved going outside and just making them believe they are scientists on a mission to complete an activity and they are in their own world when they are out there" (Alicia, interview one, 10/18/10). 
The lack of suitable green space to take students when doing science related activities showed up as a barrier when teaching science. Being able to access green space means more than just the playground (Appendices I and K). The limitation of provisions for going outside showed up in five of seven (71\%) of the participating teachers' responses. The ability to keep students on task and engage them while using EG significantly increased the ability to engage the students in science. This was evidenced in Alicia's response:

...I have found it great to do in the afternoon. It is the hardest part of the day. That is when they are the most hyper and kind of start losing it but integrating the GLOBE program I have been able to reel them back in and make them focus (Alicia, interview one, 10/18/10).

This finding showed up in a way that defines elementary education. It got the students to think beyond themselves. Access to the outdoors provided a place to explore and not to avoid (Pretty et al., 2009; Louv, 2008, p.2). This is a barrier that is not defined by a simple category, but this teacher spoke to the barrier with didactic candor.

I think just, bringing more to real life with things that we can do outside of the school. Going on nature walks and having the accessible like you [sic] bringing in things. This is awesome and I wouldn't have been able to do that right away. I don't think if I didn't have GLOBE that if I wasn't connected with you (Amy, interview three, 4/4/11).

\section{Classroom Observations}

The researcher observed only the English version of EG being utilized in the classrooms affiliated with this study at both schools, Jack and Jill Elementary and Jane Doe Elementary. 
Language is a problem for the English as a Second Language (ESL) student (Nedeff, 2010). This is especially true with science where learning new vocabulary is a major focus. Jack and Jill Elementary School has 178 students whose native languages are not English. There are 44 languages and over 46 countries represented (Nedeff, 2010). Only one teacher cited language as a barrier during the interviews. This science curriculum is available in the six United Nations languages (English, Spanish, German, Arabic, Mandarin Chinese, and French.

\section{Table 2 Barrier Categories found in the Classroom Observations}

\begin{tabular}{lcl}
\hline Categories & Percent of teachers (n=7) \\
\hline Lack of outdoor resources (e.g. & $7 / 7$ & $(100 \%)$ \\
green space) & & \\
Hands-on (needing more prep) & $7 / 7$ & $(100 \%)$ \\
Time planning w/ integration & $7 / 7$ & $(100 \%)$ \\
Accommodations & $6 / 7$ & $(85 \%)$ \\
\hline
\end{tabular}

During the observations, the researcher witnessed accommodations for ESL students (Table 2). These took the form of mentoring and utilizing the school ESL coordinator. Whenever the ESL student was removed for tutoring, time was lost in the instruction and the inclusivity of the classroom experience was a factor. The National Science Education Standards list the ability to communicate, analyze and critique the work of other students as a content standard (NRC, 1996, p.6).

There was vigilance using the available time allotted when teaching science in the studied elementary schools. The seven teachers approached the science lessons knowing time was a limiting factor. This required exceptional planning on their behalf. When necessitated, the studied teachers sought the advice of other members of their school faculty. This was observed in team teaching of science lessons (Sterling and Mary, second classroom observation, 11/12/10). 
The barrier categories listed in Tables 1 and 2 were in evidence in all the teachers' classrooms when teaching science lessons. The need for resources became paramount when making sure there were hand trowels to dig in the soil when doing the EG lesson Scoop on Soil. When Linda did the Mystery of the Missing Hummingbirds (MOMH), there was a need for a hummingbird feeder, so one was procured and hung by the class as a collaborative exercise (Linda, second observation, 5/25/10).

On 5/25/10, the researcher entered the classroom and observed Linda organizing the kindergartners where five students were on floor doing puzzles, and Linda was helping a student with reading. It was a nice day with temperatures ranging from75-80 degrees at 10:36 a.m. Linda decided to integrate math with the science lesson from EG. In order to do this, she began by having the students sit on the floor as she assembled the hummingbird feeder. One student asked if the researcher was a parent and looked at a pink sticker on his leg identifying that he was a visitor. The researcher smiled at the student and answered, that he was not a parent. Linda began by talking about the ruby throated hummingbird bird (RHB) and how it flapped its wings 60x/second and then had the students try flapping arms as many times as possible. She timed their efforts. Linda started reading MOMH at 10:41 a.m. being very conscious of the time and need to ready the hummingbird feeder. One little boy said out loud, "If I get a bird, I am going to feed it gummy bears.” There was excitement among the seated students, and they were engaged with listening to the story being read to them. The class consists of 20 students but only 17 were present at the time of the observation. Linda asked, "What are two things you do in summer?”

Linda had the students write in their EG science journals as they learned about the size of the RTH. She distributed an EG silhouette which she then explained was the actual size of the 
RTH. Coloring pencils were distributed to color the silhouettes which each student had. The students had class sets of scissors to use to cut them out. There was some disturbance with one little girl looking for her purple handled scissors that she eventfully found. Lunch was at 11:06 a.m., so Linda made sure the students were ready to cut out and color their RTH. She was very patient in getting them to stay on task which the researcher counted 16 out of 17 students doing. As students lined up for lunch, one girl asked, "What is that tree doing in window?" The students went to lunch and returned at 11:36 a.m., still wondering what that tree was doing in the window? The researcher noted that Linda was accounting for every minute of instruction time. The tree was a hibiscus shrub that was in flower. Linda spoke to the aide present to be sure to place the hibiscus where one student would not "mess with it." This student had an IEP and had been taken out of the class earlier. Linda explained, "Will put feeder on window outside with hibiscus.” Linda was making accommodations for all students, including those not present. The student with IEP left with aide at 12:03 a.m. Linda started a math lesson with money and how to make change, and then had students color their RTH silhouettes and there was some discussions among kids seated as whether they were going to make male or female RTH? This was done by properly coloring in the silhouettes according to the proper gender for male and female birds. Linda assisted students as needed and had a piece of clay weighing about 5 grams (the mass of a nickel) to give to each student to affix to their RTH. A student asked, "Was size of cut out same as real hummingbird?” She explained that this was the actual size of the bird and gave each student a piece of clay which weighed about 5 grams (the mass of a nickel). She passed a nickel around explaining this was how much the bird weighed.

Linda started a class discussion about the identification of the RTH by color. She asked, "Male or female?" The students replied, "Male or female" in unison - most said male when 
being told what the color was and then Linda used flash cards to quiz the class. She showed a video of RTH and then asked how they made the humming sound? The class hummed in unison. Linda explained "with their wings."

She asked the students to make up a question about RTH which they were to research at home, and then went around room directing students. Some students want to copy from board where several sample questions had been written, but Linda sent them back to their seats. One girl asked, “Do they like to hum?” The researcher wrote in notebook margin that students did not get that hum is from wings flapping at high rate. Linda asks, "What do they eat?" Some students do research in collection of books by door (room library). She went around the room and looked at students' questions and reads them aloud, “Do they migrate?” After lunch, there are now 20 students in class and period ended at 12:50 a.m.

The actual hanging of the feeder occurred the next day and Linda had students help make the sugar solution as she sat in front of them and they on the floor. They placed the feeder the outside window with a suction cup hook. All the time was scripted and used to accomplish the lesson goals. Time became a factor again when students needed to access the computer lab in order to research questions about the RTH. This became especially relevant when students needed accommodations for language and special needs.

The barrier categories identified from observations were lack of outdoor resources, time management mitigated with integration, and accommodations (for special needs students). Time management and nascent outdoor resources were the barrier themes identified from observations. The barrier categories of hands-on and accommodations were collapsed under the theme of managing time. 


\section{Journals}

When examining the journals, the findings from the analysis of this data provided reliability to the findings from the interview transcript. The categories of time, lack of outside resources, and accommodation showed up in this order from the reading the journals, as is noted in Table 3.

\section{Table 3 Barrier Categories found in the Teachers' Journals}

\begin{tabular}{lcl}
\hline & & \\
Barrier Categories & Percent of teachers $(\mathrm{n}=7)$ \\
\hline Outdoor resources lacking & $7 / 7$ & $(100 \%)$ \\
Time & $5 / 7$ & $(71 \%)$ \\
Accommodations & $5 / 7$ & $(71 \%)$ \\
& & \\
\hline
\end{tabular}

The journal barrier categories for RQ1 are time, lack of outdoor resources, and accommodations. These three barrier categories collapse into the theme of time management. The teachers liked to do hands-on projects, but these had a barrier of time. Sterling, a $4^{\text {th }}$ grade teacher, paired her gifted kids with special needs students in a mentoring situation with a $1^{\text {st }}$ grade teacher. This situation showed the barriers of doing hands-on science and accommodating the needs of students with special needs, as the 4th graders mentored the 1st graders in this science activity. Sterling addressed the barriers with a $1^{\text {st }}$ grade teacher, who brought her class to Sterling's 4th grade classroom.

Today we made cloudscapes (Appendices L and M) with $1^{\text {st }}$ grade. We made sure to pair my SPED kids with her gifted kids. It was a bit crowded in the room but a lot of fun. All of the groups did really well! They worked together and were very respectful of each other space. 
Next time we will have bags of supplies pre-made so that group has all of the materials and we don't waste time passing them out.

My guys were a little upset they couldn’t keep the model but they are excited to know that they will see them in the hallway (Sterling, journal, p. 39).

Change over Time for RQ1

With the study duration being one year, there were some discernible changes observed in the teachers' instruction. Noticeable was a desire to get the students before a task involving science. This was not easily quantifiable since there was no accepted scale established before the study and there was no pre and post test. The participants at Jack and Jill Elementary were observed to more easily integrate EG when teaching, so this lessened the barrier of time as a restraint to teaching science. With the teaching materials (e.g. student journal pages, laboratory recording pages) readily available from the EG curriculum resources, the restraints of less time to teach elementary science were mitigated. This was most apparent when modeling inquiry science teaching, since the storybooks with the GLOBE Kids acted out inquiry investigations for the reader, the elementary student. As the students were being entertained with a read-a-long story, they were also learning science. The teacher was able to give a reading lesson and a science lesson at the same time. Through integration of reading and acquiring language arts skills, EG addressed the barrier of less time. Integration would be shown to have an impact on barriers in RQ2.

Triangulation of Data from Observations Journals, Interviews and Student Artifacts for RQ1 
The triangulating the data from journals, interviews, and observations strongly support time as a barrier for instruction. It obviously was not found in the student artifacts in a blatant manner. Two student artifacts (Appendices $\mathrm{L}$ and $\mathrm{M}$ ) show that time is needed to gather materials for an EG science investigation (e.g. feathers, tinsel, pipe cleaners). Appendices $\mathrm{H}$ and J show green space used for EG investigations and that the lack of it is a barrier to do science with the curriculum. The barrier of needing green space showed up in the observations and journals for all seven teachers. The student artifacts showed the need for outdoor exploration, specifically an area to dig and collect soil samples for the EG module Scoop on Soil. Of the 12 student artifacts used to represent EG student investigations, student artifact drawing (Appendix N) of soil findings showed the need for providing a suitable green space for completing the investigation. This correlates with the finding that green space is required for completing science activities when using EG. This is particularly apparent for doing the module, The Scoop of Soils.

\section{Research Question Two}

RQ2: What impact if any has the use of Elementary GLOBE (EG) had on these barriers?

There were five interview questions asked about the impact of using EG when teaching elementary school science in the studied schools.

1) What were your thoughts about using the Elementary GLOBE in the classroom? (This was asked in interviews one and two.)

2) How could you have improved the effectiveness of Elementary GLOBE when teaching about Global warming and related issues? (Asked in interviews one and two.)

3) Describe the changes that you have observed in your classroom when teaching with elementary GLOBE? (Asked in interviews one and two )

4) How do you deal with the barriers of teaching science in elementary school? (Question asked in interview one and two.) 
5) Since using Elementary GLOBE how have you been impacted in the classroom? (Question asked in interviews one, two, and three)

Interviews

When conducting the interviews with these questions, the lens of how EG impacted the barriers identified in RQ1 was the focus. The teachers cited the limitations of using their district approved science curriculum due to lack of support and resources for implementing it. Several teachers endorsed hands-on investigation found in EG. This was evident with Linda's viewpoint, "It is more of an inquiry-based format than our textbook is and it just goes more in depth to what we already have” (Linda, interview two, 9/29/10). EG provides a curriculum that includes more inquiry-based activities supported by National Science Education Standards (NRC, 1996). It also deals with the lack of time experienced by elementary teachers who must plan for multiple classes. For example, Amy thought EG was wonderful "because she did not have to create [a] lesson plan" (Amy, interview one, 10/19/10). This related to the "time” barrier identified in all the RQ1 interviews, journals, and observations; none-the-less, only one teacher commented on it in respect to RQ2. This was a surprise. This might be accounted for in the difficulty of the teacher's class preparation, number of preparations taught, and grade level. Amy had to create seven lesson preps daily for third grade. It was unusual that the ease of using the prepared EG lessons received less comment in the interview responses from the other participants. 


\section{Table 4 Impact on Barrier Categories Found in Interviews for RQ2}

\begin{tabular}{lcc}
\hline Impact Categories RQ2 & Percent of teachers (n=7) \\
\hline Hands-on impact & $6 / 7$ & $86 \%$ \\
Time management impact & $5 / 7$ & $71 \%$ \\
Integration impact & $4 / 7$ & $57 \%$ \\
Outdoor resource impact & $4 / 7$ & $57 \%$ \\
Teacher belief in teaching & $3 / 7$ & $43 \%$ \\
Students like science/nature from EG exposure & $3 / 7$ & $43 \%$ \\
& & \\
\hline
\end{tabular}

EG is an inquiry-based science curriculum easily inserted in the early elementary grades (K-4). Teaching inquiry-based science requires teachers to guide their students with questions. The one teacher with National Board Certification and 23 years of experience realized the significance of the EG inquiry-based learning, so she was more cognizant of the impact on this barrier, which is not easily defined and should be studied in future investigations. "It is more of an inquiry- based format than our textbook is and goes more in depth to what we already have” (Linda, interview two, 9/29/10). The participating teachers are given a textbook and expected to teach from it to meet state standards. This is perhaps the most profound impact that EG had on the teachers in that EG permits the integration of the core subject area of reading and math through storybooks mirroring science investigations and activities paralleling these activities. By using the EG curriculum, the teachers instruct with inquiry-based tools. The storybooks are inquiry-based activities, which the classroom students follow through the GLOBE Kids teaching the lesson with science investigations. These lessons are designed so they can be tailored to meet 
and accommodate diverse student populations. Linda thought "the lessons are well developed" (Linda, interview two, 9/29/10).

Some teachers were more vocal in their dislike of their district's science curriculum. When gauging the impact over a short period of time, teachers noticed a difference in how their students responded to the EG and related the impact of using it with their students. "I thought [it] a nice alternative to teaching science instead of just using the textbook and things XYZ County wants us to use. It gave the students another way of learning and they really, really enjoyed it" (Mary, interview one, 6/3/10). When asked for the teacher to expound on some of the activities, she related the experience of inquiry being transferred after using EG with some students carrying the activity home with them. These students initiated their own similar project at their place of residence.

We went outside and dug in the soil (Appendix J) and looked in what was in the soil after we had done the project. ....They wrote everything about it, took pictures of them. They went back out and put it back in a different place and then a few of them actually went home and were allowed to dig up around their house and they came back and talked about what they found at their house different from here (Mary, interview two, 10/15/10).

When teaching out of their endorsed areas, teachers can be hesitant and even reluctant to accept new challenges. Elementary teachers tend to be trained as generalist and are expected to cover any subject assigned to them. This was especially evident in the case of Sterling.

...I am a social studies person with my specialization in social studies and reading science is harder for me to do. It [EG] gives other ideas and resources outside what the textbook tells me to do. The networking with 
the other grade levels has helped also because I know they are doing some of the same things and I can pull from there, their resources also (Sterling, interview third interview, 12/21/10).

When asked if she could integrate science lessons into social studies, Sterling deferred from accepting more responsibility than she could handle:

We probably could but I don't because I am solely the science person on this side now so I feel I am trying to learn it and teach it and make it not boring and not overwhelm myself all at the same time which is where this [Elementary GLOBE] has been nice (Sterling, interview one, 10/19/10). Often elementary teachers are given a textbook and expected to teach the subject. This can be very difficult when dealing with diverse student populations. One teacher had a classroom consisting of nine students with special needs, 11 different language speakers, and two students who were non-readers:

If they are just using the textbook you have certain kids who have trouble with concentrating and paying attention when you are just reading it, they are not really interested but with that [Elementary GLOBE] they are all very into looking at me, listening to the stories. Really when [sic] they are doing that, [there is] no fiddling around (Allison, interview one, 10/20/10). These observations paralleled another teacher's experience when she described the accommodation that EG offered in very similar wording:

I have the collaborative room, so a third of the kids are special needs and learning disabled in reading is a tricky thing so it was nice to have the read aloud even though I didn’t do as well as I think I should have. That 
didn’t require them to read and get frustrated which was nice. I was able to present it in a more interesting way than the textbook (Sterling, interview one, 10/19/10).

It is often difficult to relate to students with attention spans accustomed to immediate gratification, so the designers of EG developed the GLOBE Kids to model investigative exercises with accompanying curriculum. Having fictional characters model inquiry-based lessons impacted the lack of time to teach science. This issue surfaced in these teachers' responses:

...I enjoyed teaching them because they enjoyed it and the stories are so interesting. I think it is neat just neat just to see them when they get it when you are reading because it is kids too, their age because they can relate to those GLOBE Kids. I like it and will continue to use it (Allison, interview three, 3/10/11).

The teachers noticed that their students enjoyed going outside when performing tasks related to science involving EG. The GLOBE Kids contributed to this as they modeled investigations in the outdoors. This became apparent in one kindergarten class: The students are more aware of the season of autumn. They talk all the time how they saw leaves changing colors and it just has opened another door for their imagination. The day we completed the GLOBE activities they have been very engaged because it is something new to them other than writing and reading (Alicia, interview two, 10/18/10). When prompted to explain how her students were engaged, she elaborated with further details that focused on the curriculum's significance: 
Going outside first of all, they love going outside and just making them believe they are scientists on a mission to complete an activity and they are in their own world when they are out there. It is quiet time and it's their time to express what they see and how they feel out there in the season. I have found it great to do in the afternoon. It's their hardest time of the day (Alicia, interview two, 10/18/10).

And...

Students are more aware of the outdoors and the weather. I even had some students bring in leaves from recess because we did the fall season lesson (Appendix O). Just being [they were] more aware of the weather and their surroundings outside than they were prior to teaching with GLOBE (Alicia, interview two, 10/18/10).

In her third interview, Alicia expounded on her thought about the impact that EG has had on her students. She was prompted to explain her answer to the impact that EG had on her students by adding a statement to the curriculum's effectiveness:

I think it has been very effective. The kids really enjoy [it]. Whenever I say we are going to have a science lesson and we get out our science lesson and we get out our science journals (Appendix G) they seem very excited so it's positive (Alicia, third interview, 3/8/11).

The interviewer asked, "How positive besides excited? Can you give me some examples?" Well I have seen them think outside the box with their creativity which we don't get to do a lot anymore because of the standards we have to follow 
and have been able to explore their imagination through the GLOBE program (Alicia, interview three, 3/8/11).

Using EG impacted the barrier of going outside, so that teachers used the available areas of green space where found, either in a nearby park (Appendices $\mathrm{T}$ and $\mathrm{U}$ ) or trail adjacent to the school. This mitigated the lack of suitable green space but was of significant concern for doing investigations from EG. It should be noted that having a playground and nature area are not synonymous. Both studied schools have playgrounds with a fence around them (Appendices I and K). Both school playgrounds do not have trees in the fenced in areas. Peter co-opted this reality and changed his lesson to meet the needs of the students and teach science using EG.

Once we got outside to do one of the activities, the kids were after it. They wanted to go outside again. I intra-mixed the GLOBE program with our regular curriculum so we did a little from our textbook and then we would go outside and do some GLOBE activity and they always wanted to go outside. In fact I had two girls who were in the TAG program, the gifted program, and they missed a couple [of days] and they let me know they did not appreciate missing the outdoor activity. They really looked forward to it (Peter, interview one, 6/10/10).

In this teacher's third interview, his thoughts summarized the impact of access to a large a green area with these comments:

Actually I am surprised at how easy it is take the kids outdoors if you the right school environment. I know it would be quite difficult at some schools but at Jane Doe Elementary it is very simple to take them outside and do the activity. The second year is, I think with anything it is easier 
than the first year to go out and find things that don't quite work. If you need a little more materials but I was perfectly surprised at how smoothly it goes (Peter, interview three, 12/3/10).

The interview themes for RQ2 were the impact on restrained time, utilizing available outdoor resources, and integration of EG. Time to take students outside is closely related to using outdoor resources for EG investigations (Appendices $\mathrm{T}$ and $\mathrm{U}$ ). Time was mitigated because of the more easily integrated lessons found in EG, since it encompasses the practice of language arts, social studies, math, art, and journaling. Teachers found they could integrate science with other lessons and this became a surprising reality compared to past experience that relied on using the textbook and/ or other resources. This concluded with the six teachers new to EG intent on using it again. Allison was more adamant on continued use of EG in her classes: I think overall very good. I enjoyed teaching them because they enjoyed it and the stories are so interesting. I think it is neat just to see them when they get it when you are reading because it is kids too their age because they can relate to those GLOBE Kids. I like it and will continue to use it (Allison, third interview, 3/10/11).

All the participants enjoyed the hands-on aspects to EG. This is significant because EG shows that time to do the appropriate science activity is difficult to manage when doing science and may be viewed counter intuitively since time showed up as a barrier in RQ1. Allison endorsed using EG in a very positive way. "I was excited about it because I like hands-on especially with science and social studies. Things like that, so to me, when they offered it, I was like definitely [sic]” (Allison interview one 10/30/10). She continued by addressing the district's 
curriculum, “Just if the curriculum didn't have it then we should come up with our own thing” (Allison, interview one, 10/30/10). The time needed to do handson activity showed up as a barrier with all seven teachers when answering interview questions concerning RQ1, but then six out of seven noted it had an impact on their teaching in RQ2 when using EG due to the ease of integrating science lessons with the core subjects. This should be considered an issue with the professional development in their teacher training as how to best integrate lessons covering science with reading, math, and social studies. The teachers liked the fact that the materials for teaching were available with EG.

Having a suitable green space (Appendix J) impacted science activities at this school, because there was limited space to take the students outside. Even though there is a play ground, it is fenced in and has no trees within its boundary (Appendix K). This impacted teachers' planning so they were more aware of using what coveted green space was available. A proposed garden with13 raised beds on school grounds should ameliorate and provide more greenery to the barren playground. These beds will contain vegetables such as eggplants, pear tomatoes, rainbow chard and tomatillos (Rye, 2011; Subramanian, 2002). This was added after the study concluded.

I think it is making aware of science everywhere. Science isn't just when we are learning about it in school and if the kids aren't exposed understanding that it is everywhere in the real world they are just going to think it is school related and especially since I think we have so many resources especially with this garden coming that they are going to realize that it is everywhere and it is what they eat. They think it is from just a book, science” (Amy, interview two, 3/31/11). 
Later, Allison explained how she felt about doing science when asked about her thoughts using EG in the second interview, "We have done some seasonal things outside and did the hummingbird lesson (Appendix V). I think I am getting better at it and learning a little as I read the materials. The kids seem to be enjoying it" (Allison, second interview, 12/15/10). Being able to do science outside is instrumental when exploring the natural environment (Rickinson et al., 2004). Another teacher commented on this in her answer.

We went outside and dug in the soil (Appendix $\mathrm{J}$ ) and looked at what was in the soil after we had done that project. They investigated the soil. They wrote everything about it, took pictures of them. They went back out and put it back in a different place and then a few of them actually went home and were allowed to dig up around their house[s] and they came back and talked about what they found at their house[s] different from here” (Mary, interview two, 10/15/10).

Learning how to deal with time restraints was the most observed impact on barriers found in RQ1. How to manage the time to present science investigations became a category repeating itself throughout the study's findings. Allison connected the needs to do hands-on with lack of time to include educating herself while invested with the experiment (Allison, interview three, 3/10/11). EG provides activities that mitigate the lack of time due to reducing preparation effort. All seven teachers looked forward to doing EG activities with their students. This curriculum offered prepared science lessons, limiting the preparation time for instruction of inquiry based instruction, a content standard for elementary science teaching (NRC, 1996, p. 121).

I try to make it as hands on as I can. Do the experiments. There is a press for time so skim over the reading and look at the pictures and try to do as 
much hands on. I buy stuff for the experiments if we don't have it. I like doing the outside stuff. If they see it, I need to see things too (Allison, interview one, 10/10/10).

As cited in the aforementioned paragraph some teachers found EG assuaged the lack of time because of not having to make lesson plans (Amy, interview one, 10/19/10). She was relieved that she did not have to make plans and had suitable materials to conduct science investigations from the EG curriculum resources. Being able to integrate EG with math, social studies, and language arts, gave the teachers choices to do science lessons and other coursework fulfilling state CSO (Appendices I, M, N, O, P, Q, T, and V).

Available green space allows the teacher the opportunity to do activities but it is a significant barrier if there is none (Appendix $\mathrm{J}$ ). The participants were able to teach elementary children to value nature through science classes that involved doing activities outside. The impact of getting students outside, a barrier found in RQ1 should not be understated. Amy found her students to appreciate nature by going outside: "Going on nature walks and having it accessible for bringing in things. That is awesome and I wouldn't have been able to do that right away. I don’t think if I didn’t have EG...” (Amy, third interview, 4/5/11). Peter commented on his students appreciating nature from doing an EG activity outside:

I noticed they were getting much better at making detailed observations, more detailed observations then the first time and the second time we went down had to walk the trees and the saw some things they didn't see before like there was a little tree not very tall maybe ten feet tall and there was a bird nest in it. They couldn't see that bird nest when they were down in the summer but when we went down in the fall they saw it. They were just 
more observant and it wasn't always things that went with the lesson

(Peter, interview one, 6/10/10).

Sterling and Mary also noted changes in their students’ interest in nature, not specifically science associated with a lesson. This impacted the barrier of limited green space for doing EG activities and the barren surroundings of the playgrounds devoid of trees. This suggested a change in the way her students viewed the world outside. They brought in leaves and other items found on the playground. Sterling's students collected artifacts of nature (leaves) to bring back to their classroom to obviously keep a part of nature that they felt ownership of:

We kind of carried it on over to our recess of the other times and they have done that on their own so that's been nice. It hasn't been a science thing. They have moved it across the day, throughout the day (Sterling, interview one, 10/19/10).

And...

That is something more and they actually go out and see what we have and experience especially with the one where they go out and look around and here they have the seasons even all year around and go and say this season the flowers are dead and this season the flowers are blooming. What kind of animals, bugs and insects are around there so it is more hands on and they can physically see it, not just something they are reading in a book (Mary, interview three, 10/17/10).

Alicia found her students to be more aware of nature and to be more engaged with their surroundings. This is a significant impact for kindergarten students who are typically in the 
preoperational stage of cognitive development and think little beyond their self (Piaget and Inhelder, 1956).

The students are more aware of the season of autumn. They talk all the time how they saw leaves changing colors and it just has opened another door for their imagination. The day we completed the GLOBE activities they have been very engaged because it is something new to them other than math and writing and reading (Alicia, interview one, 10/18/10). Allison explained that her students remembered the stories involving the GLOBE Kids promoting nature:

They seemed to understand it more where it sticks with them. Not just reading a text and writing it for a test. It is more relating to it and they remember it and store information. I think they pay attention better. It was a long story but it kept their attention.

Interviewer: Can you think of anything specifically that would indicate or remind you they did remember it longer?

Just them talking about it. Like I hear them discussing the hummingbirds and they remember the names of it. I heard them talking about it today. Just a few of them. Then the seasons, any questions that I ask they remember them. Beginning of fall, what it was like (Allison, interview two, 12/15/10).

The teachers were impacted by their confidence in be able to teach with EG. Allison seemed to look forward to teaching as indicated in her comments from interview three: 
I enjoyed teaching them because they enjoyed it and the stories are so interesting. I think it is neat just to see them when they get it when you are reading because it is kids too their age because they can relate to those GLOBE Kids. I like it and will continue to use it (Allison, interview three, 3/10/11).

Alicia, a kindergarten teacher, used the EG because she did not have a science curriculum. She found that EG could be easily used to integrate teaching science with math. This mitigated a barrier found in Table 3 .

... I have never been told and like I said I don't have a science curriculum so this GLOBE curriculum is all I am using. Some of my kindergarteners have never been exposed to science before so for some of them it is very challenging. They have no background in it. A student who has no background in science, it is more difficult to get them engaged in talking about nature. Like one of the things I decided to do, I tied science into math recently just because of the GLOBE program and my brain is on science. I taught them symmetry today and they were to go home and find artifacts outside that had symmetry, leaves and stuff from outside and we are going to talk about them when they bring them in tomorrow (Alicia, interview one, 10/18/10).

Because the elementary school day can be fractured in its organization with assemblies and special events, finding a full period to teach a science lesson can be daunting. The EG curriculum mitigates these issues by providing easily inserted lessons. This is due to their versatile applications especially with accommodations for students with special needs. "That 
didn’t require them to read and get frustrated which was nice. I was able to present it in a more interesting way than the text book” (Sterling, interview one, 10/19/10).

We have science from 9 - 9:50 and then we have to go to specials so any day we are doing a lab it gets stopped and they have to move on and they have to come back and that always interrupts the flow of things so that is another barrier. How to overcome that? I don’t know (Sterling, interview one, 10/19/10).

The teachers had to balance daily scheduling with teaching science, so Sterling learned this was possible by utilizing EG. Mary realized she could affect students with her new found enthusiasm for teaching science by using EG:

My kids were more engaged and more excited. They couldn’t wait until the next day and they would come in and go outside. They couldn't wait until the next day to explore and do the soil. I just think they were really excited to see me. They knew that I talked it up so much they were so excited to do it (Mary, interview one, 6/3/10).

If they are just using the textbook you have certain kids who have trouble with concentrating and paying attention when you are just reading it, they are not really interested but with that they are all very into looking at me, listening to the stories (Allison, interview one, 10/10/10).

Because of easily accommodated lesson plans, EG impacted teachers through this realization and was evident in Allison's experience with using it. This was noted in an observation from Amy: 
I think because it had multi steps to the task so the kids were seated for awhile and they were focused in their classroom and then they were outside and they go to get up and go outside. When we came back in it was hands on so I think because of meeting all the different senses and all the different learning styles it was really beneficial for them and for myself [sic] (Amy, interview one, 10/19/10). The impact on Alicia's students encompassed a new view on the children's world. This is an age where children are egocentric, so having them become aware of the greater world is an impact.

Students are more aware of the outdoors and the weather. I even had some students bring in some leaves from recess because we did the fall season lesson. Just being more aware of the weather and their surroundings outside then they were prior teaching with GLOBE. It heightened their awareness. It is important. At this age you are never sure what you will get sometimes (Alicia, interview two, 12/2/10).

Alicia believed that EG impacted her students by presenting opportunities "to think outside the box." She was aware of the time restraints to teach to standards but also the need for her students to be aware of nature and science. She summarized her observations this way. The kids really enjoy it. Whenever I say we are going to have a science lesson and we get out our science journals they seem very excited so it’s been very positive. It heightened their awareness. It is important. At this age you are never sure what you will get sometimes. 
Well I have seen them think outside the box with their creativity which we don't get to do a lot anymore because of the standards we have to follow and have been able to explore their imagination through the GLOBE program (Alicia, interview three, 3/18/11).

There were two themes that emerged from the teacher interviews for RQ2.

They were being able to integrate EG with other subjects so time class time could be used more effectively with integrating language arts, social studies, and math. The integration theme is evident in this teacher's comments:

The project that I used I could use it for reading because you have a story. Definitely science you could use it with math, even social studies because it is geographic different areas. You could use it definitely across the curriculum (Mary, interview one, 6/3/10).

And...

I think it brings it more to their level. They love reading and interactive read aloud and when they see the kids they can relate to them better than the teachers throughout a story are just adults doing it (Amy, interview three, 3/31/11).

Peter integrated his teaching in many ways with science and other subjects:

It [EG] can [be] tied in with mostly anything. We will be reading a story and the kids will mention something they did with GLOBE and that is the same type of activity we did. Hummingbird comes up and they mention oh yes that was in GLOBE. They don't actually mention GLOBE but does say we did that in science. The measurement, comparing temperatures 
and things like that. Social Studies that mainly comes into current events. We talk about current events every morning and it is a good time there also (Peter, interview three, 12/3/10).

I can't even count the ways [that you could integrate EG]. We read the story about the hummingbirds. Any time a South American county comes up they will say where that is in relation to Costa Rica or we have to get ready because it takes us about five minutes to walk down, how much time do we have and when we have to leave and then we have to get back. We have to schedule things. Directions as far as the direction we are walking and talking a little bit about when the sun is up, how can we use that to help us know directions when we are out walking around (Peter, interview two, 9/28/10).

The first was the mitigating aspects on time when using EG. The time mitigation was due to the ease of integration, availability of hands-on activities with obtainable resources, and provided accommodations through teaching with EG. The second theme was the behavioral change of students regarding science. This was found in the interview responses of the teachers and their interpretations of student behavior and appreciation of nature. Mary said, "They are more engaged in science, they enjoy it more. They are more engaged for sure” (Mary, second interview, 10/11/10). She had also said similar words in her first interview:

My kids were more engaged and more excited. They couldn’t wait until the next day and they would come in and go outside. They couldn't wait until the next day to explore and do the soil. I just think they were really 
excited to see me. They knew that I talked it up so much they were so excited to do it (Mary, first interview, 6/3/10).

Alicia found that her students had a new appreciation for science through their awareness of the change in the seasons:

The students are more aware of the season of autumn. They talk all the time how they saw leaves changing colors (Appendix O) and it just has opened another door for their imagination. The day we completed the GLOBE activities they have been very engaged because it is something new to them other than math and writing and reading (Alicia, first interview, 10/18/10).

The hands-on investigations of EG impacted the barriers found in RQ1. The EG learning activities are designed to be implemented with ease and flexibility (GLOBE, 2006, p.6). These lessons worked through the integration of language arts, teaching inquiry process skills, and accommodating student with special needs. The EG activities mitigate the time crunch often felt by teachers. EG correlates to National Science Education Standards, National Geography Standards, and the Principles and Standards for School Mathematics (GLOBE 2006, Appendix 1). The positive impact of using EG is supported through the comments of five of seven teachers in the study. Integration is a third theme since it encompasses mitigating time, uses hands-on techniques, and makes use of the interdisciplinary aspects of EG.

Seven out of seven, teachers indicated they want to continue using EG. The one teacher with National Board Certification indicated that her teaching had changed since she had begun using EG. Now, when questioning students, she attempts to wait longer for answers while facilitating an inquiry-based activity. The curriculum's ease of integration assuaged the major 
barrier of time management found in RQ1. When using EG, science and literacy are connected though content that is meaningful and stimulating to elementary students. The teachers' answers to interview question two for RQ1 show this unequivocally. "It helped them understand it better and it was nice that it came from other kids like in the story and it was a classroom that kids could relate to it (Allison, interview one, 12/15/10).” "They thought that was neat because they could relate to them because they are kids" (Mary, interview one, 6/3/10). Mary explained to her class that the GLOBE Kids would 'stick' with all the books. She added, "They loved the dog and other characters they have in the books because they are kids and they can see well it is not just grownups doing this stuff. Kids are doing this stuff” (Mary, interview three, 11/17/10). "They really connected with those soil kids and the puppy in there" (Sterling, interview three, 12/21/10). "I think it brings it more to their level. They love reading and interactive read alouds and when they see the kids they can relate to them better than the teachers...” (Amy, interview three, 3/31/11).

\section{Classroom observations}

In all classrooms, the students were engaged and on task when doing EG activities. The ease of integration of inquiry-based science activities impacted the delivery of teaching by making it easier with EG (Table 5). This ease was demonstrated with the availability of easily acquired material to do the EG activities thus reducing the preparatory time for the teacher. This showed up in all the classroom observations. There was accommodation for special needs students in the observed classrooms of the teachers who were using EG for the first time. This was seamless and easily implemented with best practice pedagogy through the observed classrooms. 


\section{Table 5 Impact on Barrier Categories Found in the Classroom Observations}

\begin{tabular}{lrl} 
Impact Categories & Percent of teachers (n=7) \\
\hline Getting student outdoors & $7 / 7$ & $100 \%$ \\
Hands-on (needing less prep) & $7 / 7$ & $100 \%$ \\
Mitigation time management & $7 / 7$ & $100 \%$ \\
Mitigating accommodations & $6 / 7$ & $86 \%$
\end{tabular}

Integration of different subjects with EG mitigated time management by allowing the teacher to cover more subjects in the same time frame. On 9/17/10, the researcher arrived at Jack and Jill to observe Sterling teach EG's Scoop on Soil. He entered the classroom at 0859 and students were on the floor doing an activity unrelated to science. It was rainy but Sterling had decided to go outside. There were five students playing UNO on the floor at that time. At 0902, Sterling called attention for everyone to get seated which they did in five seconds. The class had read the book the day before and talked about it the previous week.

Sterling asked, "Soils can be what colors?” Students responded brown, red, white, black, and soft like flour. She had them partner off since there was not enough trowels. "Mr. Sam not pleased with 28 holes," she told the class and distributed the bags with a safety reminder. Suddenly, at little girl exclaimed, "Hey you are copying me.” Sterling asked, "Who is your partner?” She proceeds to hand out trowels at door and was very aware of time. The researcher noticed there was a high degree of excitement. Sterling had one adult assistant. She informed the class by holding up a bag, "How far fill bag." The researcher overheard a little girl, say, "I love science.” Another little girl said, "Someone littered on the ground.” The class was now along the trail adjacent to the school (Appendix J). A little boy became excited, "Look what 
I found. It's a rolly polly.” The researcher thought, these children have not been outside to look at nature. Sterling told several students, "Why not dig here? Don’t dig in the same place.” The researcher noted that the students were having fun doing the investigation. A little boy excitedly said, "Look at how much I got?” A little girl was overheard, "I found a bug” and another said, "I may puck,” and another, "I found a blue berry.” The researcher stood nearby two little girls with one seated on ground. The girl seated on ground was digging and filled bag for girl standing. They were unfamiliar to being in the woods, so Sterling asked them to spread out (time was 0925). Little girl, "I found 5 different kinds of dirt.” Another girl exclaimed, "Oh my gawd.” The researcher thought they truly love being outdoors. A little boy found a rock which was actually concrete that he took back to the room when they went back. Six students stood around Sterling while examining bag; the boy with rock (concrete) thought there was a tooth in rock. Later researcher learned he had an IEP.

The class returned to room and half of class gathered around Sterling examining their bags. One group found an orange spider. Someone asked, “Is she going to kill it?” Later researcher learned the class had 9 special education students, 11 different language speakers, and 2 non-readers.

The researcher wrote in the margin of his notebook: The experience was new to over 50\% of class-soil, woods, leaves, trees, FUN, excitement the entire time observed (total 55 minutes).

\section{Journals}

The impact categories identified in RQ2 and those found in the teachers' journals paralleled those identified for RQ1 in so far as barriers. The impact on those barriers includes mitigation on ease of use for EG lessons, getting outside in adaptable green space, and 
integration with other subjects as shown in Table 6. This impact on migrating time showed up in seven out of seven teachers’ journals

Table 6 Impact on Barrier Categories Found in the Teachers’ Journals

\begin{tabular}{lcl} 
Impact Categories & Percent of teachers $(\mathrm{n}=7)$ \\
\hline Outdoor resources adjusted for & $7 / 7$ & $(100 \%)$ \\
Mitigating use of time with integration & $7 / 7$ & $(100 \%)$ \\
Hands-on ease with accessible resources & $6 / 7$ & $(86 \%)$ \\
Ease of student accommodations & $3 / 7$ & $(43 \%)$ \\
\hline
\end{tabular}

Teachers readily accepted the interdisciplinary use of EG. The teachers liked the handson lessons related to language arts (e.g. journaling), math, and social studies. Three of the seven teachers commented on the need for having a suitable green space (Appendices $\mathrm{H}$ and $\mathrm{J}$ ) to do activities related to EG, but realized the importance of using what they had available. The use of EG mitigated the restraints of time by the provision of having prepared lessons with available resources. Ergo the limitations set by time and scheduling showed up to a lesser degree. Handson showed up to lesser degree: 86\% compared to 100\%. (Table 4 and Table 1) The impact of EG on the barriers was most notable in that the teachers became aware of them and sought the most readily addressable solutions, such as using nearby green space either in a nearby park (Appendix H ) or trail adjacent to the school (Appendix J). Being able to integrate EG with other subjects had a significant impact allowing science to be taught while also integrating language arts, social studies, and math:

The project that I used I could use it for reading because you have a story. Definitely science you could use it with math, even social studies because 
it is geographic different areas. You could use it definitely across the curriculum (Mary, interview one, 6/3/10).

And...

I think it brings it more to their level. They love reading and interactive read aloud and when they see the kids they can relate to them better then the teachers throughout a story are just adults doing it (Amy, interview three, 3/31/11).

Peter integrated his teaching in many ways with science and other subjects:

It [EG] can [be] tied in with mostly anything. We will be reading a story and the kids will mention something they did with GLOBE and that is the same type of activity we did. Hummingbird comes up and they mention oh yes that was in GLOBE. They don't actually mention GLOBE but does say we did that in science. The measurement, comparing temperatures and things like that. Social Studies and mainly comes into current events. We talk about current events every morning and it is a good time there also (Peter, interview three, 12/3/10).

I can't even count the ways [that you could integrate EG]. We read the story about the hummingbirds. Any time a South American county comes up they will say where that is in relation to Costa Rica or we have to get ready because it takes us about five minutes to walk down, how much time do we have and when we have to leave and then we have to get back. We have to schedule things. Directions as far as the direction we are walking and talking a little bit about when the sun is up, how can we use that to 
help us know directions when we are out walking around (Peter, interview two, 9/28/10). Allison commented in her journal, "I loved the fact the materials needed were there for us and very kid friendly for the students” (Allison, journal, 11/2010, p.3).

\section{Change over Time for RQ2}

Since this study occurred over a period of 18 months, there were some changes observed in the teachers' instruction. With EG designed as a hands-on curriculum, and elementary school emphasizes on manipulating things for a collaborative learning environment, the teachers welcomed a science curriculum they could easily utilize. Linda commented, "I thought the ideas with this were better than what I was using so the kids were excited in thinking about asking questions (Appendices N, Q, S and T) about the experiments we were doing (Linda, interview one, 6/3/10).” And, then in her third interview she endorses the philosophy that teachers need to think and adopt an inquiry approach to teaching science. "I think it continues to make me think and planning of how to plan. Big idea at first and then to think inquiry-based in all subjects instead of just handing it to them" (Linda, third interview, 12/16/10). The latter statement indicates a change in behavior caused by EG. This teacher holds National Board Certification, so this change should be considered noteworthy.

Sterling observed a change in her students' attitudes about nature and their awareness of the outdoors. They collected leaves and artifacts which they would bring back and store in the classroom.

We kind of carried it on over to our recess of the other times and they have done that on their own so that's been nice. It hasn't been a science thing. 
They have moved it across the day, throughout the day (Sterling, interview one, 10/19/10).

Amy became aware that the impact of EG had a duality to it, so that both the student and teacher were affected. This was addressed in the aforementioned except "When we came back in, it was hands-on so I think because of meeting all the different senses and all the different learning styles it was really beneficial for them and for myself (Amy, interview one, 10/19/10).” Allison reported a similar change in behavior, "I like doing the outside stuff. If they see it, I need to see things too (Allison, interview one, 10/20/10).” This change coincided with the interview response of Peter.

Once we got outside once to do one of the activities, the kids were after it. They wanted to go outside again. I intra mixed the GLOBE program with our regular curriculum so we did a little from our textbook and then we would go outside and do some GLOBE activity and they always wanted to go outside (Peter, interview one, 6/10/10).

After several months, Mary elaborated on the observable change in a more charged manner and how her students’ outlook [had] changed.

They get to really experience it and understand it [more] than just me talking. To them it is more of an investigation and they actually get to participate and look at things and touch things depending on what GLOBE activities, so that is why I think it really works (Mary, interview two, 10/15/10). 
Triangulation of Data from Observations, Journals, Interviews, and Student Artifacts for RQ2

Seven out of seven teachers' demonstrated behavior that impacted the barriers found in RQ1 (e.g. time, green space, accommodation). Six out of seven teachers demonstrated that EG could impact their lack of time, teach to standards, and accommodate students with special needs through integration of science with core subjects like reading and math. Three of seven commented on accommodation in their journals. This was in evidence in all the teacher observations. Student artifacts (Appendices G, L, M, N, O, P, Q, R, S, T, U, and V) showed the ease of using EG, across the K-4 grades. These artifacts provide evidence of integrating math, meteorology, language arts, and social studies.

\section{Research Question Three}

$R Q$ 3: What factors/conditions made EG difficult for teachers to use and what factors/conditions made EG easy for them to use?

There were two interview questions asked about the factors/conditions making EG difficult for teachers to use and what factors/conditions made it easy for them to use.

1) How much teacher training do you think should be required to teach elementary science? (Question asked in interviews one and two.)

2) Is there anything that you would do differently when teaching science to your students in the future? (Question asked in interviews two and three.)

Table 7 sets forth the factors/conditions that made EG difficult/easy for teachers to use. 


\section{Table $7 \quad$ Factors/conditions Categories Found in Interviews for RQ3}

\begin{tabular}{llc}
\hline & & \\
Categories RQ3 & Percent of teachers (n=7) \\
\hline Teacher without prior EG training (difficult) & $6 / 7$ & $(86 \%)$ \\
Teacher behavior change (easy) & $6 / 7$ & $(86 \%)$ \\
District curriculum use (difficult) & $4 / 7$ & $(57 \%)$ \\
Time management (difficult) & $4 / 7$ & $(29 \%)$ \\
Teacher with prior EG training (easy) & $2 / 7$ & $(29 \%)$ \\
& & \\
\hline
\end{tabular}

Interviews

When the researcher asked interview questions seeking to identify factors which made EG difficult to teach the following responses were recorded. The researcher addressed the difficulty factors first, and then attempted to identify the factors which made teaching science easier in subsequent analysis. The first interview question attempted to surmise the training teachers required to instruct elementary science.

Allison responded, “I don’t know how much. More than what’s offered. [I would like] Professional development classes to get more ideas. Because we go to all these conferences for reading. I think we should do it with science too" (Allison, second interview, 12/15/10). She was not sure of how much training that was needed to teach science, so her awareness of professional development required for teaching science is a factor identified as difficult. Allison taught second grade and had five years of experience.

Amy, a third grade teacher, also seemed unsure of how much training was needed to teach elementary science. There was a significant difference in magnitude of her answers that she suggested for professional development (coursework) between interviews one and two: 
I think it depends on what you have to use and what your resources are. With Elementary GLOBE you need a little bit of a background but just basic as in going to college classes and learning how to teach the kids and deal with them but if you are thrown a science book I think you need more guidance (Amy, first interview, 10/19/10).

A lot more than what I've had. I think as you specialize as you go into the middle schools, you specialize in a content area; I think elementary school should have that also. I think we need more classes and not just general classes on math or general in science. I think we need more involved in all of them (Amy, second interview, 3/31/11).

Mary, a first grade teacher, indicated that she would also have liked to have had more science training to feel better prepared:

You know we only have to have one class. I think for some teachers it doesn't matter because they don't teach science but I am a science teacher, so I wouldn’t have minded having another class on science just to get more ideas and get a better way of teaching it besides just using the curriculum they [XYZ County] give us (Mary, first interview, 6/10/10). Alicia, a new kindergarten teacher, indicated that coursework should be more than one elementary science methods class:

I think two classes would be good. You could base one class solely on GLOBE. I think would be neat where the teachers would actually do the activities that they are going to implement in the classroom. Then another 
class based on science outside of GLOBE, just background information (Alicia, first interview, 10/18/10).

In her second interview (12/2/10), she reinforced the need for more professional development:

I think one or two courses at the college level are sufficient. I think that would be great too, because you could see the lessons [EG] done and become really familiar with the program before the school year begins which would be nice (Alicia, second interview, 12/2/10).

Alicia wanted additional training with EG to more thoroughly familiarize herself with it. This is significant because she had been introduced to EG in an elementary science methods class while completing a master’s degree at a nearby university. Even though she had high praise for the methods class, she still felt the need for extra coursework to teach elementary science. She said, "I think that class taught me more about science then I learned through any other class at WVU. It was very hands-on and [to] me that is the most effective way to teach. I would have loved to have more than one or two, I remember” (Alicia, interview two, 12/2/10).

Sterling holds an endorsement in social studies, and she appreciated the fact that EG provided materials which allowed the students to do science outside (Appendices L, M, N, O, and T) with the curriculum included with the EG notebook and the storybooks. EG contains resources that come with the curriculum. These resources make teaching science easier because the preparation for teaching reduces the time to gather materials.

I would love to be given ideas. That's why this is nice. I have the science book and I have those labs that they give us but I don't have the materials for the labs that the county curriculum requires. I don't have all those 
things so with the GLOBE we can [go] outside and find the soil samples or we can go outside and look at the clouds that are doing whatever and it is nice because I do not have the materials and it is intimidating but they are easier to access from GLOBE then they are the specific ones the book has. Sometimes I get stuck doing labs in science with the book [school district issued] (Sterling, interview one, 10/19/10).

All the participants, seven out of seven, wanted to improve their science teaching and each had their preferred methods on how to do it. Included in the seven was the one case who had earlier taught with EG. Some wanted more instruction on using hands-on science labs and one looked forward to having a science night for the parents in the fall.

I think it is important in kindergarten, [to do] hands-on activities that will keep them actively learning rather than just reading and writing so like the hummingbirds (Appendix V) was interactive to them and that was a great activity so I don’t think I would change anything other than trying to come up with more activities for interactive science lessons (Alicia, interview two, 12/2/10).

There was universal approval for using EG in their science instruction, and the teachers with less than 10 years of experience (that was five of seven) welcomed the opportunity to learn more EG hands-on activities through inservice training.

My plan [is] because I really like the Elementary GLOBE it has hands-on [activities] and it gives ideas of things to do so it is easier for them to learn so I definitely want to continue to use that and it is hard at first to [do] them all because it is learning the curriculum but after I do a few of 
them then I will know how to do those and I could add to it and eventually do them all and then even with my CSO’s I want to eventually have like everything will be learned in stations where there is hands-on (Allison, interview three, 3/10/11).

Since teachers encounter time restraints, learning to improve their science instruction within limitations is an ongoing challenge. This is especially apparent when trying to teach the broader concerns of issues such as global climate change and environmental concerns. In a school like Jack and Jill Elementary, with 700 students, teaching beyond your expectations can be daunting as this teacher explained: "Just knowing what is going on environmentally. I try to do my best by planning ahead for all eight classes every day and it is kind of overwhelming” (Amy, interview three, 3/31/11). Additional training to teach science was seen as a limiting factor by her. As had been identified in RQ1, time was also seen as a difficulty factor when teaching science, even with the most experienced teacher in the study. With 32 years of experience, Peter summarized his thinking this way:

I just wish I had more time. That is the main thing. I am always doing little things different but as far as major changes, no. I like teaching science and we do as much hands-on as we can. This year for the first year we did a family math night at Jane Doe Elementary just a few weeks ago and it went over very well so we are thinking about maybe in the spring doing a family science night just to get the parent in and some hands on activities and see some of the things they can do at home. Other than that, just enrich the students a little more with projects to do at 
home. But I think [the] curriculum is going very well (Peter, interview three, 12/3/10).

Peter was the only teacher who had previously used EG in his classes. His interview answers provided important insights on teaching with EG. He was able to easily integrate science in his daily teaching responsibilities, but still felt time was a major factor to teaching science. Peter acknowledged the need for additional science training if teachers were to go beyond the textbook.

Well to teach it effectively I don't think you are going to need a lot of training if you are just going to teach straight from the textbook but I think if you are going to do hands-on activities that make it relevant to the kids, I think they definitely need at least one methods class that works on doing activities and having the kids getting comfortable making predictions [inquiry] and things like that so I would say at least one full semester of nothing but a science methods class (Peter, interview two, 9/28/10). When asked what she would do differently, Linda, the second most experienced teacher (23 years), added that she would focus more on using inquiry and discovery based learning: Again I would focus on inquiry and discovery based learning. In kindergarten you always do hands-on things with science. That is the only way to get them to do it. The change probably for me is that not giving away why you are doing what you are doing until they get their hands on it and figure it out as opposed to telling them at the start. That has probably been the biggest challenge for me. I wish I had GLOBE as I was doing national board. I probably would have had a better understanding of 
the process of national board and with accompanying it probably is what changed my direction of that thinking because it is the exact same way of thought. I probably wasn't and I don't want to say aware but certainly not really utilizing that method of teaching before I did national. That was the biggest thing national board did [sic] for me was probably in the science field, as far as changing the way I thought about my planning and teaching and GLOBE is right along the same lines. It is the same thought theory (Linda, interview three, 12/16/10).

Sterling expressed how she wanted to improve her teaching by wanting more professional development to learn elementary science hands-on activities and acknowledged time was also a factor in teaching science just as Peter had stated previously (interview three, 12/3/10).

I need to know more. Like this year is the first year we done this and I feel it was more trial and error and we are winging it and I don't know what to expect. With the clouds particularly if we did it over time instead of having set weeks to do it that would have been easier because we really struggled getting outside because it rained I think that full week. I think that is how it changes, just be more prepared. I don't feel like we were this time. We were but the weather hurt us (Sterling, interview three, 12/21/10). Interviewer: Would you enjoy more inservices if you could get them? Yes that would help all of us especially after we have done this for a year. Now we know what we don't know. Before this we didn’t know. We were 
like, yes we will do it but we didn’t know if we were lost or confused or what we didn't have (Sterling, interview three, 12/21/10).

The second interview question regarding future teaching provided more information to address RQ3 than the interview question asking about teacher training. This was presumably due to the studied teachers focus on taking coursework, and then listing their previous experience with a methods course on elementary science. When asked, "Is there anything that you would do differently?” The teachers provided answers offering insight into usage of EG. These included more hands-on experience, professional development, practice with inquiry based curriculum, and additional in-service opportunities.

The themes for RQ3 were need for more professional development as a difficulty factor and desire for more time to teach elementary science. The ease of using EG (ease factor) was found to be a category but not present enough to be a theme. The self-contained, pre-prepared, resources contained with EG made it easier to use. As the teachers got experience using EG, they became more comfortable with the curriculum and inquiry-based investigations. In the early interviews, the teachers with less experience ( $<7$ years) had more difficulty in learning to use EG, but by the third interview, they had become familiar with the curriculum and could apply the inquiry method. In this group ( $<7$ years experience), there was noticeable change in way the teachers taught science. They had more excitement and enjoyment in the delivery of pedagogy. This agrees with research about teachers building self-efficacy through building on what they already know (McDevitt, Heikkinen, Alcorn, Ambrose, \& Gardner, 1993). Linda acknowledged this in interview two, "Maybe it is more a willingness to let go of the textbook. Instead of textbooks and work sheets, make it more hands-on.” Though not measured, teacher self-efficacy 
improved as the less experienced teachers ( $<7$ years) became more familiar with using EG. This should be studied in future research regarding the use of EG.

\section{Classroom Observations}

Since there were 24 classroom observations done over 18 months, several cogent statements can be made regarding the difficulty/easy factors found. Mitigating time through integration with reading, journaling, math, and social studies made it easy to use EG. This was observed in seven out of seven participants. As shown in Table 8, the extra time needed to do inquiry-based science activities was observed as a difficult factor but mitigated by having available resources (e.g. storybooks, handouts, scripts, web resources) from the Elementary GLOBE Resource Kit K-4.

Table 8 Factors Found in the Classroom Observations Making EG Difficult/easy to Use

\begin{tabular}{lcc}
\hline & & \\
Categories & Percent of teachers (n=7) \\
\hline Hands-on preparation extra prep (difficult) & $7 / 7$ & $(100 \%)$ \\
Time mitigation w/ integration (easy) & $7 / 7$ & $(100 \%)$ \\
Accommodations (easy) & $6 / 7$ & $(85 \%)$ \\
& & \\
\hline
\end{tabular}

On 2/16 the researcher arrived 1025 at Allison’s second grade classroom and waited in hallway. The researcher noted that students were reading and 17/17 students were engaged with writing a story. Allison had a WVU student assisting her. At 10:25 a.m., Allison asked, "Who wants to share?” She called on a boy to read a story about a raptor and went around room calling on students to read from their books ranging from alligators to volcanoes. Some students leave by groups at 10:30. A little girl smiles at me (I am not invisible and noticed). 
Allison says, "Gonna do science” (10:32 a.m.) and brings them to attention with "Class, class, class. Remember the GLOBE Kids?” A little girl raises her hand, "Yes, mystery of the missing hummingbirds.” At 10:35 a.m., Allison begins to read Discovery at Willow Creek while seated in front of class sitting on floor. The class is attentive and 19/19 students are on-task. Allison does a good job doing the reading theatre. A little boy raises his hand and says, "Scientist study everything.” Allison says, "They write in their journals like you do.” The students mumble, "Yes." Allison stops reading open ended questions about the story. She uses previous EG storybooks to compare to what learned from Discovery at Willow Creek. She asked the students to list differences from fall and those found in Willow Creek book. Students remain engaged and Allison begins to ask more questions. She says, "There are actually water boatmen (water sliders)." Students raise their hands when have a questions. Allison asks, "Where does all the water come from?” The students say in unison, "Rain!” A boy adds, "Water melts and flows down the stream.” The researcher notices the enthusiasm and one girl wanting to do an activity from EG.

At 10:48 a.m., Allison introduces an activity on measurement (Appendices P and Q) that accompanies Discovery at Willow Creek. Allison stands in front to show pictures from story and demonstrate the measurement handout. A girl proudly answers an anticipated question and all class members engaged. Allison uses a pencil to measure the door as a demonstration and distributes pencils to all the students. She says, "You are going to get one other measuring tool." She proceeds to distribute a paper clip and follows with this question, "If going to measure the white board, would you use paperclips of pencils?”

Allison introduces standard and non-standard measurement (Appendices P and Q). Boy asks question about difference. "Now I want you to measure a pencil. What would you use?" 
Class says again in unison, "Paperclips!” She asks the class to find something to measure. Allison smiles at student entering room and checks object to measure (11:07 a.m. is time). Allison asks one student to estimate boy's object. She looks at me and smiles (researcher thinks not being hidden enough?) Boy says 30 and then measures 9 pencils. Boy is from country other than United States so diversity is an issue. Allison shows him how to measure with pencil. Answer is 7 pencils. Researcher writes in his notebook, Diversity an issue: Boy measure includes flower pot with height of plant, instead of soil surface to tip of plant when using real plant in small pot to take a measurement. Observation concludes at 11:05 a.m. and class lines up for lunch.

EG offers accommodation for students with special needs and opportunities to integrate subject (e.g. math, reading, climate studies). This was in evidence in the observation with Allison as EG impacts barriers through integration and accommodation.

\section{Journals}

As noted in Table 9, the teachers found EG to be both easy to use and difficult because of needing the time to do the lessons and lack of available outside resources. "I wish that we had more time to do science in school. I think the students really have enjoyed and learned from the GLOBE curriculum. The GLOBE is very easy to adapt and incorporate [in] multi-subject areas” (Amy journal, no date, p.8). Another teacher wrote:

- $\quad$ "I loved the fact the materials needed were there for us and very kid friendly for the students” (Allison journal 10/17/10, pp. 1-2). She continued: "We did our journal entry at the end - outside. I wanted to do it outside for a few reasons:

o The students enjoy being outside and learning in such a way.

o It kept their environment fresh in their head 
o It was chilly/cool day to be out in it while you're writing helps you describe it better.

o Once inside the students colored their pics the way they saw them outside" (Allison journa1, 10/7/10, pp.1-2).

Table 9 Factors Found in the Teacher Journals Making EG Difficult/easy to Use

\begin{tabular}{lrl} 
Difficult/easy Factor Categories & Percent of teachers (n=7) \\
\hline Accommodations (easy) & $6 / 7$ & $(86 \%)$ \\
Time mitigation with integration (easy) & $5 / 7$ & $(71 \%)$ \\
Outdoor resources lacking (difficult) & $4 / 7$ & $(57 \%)$ \\
Available resources included w/ EG (easy) & $4 / 7$ & $(57 \%)$
\end{tabular}

The teachers enjoyed using EG and how their students were impacted making it easy for the teacher to use. Linda wrote, "Loved the lesson-very engaged, virtually no discipline problems” (Linda journal, 5/12/10, p.7). The accommodations provided by EG made it easy to implement as was demonstrated in Linda's journal entry. The availability of teaching resources included with EG made it easy to use as Linda wrote:

Used samples of soil from outside room and mixed in jar with $\mathrm{H}_{2} \mathrm{O}$.

Students took turns shaking jar, then set timer and waited 2 min and recorded observations (Appendix R). Discussed colors would need to record. Began reading "Scoop” story and reset timer for 10 min. Recorded again at $10 \mathrm{~min}$. Kids had good discussion about what they saw settling to bottom. Predicted what it could like in 24 hours” (Linda journal, 5/13, p.9). 
Time was always factor to consider, making it difficult to use and plan EG. Mary commented on this: "I was a little nervous having them (students) dig through their soil since I had only 30 min but they did a great job. They were so excited to share what they found” (Mary, journal 5/8, p.4). The ability to accommodate for students with special needs was shown to make EG easy to use as Peter wrote in his journal: "It's interesting the boys who are the biggest behavior problems in class were really into outdoor activities. They were actually helping out some of girls who were sort of holding back. Student (LD) had a good day” (Peter journal, no date, p.5). The ease of using EG was also noted in Sterling's journal:

Today I read the Scoop on Soil. I was honestly concerned that it would be to "babyish" for $4^{\text {th }}$ grade but they loved it! It is hard finding something that all 36 will sit and listen to, but it worked out well” (Sterling journal, 5/10, p.3).

\section{Change over Time for RQ3}

The teachers became aware how much training was needed to teach with EG. Over the course of study, they learned that practice with the curriculum makes for more efficient use of time scheduled for teaching science. Sterling realized the value of practice when instructing science. "I think personally it [is] trial and error. I would love to be given ideas. That's why this is nice [referring to EG]” (Sterling, interview one, 10/19/10). Teacher training was evident as the most common difficulty category with RQ3.

The one teacher who had had prior training with EG considered it an easy curriculum to use. The hands-on activities were a rationale for using EG. With a new garden planted for use at one [Jack and Jill Elementary] school, it should provide an incentive to get teachers involved 
with EG lessons. Two participants already had expectations on how they would utilize the garden. As the teachers became more familiar with EG at this school, they realized how easily it was to integrate a science lesson with the core subjects of reading, writing, math, and language arts.

The GLOBE Kids in the storybooks, model learning activities that support learning the core subjects of reading, writing, and math. The teacher noted this and used it to work on writing skills in science journals. This became more apparent as the year progressed.

That is something more and they actually go out and see what we have and experience especially with the one where they go out and look around and here they have the seasons even all year around and go and say this season the flowers are dead, and this season the flowers are blooming. What kind of animals, bugs and insects are around there so it is more hands on and they can physically see it, not just something they are reading in a book (Mary, interview three, 11/17/10).

And...

..hands on activities that will keep them learning rather than just reading and writing so like making hummingbirds (Appendix V) was actively interactive to them and that was a great activity so I don't think I would not change anything other than trying to come up with more activities for interactive science lessons (Alicia, interview two, 12/2/10).

This thinking parallels that of current research (Hachey and Butler, 2009; Pretty et al., 2009; Louv 2008). Gardening and nature-based play integrates meaningful activity while establishing scientific attitudes (NRC, 1990, p.14; Subramanian, 2002). Pretty et al., (2009) 
suggest gardens be used as a regular part of the curriculum and encourage more outdoor free play for children aged 6-11.

Triangulation of Data from Observations Journals, Interviews, and Student Artifacts for RQ3

All observations show ease of integration saves time for teachers to instruct in language arts, math, and social studies. Student artifacts provide evidence for the ease of interdisciplinary integration (Appendices G, L, M, N, O, P, Q, R, S, T, U, and V). "I loved the fact the materials needed were there for us and very kid friendly for the student” (Allison journal, 11/10, p. 3).

We reviewed the Willow Creek book and talked about how the GLOBE Kids measured - it was great how it tied right in w/ measuring and the students hardly realized it (Appendices P and Q). I like being able to relate what they are doing to the kid's in the book. I'm so thankful Vance brought in real plants for us to measure! The kids enjoyed measuring an actual plant with the rulers. It made the lesson more real (Allison journal, 11/10, p. 11).

The walk from the room to back parking lot, fresh air, and new environment was everything they needed. Students were noticing everything...cars in McDonald's Parking lot driving, a roof on a house hidden in trees, bees, signs, tall/short trees. They were very detailed. The pictures are great. It was like they were able to escape and express what they were seeing through their own eyes (Alicia journal, 10/7, p.1).

The teachers' journal entries corroborated the integration observations in six out of seven journals. The interview answers and student artifacts provide substantive significance (Patton 
2002, p. 467) for ease of integration, use, and time saving modality of EG. These are easy factors associated with utilizing EG.

The students enjoyed science, which made the use of EG easier for the teachers to implement. All 25 observations give evidence for favorable student involvement and impact. The researcher witnessed demonstrative behavior of children having fun. There was one observation where the children were playing "patty cake" with soil from the Scoop on Soil EG module (Mary observation 4/29/10). One teacher recorded this journal entry: "The kids were so quiet and engaged. I was amazed. They went from being wild and disruptive to...eager to learn quiet students” (Alicia journal, 10/7, p.1).

The interview questions for RQ3 support the observations and journal entries for students enjoying EG and making it easy to implement. Interview question two provided the most support for student engagement and impact making it an easy to use factor. Alicia reinforced this factor by how she would teach.

...hands on activities that will keep them actively learning rather than just reading and writing so like making hummingbirds (Appendix V) was interactive to them and that was a great activity so I don't think I would not change anything other than trying to come up with more activities for interactive science lessons” (Alicia, interview two, 12/2/10).

Allison changed with her students. "My plan because I really like the Elementary GLOBE because it has hands on it gives me ideas of things to do, so it is easier for them to learn so I definitely want to continue to use that...” (Allison, interview three, 3/31/11). Linda states a similar tone, "I think it's given me a better format to plan my own lessons and have them more 
inquiry and hands-on based” (Linda, interview two, 9/29/10). Teacher attitude change was another easy factor noted but not in numbers to warrant a category for RQ3.

\section{Research Question Four}

RQ4: How has the adoption of Elementary GLOBE impacted the teachers, including their approach to delivery of science instruction?

\section{Interviews}

There were four interview questions ascertaining the impact on the teachers using EG.

These questions addressed the delivery and approach to teaching of science instruction with particular interest to implications for practice.

1) What do you do with the student science journals and other student produced artifacts from EG? This was asked in interviews one and three.

2) What is the role for the school in promoting science in the elementary class room? This was asked in interviews one, two, and three.

3) When teaching with EG, how many ways did you find to integrate the lesson with other courses taught at your school? This was asked in interviews one, two, and three.

4) Please tell me how your science teaching with EG has gone since last time we talked? This was asked in interview three.

The adoption of EG impacted the teachers and their teaching in several apparent ways.

The teachers became more cognizant of how to teach science given time restraints. They also showed heightened awareness when addressing environmental concerns with their students and improved their science education delivery with use of available resources. As shown in Table 10, there impact of getting more of the school population involved with the broader perspective on environmental issues. The impact and delivery categories are set forth in Table 10. The 
parent connection should receive special note as it extends the learning of science into students' homes.

\section{Table 10 Impact and Delivery Categories Found in Interviews for RQ4}

\begin{tabular}{lc} 
Categories RQ4 & Percent of teachers $(\mathrm{n}=7)$ \\
\hline Integration (ease) & $7 / 7(100 \%)$ \\
Parent connection & $6 / 7(86 \%)$ \\
Teacher collaboration & $4 / 7(57 \%)$
\end{tabular}

Interview question three provided the most insight on the impact of the EG usage. This can be seen in the following comments:

The GLOBE Kids obviously integrate into reading. By putting it up on the white board for them to see then that helps them and they are reading it even though they don't realize it. Then [it is] social studies, which is geography with the hummingbirds (Appendix V) where they are and where they go [sic] (Allison, interview two, 12/15/10).

And...

By myself being more aware of what's going on. I think it is easily pushed aside after locking in so much information and being here so long and grading papers and then you go home and I don't think I take enough time to watch the news and really focus so that I know what is going on as well as I should so I can talk with the kids.

Interviewer: By bringing your personal knowledge into the classroom? 
Yes! It really helps when you speak through your heart (Amy interview three, 3/31/11).

I integrated like the Willow (Discoveries at Willow Creek) with math when we talked about the measuring, non-standard units (Appendices P and Q) . They always integrate with reading, when we are reading a story they are listening and comprehend it. ..we have done the seasons and the hummingbird (Appendix V ). We talked about the measurement of the bird and small. How small it was compared to their hand. Yes, so that is social studies and also with that one the temperature because we did it right after we talked about temperature so Celsius and Fahrenheit and the calendar (Allison interview three, 3/10/11).

The teachers became adept at using the available time to present science lessons. EG was designed to permit flexible usage and Amy endorsed this reality in her comments:

I think it was easy to integrate it because it opened for a variety of other classes with adding the math in it and adding the write so I think it was very easy to take one of the lessons and then integrate it throughout the day or throughout the unit actually with other classes too.

Interviewer: Do you try to do it all the time when you do it throughout the day?

I try to but not always, depending on our schedule because I think you have to be extremely flexible at this age because there are so many things happening and going on throughout the day but ultimately that is the goal doing it (Amy, interview three, 4/5/11). 
By being able to integrate science lessons with language arts and math, the teachers consistently showed higher self efficacy (Bandura 1997) in being aware of the positive effects that EG had on their students. The hands-on science activities appeared to have an effect as this teacher relates:

We integrated it with writing because when they finished a GLOBE lesson we would then follow up with the journal writing about their observations so we integrated it with writing and I would say use math as well talking about seasons and how many sunny days and how many cloudy days we had so math and writing (Alicia, interview three, 3/8/11).

The GLOBE lesson we just did on clouds, I was able to integrate into reading, core science. Even art because they did art work with it and writing because they went outside to observe the clouds that day and then wrote all about them. I could have integrated it with math. I just didn’t with this class.

Interviewer: I saw some of the work that they did in the hallway. I am sure it is entertaining for everybody at the school (Appendices L and M).

Oh yes (Mary, interview three, 11/17/10)!!

The ease in which EG can be integrated was not lost on the most experienced teacher and the only teacher who had received training on how to use EG a year earlier.

It can tie in with mostly anything. We will be reading a story and the kids will mention something they did with GLOBE and that is the same type of activity we did. Hummingbird (Appendix V) comes up and they mention oh yes! That was in GLOBE. They don’t actually mention GLOBE but 
[they] say we did that in science. [We did] The measurement, comparing temperatures and things like that [sic]. Social Studies that mainly comes into current events [sic]. We talk about current events every morning and it is a good time there also (Peter, interview three, 12/3/10).

Most elementary schools endorse curriculum projects which students do to enhance their courses. EG provides the opportunity to enhance students' creativity with science related projects (Appendices L and M). The curriculum has science investigations that include the need to draw in journals, compare and contrast data using drawings, and record student views of nature (Appendices N, S, T and O). These science activities encourage students to discuss their findings in class and also with other students outside of the classroom.

With the kids I have done the Big Picture View where they drew the picture, the big picture outside and I have also done the Zoomed In View and I have started reading the book, the hummingbird one, The Mystery of the Missing Hummingbirds. I have been reading that with the kids and I read a little bit each day to kind of keep them guessing and keep them thinking. That is about all I have done right now. Because of the Big Picture and the Zoomed in View is the focus of seasons, I have also had them bring in artifacts from outside that they have collected from home that represent Fall so that's been really cool to see what they bring in. Interviewer: I look around the room and I see there are some leaves. That must be some of the artifacts that you are talking about.

Alicia: Yes.

Interviewer: And then you tie that into GLOBE? 
Alicia: I tie it to the GLOBE, yes. We are talking about seasons (Alicia, interview three, 3/8/11).

Doing investigations give the students opportunities to compare and contrast their work with others, just as real scientists do. This promotes new insights and scaffolding the lesson. Amy did this with her third grade class and explained that "even if we do the project together, we do it differently.” We hold onto them for awhile and go over and discuss each individual because even though everyone is working on the same project everyone is going to have a different point of view and different results (Amy, interview three, 4/5/11). Amy used the EG activities to initiate discussions of findings so her students could learn more about projects by examining different viewpoints. This is important as it coincides with the National Science Education Standards for grades K-4. Students should be developing ways to communicate and analyze their work and the works of others. The standards suggest that this communication could be spoken, written, or drawn (NRC, 2000).

With Amy and the other teachers, their students participated in learning science by discussions and group projects. The one school with six of the seven participants saw a larger awareness in science when some of the EG lessons were posted in the hallways (Appendices L and $\mathrm{M})$. In this school, the group projects received attention from the faculty and student body when posted in the hallways.

We displayed them in the hallways (Appendices $\mathrm{L}$ and $\mathrm{M}$ ) so the other kids could see them. I know at the first grade they were excited to do the projects and our guys upstairs being the mentors the other kids were able to see what we had done with the first grade and wanted to participate in that also (Sterling, interview three, 12/21/10). 
Sterling believed in doing collaborative work in her classes and made it a practice to discuss finding among her students.

We share them so we can see what the other ones have found and then in our reading we have done a lot of diagrams and comparing and contrasts and we can do the same stuff with the samples we collect or the clouds we see or any of that stuff and comparing with their neighbors and seeing similarities and differences or see the same things and get new things out of it so we have a lot of shared time across the board in here.

Interviewer: So the students become collaborative with other students? Yes. They are heterogeneous groups like in their reading groups they are heterogeneous groups so the science is nice because they are not with the same people all the time when they are sharing (Sterling, interview one, 10/19/10).

The school became a participant as well as the teachers. This was surprising to observe because it created a situation where once a particular class of students had done an activity, other students in the school population would inquire about it. Students are naturally curious, but the added excitement of wondering when they were going to do a similar activity furthered the excitement for everyone in that grade level. This observation is anecdotal but teachers did comment on the researcher's observation. Sterling's experience speaks to this observation. Her words show the importance of creating a positive learning activity as other students “... wanted to participate in that also.” See the aforementioned comment for the full quotation (Sterling interview three, 12/21/10). Students wanted to 'copy-cat' what other students were doing. 
The students with this project I think learned so much more then what they possibly could have about clouds and having the opportunity this year.

Plus we used fourth grade for mentors so it really helped them understand also but they visually saw what certain clouds were and they got to read about them in the book that comes with it which I thought was really neat and they connect with those kids or the students they use in their books. That was for their level this year they were able to relate to it, it was something they knew about. They could go outside anytime and look at the clouds and understand the different levels and at least know the names of them (Appendices L and M).

We hang them on the wall, depending on the project. The cloud project, they are hanging out in the hallways. The soil project, I have taken pictures of them digging and that sort of thing and I make copies of the photos for them so they can take them home. They get to take everything home at the end (Mary, interview three, 11/17/10).

The student practiced writing and language arts skills by using their science journals (Appendix G). These journals also had the added impact of being a tool for the teacher to communicate with the parents of their students.

The journals we started this year from the beginning so it will be something they will use all year and then take home at the end of the year. What I plan to do because their drawings are so elementary, I plan to write an accompanying letter to the parents explaining what we had down throughout the year and what some of those pictures and drawings were to 
mean. I talk about that in my weekly newsletter to the parents but by the end of the year they won't relate back to that. We have a weekly homework sheet that we use the weeks work for the parents to do and then a full page newsletter every week (Linda, interview three, 12/16/10).

Keeping journals allows the students to compare their observations from earlier in the year and provide a record of their science work. One teacher kept the journals for his students and then bound them at the end of the year. In this way, his students had a record of their work which they and their parents can review.

I went back and had the students compare. I put all the journals together. I kept the seasons all myself and made a booklet out of it and gave it back to them. I told them we did a little guidance with that to compare your picture of the three seasons. I didn't do any follow-up with that because it was crunch time because of missing for the snow days but I think the opportunity is there to get them compare and contract especially with that season unit that goes all year long (Appendices $\mathrm{O}$ and $\mathrm{T}$ ). Comparing their art work, I think some of them were impressed with how much more detail they had on their last drawing then they did on their first drawing. I think the opportunity is there to make a really nice holistic science opportunity. I did not do that as much this year as I hope to do next year. I think the opportunity is there. The kids got a big kick of getting it all back together and got to take it home (Peter, interview one, 6/10/10). 
The journals allowed the entire student body to participate in the EG activities and promoted discussion among the students. When the journals went home with the students, the students got more reinforcement about the many ways science affects them.

I think it is making aware of science everywhere. Science isn’t just when we are learning about it in school and if the kids aren't exposed [to] understanding that it is everywhere in the real world they are just going to think it is school related and especially since I think we have so many resources especially with this garden coming that they are going to realize that it is everywhere, and it is what they eat. They think it is from just a book, science (Amy, interview two, 3/31/11).

The EG encouraged the teachers to go beyond the textbook. "With science just get through what you can as long as you get through...” “I do not feel that I am ever pushed to go above or beyond.” (Allison, interview one, 10/20/10) Allison then added, “They just expect us to take out the text and handle it ourselves” (Allison, second interview, 12/15/10). The teachers are permitted to deviate from the curriculum but there is little guidance.

We have a CSO that we have to follow and we just are allowed to teach those I think however we choose to but we are provided with the textbooks we are supposed to use. I don't know if we have to or what. Something we talk about a lot (Allison, interview three, 3/10/11).

Allison used student feedback to guide how she approached science teaching. Her delivery of science teaching significantly changed after adopting EG. Prior to adopting EG she said, "We are expected to read it and figure it out and do what we can with what we have (Allison, interview one, 10/20/10).” After using the curriculum with the GLOBE Kids she 
showed self-efficacy (Bandura, 1997). Knowing that she could change her students with instructing science promoted a positive projection for teaching. Allison demonstrated that the EG curriculum could elicit changes, in how teachers perceived their delivery of professional content knowledge. This was the first year that Allison had used EG, so to make a change in her attitude is a finding to note.

I enjoyed teaching them because they enjoyed it and the stories are so interesting. I think it is neat just to see them when they get it when you are reading because it is kids too their age because they can relate to those GLOBE kids. I like it and will continue to use it (Allison, interview three, 3/10/11).

Allison was not the exception to self-efficacy. When asked what the role of the school was in promoting science, Alicia a first year kindergarten teacher said, "I have frankly no idea. I have never been told and like I said I don't have a science curriculum, so this GLOBE curriculum is all I am using” (Alicia, interview one 10/18/10).

Using EG, Alicia impacted her students by exposing them to the outside in ways that encouraged them to observe their surroundings. Through the process, she believed in making a positive impact on her teaching and what her students learned. Research shows that having students learn in green spaces promotes learning (Robert Wood Johnson, 2009; Rickinson et al., 2004) Being a new teacher, she sought advice from colleagues. EG also impacted her teaching in how she collaborated with other teachers.

I have also talked to some second grade teachers about how they are implementing GLOBE. I haven’t really talked to any teachers who aren’t implementing Elementary GLOBE and are doing science in their room so 
as far as kindergarten goes. The GLOBE program is awesome to promote science (Alicia, interview two, 12/2/10).

This collaborative atmosphere of teaching had a positive effect on her first year of teaching. In the later stage of this study, the school planted a garden for use by parents, children, and faculty. Alicia commented on the involvement of the school community. "They are very involved in the science curriculum and a lot of other teachers here are as well so it encourages me to teach GLOBE and teach science because of the importance of it at Jack and Jill” (Alicia, interview three, 3/8/11).

Linda understood that schools are accountable for standards, which are addressed in assessments. She tried to explain the dichotomy of teaching science with the lack of priority it was given.

I think from top down it is again making sure the teacher is supplied and the materials are there, making it a focus of the curriculum. Now it is becoming a part of what is scored, well it has always been scored on the standardized tests but started to be weighted more and looked at more as far as no child left behind evaluations so I think it is important to arise. Unfortunately what gets done is what gets tested (Linda, interview one, $6 / 3 / 10)$

This changed during the course of the study with the realization that EG could be integrated easily if the teacher chose to take the time to prepare the science instruction with another subject such as math and/or language arts.

I think that formatted lessons, any time you do and I call them a packaged lesson or when we used somebody else's lesson that is inquiry-based it 
helps you in planning your own, so even when I am working with things

that are outside what GLOBE does, I think it's given me a better format to

plan my own lessons and have them more inquiry and hands on based.

..every time you teach science, you are using math and English and

language arts and that it can certainly be integrated at the time... (Linda,

interview two, 9/29/10).

The theme for RQ4 was the ease that teachers found in integrating science with other subjects. After one grading period, they became more comfortable with using EG. This showed in the delivery of science instruction and also in collaboration with other teachers, especially those in the research sample of six teachers. They shared their experiences using EG, making the science teaching a collaborative effort.

\section{Classroom Observations}

When using the storybooks the teachers understood that the GLOBE Kids functioned as models to mirror inquiry-based science instruction. As noted in Table 11, the teachers' delivery of science was observed to change when teaching with EG.

\section{Table 11 Factors Found in the Classroom Observations on Delivery and Approach}

\begin{tabular}{lc} 
Categories & Percent of teachers (n=7) \\
\hline Teaching inquiry excelled from delivery of storybook scripts & $7 / 7 \quad(100 \%)$ \\
Time mitigation w/ integration & $7 / 7 \quad(100 \%)$ \\
Easier to teach when students engaged and excited & $7 / 7 \quad(100 \%)$ \\
Accommodations & $5 / 7 \quad(71 \%)$ \\
Teachers had students mentor students & $2 / 7 \quad(29 \%)$ \\
& \\
\hline
\end{tabular}


Allison and Mary told their students that the GLOBE Kids would stay with them throughout the year. By using the storybooks to practice reading, the teachers delivered science content that was entertaining and created a continuity of instruction that was kid friendly. Amy, a third grade teacher, found this to be also true about the EG storybooks. The researcher observed her class on 4/15/11 at Jack and Jill. He arrived at 10:25 a.m. and found her students sitting on the floor with Amy reading Mystery of the Missing Hummingbirds (MOMH). Her class consisted of 20 students and all were present and engaged with the read-a-long. There was girl doing artwork of a bird (integration). Amy talked about Costa Rico where the ruby throated hummingbird migrated for the winter and could find food and shelter, so the lesson provided integration with instruction on geography. MOMH has a character in Costa Rico who speaks Spanish, so this provides a lesson about another culture and global climate change. Amy leads her students with open ended questions in an inquiry-based discussion using scaffolding. She instructs the students to write in their journals (Appendix G) what they learned, and then they are sent to the computer lab until 12:00 a.m. She tells them, "Everyone needs a pencil. You don’t need a partner." The researcher then overheard her ask a special needs student, "Do you need a partner?” The student said, “No.” Amy had prepared a hummingbird folder, which she instructed her class to access. EG provides suggested websites on the ruby throated hummingbird (RTH). It was now 10:38 a.m. and Amy was concerned with the time. She explained how to how to use the class folder. One little boy waves at the researcher and he smiles back. He was the same boy who thought he had found a fossil in a piece of concrete when doing the Scoop on Soils lesson. He and another boy were looking at RTH on the screen as Amy walked around computer lab answering questions and making sure they stayed on-task. She sent some of the students to visit a website with the National Geographic Kids. Suddenly, 
five hands went up with questions. A girl asks, “Are these photographs or video?” Amy asked class if they wanted headphones to listen to the hummingbirds flying and the humming their wings make. "Miss Smith sounds so cool!" exclaimed one girl. Amy turned and smiled at the researcher, who was watching a girl help another girl in class with her headphones. The researcher observed hands going up every 2-3 minutes with questions. Amy was attentive to all accommodation needs and was assisting a student with an IEP at this time. She stopped and asked the class, "What did you learn from the video?" There were several students with IEPs so Amy was being attentive to their needs, and she asked another question, "What does slender mean?” The students were 18/20 on-task at 10:55 a.m. A girl asked, “How do you spell insects?” RTH eat insects as well as nectar. Amy informs the class, "We are going to get a garden. That's were hummingbirds go." Then she said, "We are going to have to stop, another class is coming in.” It is 11:00 a.m. There was a little boy back in classroom that had a book about RTH on his desk. Amy explained, "We don't have time to finish right now. We will finish on Monday.” Amy began to ask questions with students seated on the floor. Multiple hands shoot up. She writes down answers from the students. "They eat their own body weight. Just like kids.” A boy says, "Weigh a tenth of an ounce.” Amy concluded the lesson with an announcement that they would finish tomorrow and then the class lined up for lunch, it was 11:05.

EG provided easily obtained resources for teaching which aided the delivery of science instruction and oriented the delivery of science to nature. This delivery of instruction worked especially well for those students needing accommodation and extra guidance as observed in Amy's classroom which was very diverse in composition consisting of three African Americans, one oriental, one Hispanic, and one Indian. 
Journals

As noted in Table 12, the categories affecting the delivery of science were described as kid friendly, resources readily available, and improved when teaching outside.

Table 12 Factors Found in Teachers' Journals on Delivery and Approach

\begin{tabular}{lcl} 
Categories & Percent of teachers (n=7) \\
\hline Easier to teach when students engaged and excited & $7 / 7$ & $(100 \%)$ \\
Teaching inquiry altered delivery from script of storybooks & $6 / 7$ & $(100 \%)$ \\
Students enjoy learning outside/teaching outside important & $6 / 7 \quad(86 \%)$ \\
Accommodations available and ease delivery & $5 / 7 \quad(71 \%)$ \\
Time mitigation w/ integration ease delivery & $3 / 7 \quad(43 \%)$ \\
Available resources ease delivery and prep time & $3 / 7 \quad(43 \%)$ \\
\end{tabular}

Allison took her class outside to further her students’ appreciation of observing. Allison wrote: "It was chilly/cool day to be out in it while you're writing helps you describe it better" (Allison journal, 10/7, pp. 1-2). She later wrote:

"We went outside to observe fall now that the leaves have all changed (Appendix O) and some trees have no leaves. The students remembered what to do and had a great time working and learning outside. They did the journal entry outside again and colored inside” (Allison journal, 11/10, p.3).

This delivery showed integration of EG with practicing the inquiry-based skill of observing through journaling and drawing. Having readily available science teaching resources impacted the delivery of content as this journal entry mentions:

"We made hummingbirds from one of the lesson and they were amazed at how it was the same size and made it real for them” (Allison journal, 12/10, p.4). Allison was also approving of 
how EG met CSO requirements: "I loved how this lesson went along with our motion and force science unit which is a second grade CSO! Great lesson! Kids loved it (Allison journal 1/11, p. 5)!” “We reviewed the Willow Creek [story] book and talked about how the GLOBE Kids measured - it was great how it tied right in w/ measuring and the students hardly realized it. I like being able to relate what they are doing to the kid's in the book. I'm so thankful Vance brought in real plants for us to measure! The kids enjoyed measuring an actual plant with the rulers. It made the lesson more real. We plan to use the plants more for measuring. I can't wait for it to warm up outside to complete our season's lessons and do some and planting lessons (Allison journal, 2/11, p.11).

This appreciation of delivery outside also showed in Alicia's journal entry:

I decided the perfect lesson would be to take students outside for a science lesson. I took 10 students; we had our clipboards, pencil, and 'big picture’ journal page. The kids were so quiet and engaged. I was amazed. They went from being wild and disruptive to...eager to learning quiet students (Alicia journal, 10/7, p.1).

Alicia’s journal entry exemplified how being outdoors helps with accommodation of students with special needs like hyperactivity. "The walk from the room to back parking lot, fresh air, and new environment was everything they needed. Students were noticing everything...cars in McDonald's Parking lot driving, a roof on a house hidden in trees, bees, signs, tall/short trees. They were very detailed. The pictures are great. It was like they were able to escape and express what they were seeing through their own eyes” (Alicia journal, 10/7, p.1). She later wrote, 
"I took 10 students; we had our clipboards, pencil, and 'big picture' journal page. The kids were so quiet and engaged. I took 10 students; we had our clipboards, pencil, and Big Picture View journal page (Appendices T and U). The kids were so quiet and engaged. I was amazed. They went from being wild and disruptive to...eager to learn quiet students” (Alicia journal, 10/7, p.1).

The kid friendly storybooks aided delivery in Amy's class and she wrote: “Once again great story Discoveries at Willow Creek. The students love to hear read alouds! The books that go with the GLOBE curriculum are fantastic. The students can relate to the characters. Kids are so informational (Amy, journal no date, p.6)." "I wish that we had more time to do science in school. I think the students really have enjoyed and learned from the GLOBE curriculum. The GLOBE is very easy to adapt and incorporate multi subject areas” (Amy journal, no date, p.8).

\section{Change over Time for RQ4}

The teachers liked having a science curriculum designed to take the students outside, and could be easily integrated with math, social studies, and language arts. EG uses hands-on activities to teach science so it is ideally suited to the primary grades and it lends itself for collaborative use. The latter makes for better use of limited time in the teacher's day. Furthermore, Peter stated, "I think the opportunity is there to make a really nice holistic science opportunity” (Peter, interview one, 6/10/10). As the study progressed, the teachers indicated a familiarization with EG, so it became easier to use. The ease of using EG due to the ability to integrate it into the regular curriculum became 
apparent as the school year progressed. Four of the six teachers at Jack and Jill Elementary described that they discussed class preparations among themselves, so this may have assuaged their implementation of the EG activities. Sterling realized the value of practice when teaching science. "I think personally it trial and error. I would love to be given ideas. That's why this is nice [referring to EG]” (Sterling, interview one, 10/19/10). Language arts are a core area of teaching in the primary grades, so it was significant to hear that science should also be taught in this endorsement: "Language arts are the biggest. I still feel somehow that is still important when you are teaching science, you can still teach those same things. It certainly peaks the kids interests” (Linda, interview three, 12/16/10). Linda holds National Board Certification so her insight comes from established credentials and 23 years of experience.

Triangulation of Data from Observations Journals, Interviews, and Student Artifacts for RQ4

The observations and interview responses support the ease of EG delivery. Student artifacts (Appendices G, L, M, N, O, P, Q, R, S, T, U, and V)) support the ease of delivery use of EG. These three areas of data (observations, student artifacts, interview responses to questions in RQ4) show that that EG impacted the teachers' delivery by facilitating the ease for teaching science in a favorable way. It aided the teachers by mitigating their limited time allotted for teaching science. Six of the seven teachers’ journals stated the benefits of having a curriculum which is easily integrated. Allison's journal entries summarize the delivery impact of the other six teachers: "We did the measure up lesson. I really liked this lesson and the Willow Creek story. The students had so many 'ah ha' moments - it's so great to see that when teaching” (Allison journal, 
1/11, p. 5)! She added, “... it was great how it tied right in w/ measuring (Appendices $\mathrm{P}$ and Q) and the students hardly realized it. I like being able to relate what they are doing to the kid's in the book" (Allison journal, 2/11, p. 11).

Research Question Five

RQ5: How has the adoption of Elementary GLOBE influenced the school's function/capability as a Professional Development School within the WVU PK 20 Collaborative?

Table 13 EG Influence on the School's Function/capability as a Professional Development School within WVU PK20 Collaborative

\begin{tabular}{lrl} 
Categories RQ5 Function/capability PK20 & \multicolumn{3}{c}{$\begin{array}{c}\text { Percent of teachers } \\
\text { (n=7) }\end{array}$} \\
\hline Taking students outside & $7 / 7$ & $(100 \%)$ \\
Preservice teacher (PST) should have prior training & $5 / 7$ & $(71 \%)$ \\
University support & $3 / 7$ & $(42 \%)$ \\
& & \\
\hline
\end{tabular}

There were four interview questions asked about influences of school adoption of

EG as it pertained to a Professional Development School within the WVU PK 20

Collaborative.

1) How could you have improved your students' understanding of environmental issues? (interviews one, two, and three)

2) How important is the relationship of the elementary school in working with a nearby Professional Development School for teaching elementary science? (interview two)

3) What is role of school in promoting science in the elementary classroom? (interviews one, two, and thee)

4) What exposure should preservice teacher have to Elementary GLOBE before being placed for their internships? (interview two) 
As stated in the West Virginia University Benedum website, a professional development school (PDS) within WVU PK20 Collaborative is an institution that promotes improvement in student learning through renewal for university faculty, public school faculty, and administrators (http://benedumcollaborative.wvu.edu/). This is facilitated by strengthening practitioner research within teacher education and the public school. PDS are awarded grants that have an intensive-teacher researcher component. RQ5 attempts to address the research criteria used between specific areas of interest, Elementary GLOBE, as it applies to utilization within the applied school (PDS).

\section{Interviews}

The university affiliated with the professional development school (PDS) promotes and offers opportunities for learning inquiry based elementary science courses Categories were determined from analyzing the interview transcripts. These findings are presented in Table 13. The university affiliated with the professional development school (PDS) promotes and offers opportunities for learning inquiry based elementary science courses. One of the participants, Alicia, completed a science methods class, which included training in EG. There is a tremendous potential to offer instructional activities for elementary science coursework at this university.

Three of the seven teachers attribute their knowledge about EG to support from the university:

For me it is the support and to be handed the materials but the exposure to what the students are being taught. For me I think a part of it is the motivation and the excitement that the two provide. The support to say yes 
you are doing the right thing or here is some additional materials or the opportunity to pair with the preservice teachers and their willingness, their kind of untarnished view of sure we can try this. Sure we can do this kind of attitude I think is good as well as the professional development with what those schools provide (Linda, interview two, 9/29/10).

The two teachers with the most experience attribute their using EG to association with the nearby university. Peter attributed the connection with the discovery and use of EG. They were introduced to the elementary curriculum by one of the professors at the college of education affiliated with the PDS. "I would have never known about the literature based GLOBE program without the PDS connection” stated Peter (Peter, interview two, 9/28/10). The aforementioned comment from Linda also addresses the impact EG has had on the other teacher with experience. The support of curricular material impacts the teachers with resources that they would otherwise not likely have been exposed to if not affiliated as a PDS. There is a trickledown effect from this exposure, and other teachers often begin to collaborate with colleagues to use the same science curriculum. "I think it is really good to collaborate with other teachers. I am open for suggestions and learning about what they are doing whether it is science, math, reading or writing or social studies...” Alicia emphasized when queried about the effect of using EG at her PDS (Alicia, interview one, 10/18/10). This is important when mentoring new teachers such as Alicia who was in her first year of employment. 
Six out of seven participants recommended that preservice teachers (PST) should have some exposure to EG before being placed in their internships. The exposure ranged from "..go through the whole curriculum at the elementary level... (Amy, interview two, 3/31/11)” to “..have read it and have someone go over some of the things...” (Allison, interview two, 12/15/10).

Six out of six Jack and Jill participants indicated that it was important to have access to green space in order to teach EG outside. It had the effect of making students more aware of the world beyond their school. The one teacher at Jane Doe, Elementary also concurred with taking students outside for instruction, so seven out seven teacher participants, considered having access to the outdoors important for instruction when utilizing EG. A proposed garden at Jack and Jill Elementary had parental support and one of the study teachers served on the garden committee; it enhanced collaboration among parents and teachers.

..they actually go out and see what we have and experience especially with the one where they go out and look around and here they have the seasons even all year around and go and see this season the flowers are dead and this season the flowers are blooming. What kind of animals, bugs and insects are around there so it is more hands on and they can physically see it, not just something they are reading in a book. They have it there and see all the stages too (Mary, interview three, 11/17/10).

If provided a garden, Sterling realized her students could have ownership of the space, and subsequently teach responsibility. She explained: "A lot of things are off limits. It would be nice to get them outside and give them ownership on their playground" (Sterling, interview three, 
12/21/10). This would also incentivize being outdoors and encourage the exploration of nature which is supported by the research literature of Pretty et al., (2009).

A school garden would be nice with the soil's one [referring to Scoop on Soil] because they could see what was going on where. The garden would get them outside more because they really enjoy that and we don't have any place here where they can really get their hands dirty or do anything. A lot of things are off limits. It would be nice to get them outside and give them ownership on their playground (Sterling, interview three, 12/21/10). This augments current pedagogical thinking on defining school space. "Because in the universe there is so much to experience and so much to know, curriculum construction requires that some things be removed from the purposefully structured space called school” (Fain, 2004). EG provides a science curriculum that can be encountered through a proposed school garden by feeling soil, observing insects, and observing seasonal changes.

A garden would also provide students with the understanding of the origin of food. The hands-on experience of maintaining a garden complements science lessons and is easily integrated with language arts (e.g. writing, keeping journals). Amy recognized this when responding to the interviewer:

Lessons would be easily integrated from science from the GLOBE curriculum which is working and helping the environment knowing where the food is coming from that we are eating and then doing writing lessons, math activities with it and I think it would be easy to integrate all of the components, reading components and everything with the science then and I think kids don't understand because everything is really easy for us to 
get food and it comes from the store, that is basically it unless they live on a farm. Unless the kids don't think about all the steps ahead what the people had to do (Amy, interview three, 3/31/11).

Because change occurs at different levels and periodicity, children can have difficulty relating the duration of cause and effect relationships, especially when the effect may be unrealized for several months. This can be seen with environmental pollution such as acid rain and global warming. Linda realized the potential for using a proposed garden to address the time duration between cause and effect.

[A garden could be used to] Certainly [teach about] the process of change and the module about the colors. Hopefully the attraction of birds and certainly a discussion about what I said earlier they don’t see outside of what affects them but to see that dry weather affects the garden. The rain affects the garden. You could certainly talk about acid rain is an issue here but you could talk about that sort of thing changes. When you talk about why something doesn't grow I think you can relate (Linda, interview three, 12/16/10).

Seven out of seven participants felt preservice teachers (PST) should be exposed to EG before placement in their internships. The exposure ranged from doing one hands-on activity to going through the whole curriculum. This training should include ways to integrate EG with other classes.

I think they should have to go through the whole curriculum at the elementary level and do it hands-on first. But I think they need their hands-on experience first to see what could happen, what they think, what 
they could change because that is going to change once they go into a classroom anyway but at least they thought about it (Amy, interview two, 3/31/11).

The one participant with National Board Certification made an impassioned statement about EG use. She strongly felt that teaching with EG also teaches how science should be taught in general:

I think it should be definitely a part of the science methods class. Again even if they don't have the GLOBE curriculum in their hands to see how science has taught through them just the way it’s taught gives you a way to think regardless of what textbook or what CSO's you are handed... (Linda, interview two, 9/29/10).

The university affiliated with the professional development school (PDS) promotes and offers opportunities for learning inquiry-based elementary science courses. One of the participants, Alicia, completed a science methods class, which included training in EG. There is a tremendous potential to offer instructional activities for elementary science coursework at this university. Three of the seven teachers attribute their knowledge about EG to support of the university.

For me it is the support and to be handed the materials but the exposure to what the students are being taught. For me I think a part of it is the motivation and the excitement that the two provide. The support to say yes you are doing the right thing or here is some additional materials or the opportunity to pair with the preservice teachers (PST) and their willingness, their kind of untarnished view of sure we can try this. Sure 
we can do this kind of attitude I think is good as well as the professional

development with what those schools provide (Linda, interview two,

9/29/10).

The two teachers with the most experience attribute their using EG to association with the nearby university. Peter attributed the connection with the discovery of and use EG. They were introduced to the elementary curriculum by one of the professors at the college of education affiliated with the PDS. "I would have never known about the literature based GLOBE program without the PDS connection” stated Peter (Peter, interview two, 9/28/10). The aforementioned comment from Linda also addresses the impact EG has had on the other teacher with experience. The support of curricular material impacts the teachers with resources that they would otherwise not likely have been exposed if not affiliated as a PDS. There is a trickledown effect from this exposure, and other teachers often begin to collaborate with colleagues to use the same science curriculum. "I think it is really good to collaborate with other teachers. I am open for suggestions and learning about what they are doing whether it is science, math, reading or writing or social studies...” Alicia emphasized when queried about the effect of using EG at her PDS (Alicia, interview one, 10/18/10). This is important when mentoring new teachers such as Alicia who was in her first year of employment.

Six out of seven participants recommended that preservice teachers (PST) should have some exposure to EG before being placed in their internships. The exposure ranged from “..go through the whole curriculum at the elementary level... (Amy interview two 3/31/11)" to "..have read it and have someone go over some of the things... (Allison, interview two, 12/15/10).”

\section{Classroom Observations}


The ability to more easily teach science is a theme for this question. The ease is due to generated excitement from students when using EG, especially being outside. This excitement was due to some degree from taking the students outside for EG activities. The teachers' mirrored being scientists so students were engaged and learned from exposure to EG. One little girl was observed to say something that sounded like, "I love science (Sterling, classroom observation, 9/17/10)!” Overheard, another little girl said, “Someone littered on ground,” which allows teacher to introduce being good stewards of the environment and nature. The teachers wanted to get students outside so they could do EG activities. This changed their perceptions and awareness (Sterling, classroom observation, 9/17/10). With EG learning is a conceptual task not a situational one. For example, one student excitedly exclaimed, "I found 5 different kinds of dirt.” Students were proud they imitated the EG lesson goal with words like "wow.” This was especially true with the special needs students where language was an issue and two students who were non-readers (Sterling, classroom observation, 9/17/10). The exposure to soil, woods, and leaves, found in the EG investigations was a new experience to over half of Sterling's students. Her students could "see [worms] still alive” after being sealed in a bag for several days, so they could generate questions as to why this occurred. All the students' thought it was "fun" having science outside (Table 14). After reading about hummingbirds in Mystery of the Missing Hummingbirds, one student expressed disappointment that Jack and Jill Elementary did not have a garden like the one described in the MOMH. The EG activities proffered opportunities for teachers to engage their students and making teaching easier due to the ability to integrate science with other courses. 
Classroom Observations Affected by Teaching in PK20

Table 14 Factors Affecting Function/capability as a Professional Development School within WVU PK20 Collaborative From Observations

\begin{tabular}{lrl} 
Categories & Percent of teachers (n=7) \\
\hline Teaching inquiry excelled from delivery of storybook scripts & $7 / 7$ & $(100 \%)$ \\
Students liked being outside to learn & $7 / 7 \quad(100 \%)$ \\
Easier to teach when students engaged and excited & $7 / 7 \quad(100 \%)$ \\
Accommodations provided by EG & $5 / 7 \quad(71 \%)$ \\
\hline
\end{tabular}

From the WVU Benedum website, PDS are “empowered communities” where all stakeholders participate in decision-making and determining the learning needs and opportunities for students. This includes teachers partnering with other teachers such an elementary $5^{\text {th }}$ grade teacher partnering with a kindergarten teacher. This partnering was witnessed in the study participants.

Mary, a first grade teacher, and Sterling, a third grade teacher, taught a class together where the older students (third graders) mentored the younger students (first graders). The EG activity was making a cloudscape (Appendix L). On 10/11/10, the researcher arrived at 9:00 a.m. at Sterling's $4^{\text {th }}$ grade classroom to find students in Sterling's class relaxed and listening to announcements over intercom. Little boy asked researcher, “Are you a scientist?” He shook his head in response. There were three girls on floor working/coloring. Several students were practicing spelling vocabulary words. The class was expecting the first graders, as Sterling says, 
"No hizzy fits boy and girls." Sterling wrote a list of things on the board that the students would need for making the EG activity called cloudscape.

Sterling placed a prepared cloudscape (Appendix L) on board with these words:

-2 cotton balls

-6 pieces of cloth

-2 feathers

-2 silver pieces

-8 sparkle pieces

A boy student reminded Sterling who had assigned partners and the Sterling since there were two left she assigned partners. Both teachers used the EG activity to teach socialization skills and teamwork among the students. Sterling said, "The first thing need is paper."

Mary said my students "love being on floor.” She called it, "Silent floor table.”

"Want you to hear each other but move down...need room to work." Sterling asked "Who needs blue paper?”

Mary “read book yesterday,” so timing was again shown to be important and she had reviewed clouds from EG: cumulus, cirrus, stratus contrail which students would use to make cloudscapes. This also allowed for ease of accommodating. Cooperative learning worked very well among these two different aged groups. $4^{\text {th }}$ graders really took the lead. A chart was placed on board for easy reference that most of students used. The instruction was very handson and engaging for students (Table 14). Time, time, time continued to be big factor on how to fit it all in. Mary explained: the "cotton balls were cumulus clouds," stratus were "little strips of paper," and "bent silver pipe cleaners were lightening." She said, "The feathers are cirrus clouds.” A little boy exclaimed, "They really do look like feathers in the sky.” Mary asked, 
“What clouds come from airplanes?” A little boy raised his hand, “Contrails!” Sterling had supplies in her room and she was overheard to say, "Need more glue sticks." It was evident that both teachers were practicing best practices by asking questions and waiting for responses and making sure all students had their needs addressed. Researcher watched as little girl was showing a boy how to lay out clouds so they would fit on paper. Mary announced, "Three sheets per group, fabric is stratus clouds, and place feathers last.” Researcher observed 36/36 students on-task behavior. One little girl checked out white board for clouds while researcher watched, but most of students referred to Sterling's chart on board. The researcher noted: the $1^{\text {st }}$ graders watching $4^{\text {th }}$ graders do work in about $50 \%$ of cases. Sterling announces, "We have clean up now she also said, it was 09:43 a.m." Students begin to line up at door. Mary, "Help your partner clean up.” The researcher thought this was best practice to aid on keeping students to stay on task. $1^{\text {st }}$ graders line up at 9:50 a.m. Mary said, "We will finish up in the afternoon." The researcher wrote down, time, time, again. Mary was asked a question and responded, "We get to keep them and hang in the hall.”

Time was an issue to teach science but was mitigated with proper planning and using the EG resources which produced a high on-task engagement from students receiving the instruction.

\section{Journals}

The teachers were able to easily cover their required CSO’s with EG. Allison realized this when writing in her journal, "I loved how this lesson went along with our motion and force science unit which is a $2^{\text {nd }}$ grade CSO! Great lesson! Kids loved it” (Allison journal, 1/11, p. 5). "I'm so thankful Vance brought in real plants for us to measure! The kids enjoyed measuring an actual plant with the rulers. It made the lesson more real” (Allison journal, 2/11, p. 11). 
Table 15 Factors Found in Journals Affecting Function/capability of Teaching in PDS w/in PK20

\begin{tabular}{lc} 
Categories affecting delivery/capability & Percent of teachers (n=7) \\
\hline Easier to teach when students engaged and excited & $7 / 7(100 \%)$ \\
Teaching inquiry altered delivery from script of storybooks & $6 / 7(86 \%)$ \\
Students enjoy learning outside/teaching outside important & $6 / 7(86 \%)$ \\
Accommodations available and ease delivery & $5 / 7(71 \%)$ \\
Time mitigation w/ integration eases delivery & $3 / 7(43 \%)$ \\
Available resources ease delivery and prep time & $3 / 7(43 \%)$
\end{tabular}

The teachers were able to easily cover their required CSO’s with EG. Allison realized this when writing, "I loved how this lesson went along with our motion and force science unit which is a $2^{\text {nd }}$ grade CSO! Great lesson! Kids loved it” (Allison journal, 1/2011, p. 5)! I'm so thankful Vance brought in real plants for us to measure! The kids enjoyed measuring an actual plant with the rulers. It made the lesson more real” (Allison journal, 2/2011, p. 11).

“I'd change the paper pieces of clouds into cotton balls next time-for SPEDs I'd have a template next time” (Amy journal, no date, and p.1). She wrote. EG does allow for easily accommodated lessons, giving the teachers more time to prepare.

Students enjoyed listening to the story that goes with the activity. These read alouds are engaging and very informative (Amy journal, no date, p.4). The books that go with the GLOBE curriculum are fantastic. The students can relate to the character. Kids are they are so informational. The 
students enjoy not only learning by listening but holding the objects and being able to look at them at different angles through hand lens. Thank you so much for bringing all the seeds and items for us to use (Amy journal, no date, p.5) and keep. I think next time, I would have the students go outside and do possible scavengers hunt (Amy journal no date, p. 6).

Overall I thought the lesson was successful and I continue to see and hear discussions about clouds. As we add to the "review" of clouds names, and I see them able to remember the words, I'm anxious to see how the $1^{\text {st }}$ grade teachers are able to build on what they've done this year (Linda journal, 4/10/10, p.5).

Brought together and had group discussion, recording notes on chart, making predictions about what we would find when we dug outside tomorrow (insects, roly polys, 'lost' things...).

I was excited to teach again. Because my class did such a great job. This class seemed to really enjoy the story. They took turns looking through the soil bag (Mary journal, 5/6, p.4).

I decided to take my students on a nature walk. I gave each student a plastic bag. The only rule was that their items had to fit in the bag. The students had a blast collecting items. They found rocks, flowers, bugs, cat tails, and turtle (id eastern box turtle by investigator). I thought it would be neat to take the turtle to our class. The students were so proud. We kept it in our class for the day. The students had a chance to write about 
the items they found and share them with the class (Mary journal, no date p.7).

I had to think how I was going to make the cloud system with 25 kids and no help? We read the story and made our observations. I decided to make one large cloud system. We hung it up out in the hall. Students around the school saw it. The kids really enjoyed the project. I decided to do the same thing with the other two $1^{\text {st }}$ grade classes. The kids also do a tech steps with clouds” (Mary journal, no date, p.11).

When teachers are excited about teaching, that enthusiasm is infectious and it is projected through self-efficacy. This is one of the stated goals found in the PK20 agreement: Supporting accomplished teaching is one of the most important ways to improve our schools. Incorporating EG added to the cohesiveness and esprit de corps of the school, so that all the students benefit when one class displays projects in the hallways such as Mary did. The students discuss science outside of class and science becomes concept oriented, so that learning occurs at a higher level. The teacher with 32 years of experience reiterated what Mary found: "I think the teachers learned as much as the students did" (Peter journal p.4). He added, "It's interesting the boys who are the biggest behavior problems in class were really into outdoor activities (Peter journal p.5).” Through EG can easily accommodate the K-4 grade student, it does require training and practice to foresee students encountering nature up close: “The rest of the day yesterday I spent keeping the kids out of the bags. They wanted to show everyone "their bugs." While I am glad they were excited, it was kind of annoying” (Sterling, journal 5/10, p.9). “The students were able to pick their own partners (special ed students) for digging adventure today. Like last year was surprised at how entertained they were by simply collecting soil samples (Appendix N). They found a 
variety of bugs and tried to look them up on the internet. I remembered from last year that this would take a whole science period (time) so we will do the worksheet portion next week. "I hope I can keep them out of the bugs this time” (Sterling, journal 9/10).

From the teachers’ journals (Table 15), the ability to engage students with EG was an unexpected outcome as in this excerpt: “Today we made cloudscapes with first grade. We made sure to pair my SPED kids with her gifted kids. It was a bit crowded in the room but a lot of fun. All of the groups did really well! They worked. Next time we will have bags of supplies premade so that each group has all of their materials and we don't waste time passing them out. My guys were a little upset they couldn’t keep the model but they were excited to know that they will see them in the hallway” (Sterling journal, 11/10, p.39. "We are doing electricity for the next couple of weeks. NO GLOBE lessons but I am incorporating more hands-on activities even if I think they may be boring...like the digging day because they really like it” (Sterling journal,12/10, p. 41).

\section{Change over Time for RQ5}

The interviewed teachers showed a change in their beliefs on how to teach elementary school science after they had used EG for a year. Based on interview responses, there was a noted change in self-efficacy (Bandura, 1997) of those teachers using EG for the first time.

Linda enjoyed the “can do" attitude of the student interns coming from the PDS. She learned from “...the opportunity to pair with the pre-service teachers (PST) and their willingness, their kind of untarnished view of sure we can try this” (Linda, interview two, 9/29/10). She equated it to the "the motivation and the excitement that the two provide." The two are the opportunities to work with the PST and being provided with resources such as EG. This change 
can best be thought of as enhanced collaboration among school faculty in this school. Teachers talked with one another about their science instruction, which provided a team atmosphere. Linda's encapsulation showed the most awareness.

The adoption of EG impacted the teachers' professional practice through more opportunities for collaboration. Briscoe and Peters (1997) found collaboration facilitates more opportunities to learn content and pedagogical knowledge from other teachers who are more willing to take risks. In this study, the teachers worked jointly when implementing EG and formed a science committee, which is in keeping with the goals of the Benedum Collaborative and supports the findings of Briscoe and Peters (1997). One study teacher volunteered to serve on the garden committee. This teacher intends on using the garden when implementing EG investigations where applicable:

Teaching requires practice in order to develop proficiency and learn best practices (Benedum Collaborative, 2011). Through subsequent collaboration with one PDS teacher, the researcher returned to address questions regarding magnetism (4/2/11) and the micro/macro world (4/15/11). He provided free magnets to demonstrate the origins of magnetism for the students and also set up microscopes with hay infusions, so the students could view microorganisms found in ordinary grass. This fit with one of the stated goals (Benedum Collaborative, 2011) of how public schools (PDS) and universities partner to work collaboratively, as centers of inquiry.

Triangulation of Data from Observations Journals, Interviews, and Student Artifacts for RQ5

The need for green space to teach was in evidence from observations, student artifacts, interviews, and journal entries for RQ5. The impact of EG adoption influenced the capability of 
the PDS by providing more readily available curricula to teach inquiry-based elementary science. Teachers at both schools sent student work home, so EG became known to parents. This awareness ultimately garnered attention and parental involvement with a proposed garden project at Jack and Jill Elementary School. Collaboration was in evidence among all the science teachers, six out of six, at the school with six participants. In this study, successful compliance of the PK20 agreement was found in the public display of student artifacts (Appendices L and M), team teaching, and mentorship of one new teacher.

\section{Member Check}

To further trustworthiness of the findings of this study a Participant Follow-up Questionnaire (Appendix F) was given to the teachers to examine the major themes that emerge. Their feedback elucidated the credibility, accuracy, fairness, and strength of the findings (Patton, 2002, p.560). The member check was completed by giving it to the teachers to assess trustworthiness of the findings. The researcher presented the questionnaire via the teachers' mail at their schools and also through email. This duplicity of delivery was an attempt to lessen any perceived burden on the teachers' valued time. The paper copy of the questionnaire included a self addressed stamped envelope for ease of return. All participants were contacted in this fashion. One of the original seven teachers was on maternity leave. The questionnaire was forwarded to her home address by the school through regular mail. 


\section{Table 16 Member check}

Theme

EG changes way students experience science

EG changes confidence to teach science

Time management is major barrier to teach

Student accommodation is a barrier

Teacher preference of EG over textbook
Percent of teachers (7 responded to questionnaire)

AGREE

7

5

6

4

5
DISAGREE

0

1 (one marked neutral)

1

3*

0 (two marked neutral)

Seven out of seven teachers responded to the questionnaire with the last one returned to the researcher on 10/1/11. The member check tabulation (Table 16) provided conformation of several themes found in the analysis of RQ1-RQ5. All of the participating teachers agreed that EG changes the way their students experience science. This should be studied in future research since concepts can be understood at this level of child development (Bloom 1968; 1976; 1981; Novak and Musonda, 1991). When all the participants agree to a finding, it warrants future investigation. EG changed the confidence to teach science of 5/7 (71\%) of those returning the questionnaire. The one who marked DISGREE has extensive experience, so the level of knowledge was unusual and the question may have been interpreted differently and may have even unknowingly seemed insulting. The one participant who inserted neutral explained that she liked having more resources, but felt ‘confident.' Neutral was not a choice. The questionnaire was designed intentionally that the respondents would make a distinctive selection. With a respondent writing in neutral, it indicates that he/she was hesitant about selecting the answer and justifying a choice. Six out of seven (86\%) teachers, who returned the questionnaire, agreed that 
time management was a barrier to teaching science. The one that did not agree is very experienced and has National Board Certification and when the researcher observed her, she appeared to manage time issues better than the other participants.

Four out of seven (57\%) respondents agreed that accommodation was a barrier to teaching science. The reasons for three marking DISAGREE were 1) “... have to accommodate students in almost every subject,” 2) “the GLOBE curriculum allows for natural accommodations. There is less emphasis on reading and more on exploring. It also provides group work opportunities so that students can use their strengths in their group work,” and 3) “My kindergartens beg for science time and makes all levels of abilities eager and able to participate.” EG was developed to accommodate diversity in learning styles including non English speaking students. Two of the two reasons for questionnaire respondents marking DISAGREE (one and three) actually do not address accommodation as a barrier, since one accepts that EG ameliorates the special needs students in the class and the other states how students are enthusiastic about science. The respondent's first reason for marking DISAGREE just acknowledges accommodations occur in this respondent's classroom. It should be noted that Jack and Jill Elementary has a very diverse student population and the observations, journals, and interview data indicated that non English speaking students did not receive instruction in their first language. EG is available in German, Arabic, Chinese, French, and Spanish.

When asked if the participating teachers preferred EG over the adopted textbook curriculum, five of the seven (71\%) respondents marked AGREED. The other two respondents wrote in neutral. The two respondents who wrote in neutral may have had rationale beyond this study's research questions, so this should be addressed with additional research in the future. 
*During the study, 143 students were observed. Approximately 43 of this population had special needs based on behavior and language skills. The non-English speaking students were not observed using EG in their native language, so the participating teachers’ awareness of availability of accommodations in the curriculum may have been unknown to them. EG does provide guidance for reading levels and accommodations where needed, including curriculum in German, Russian, Chinese, French, and Spanish. This question should be addressed in future studies. The school population had 178 out of 700 as students whose native languages were not English (Nedeff, 2010). 


\section{CHAPTER FIVE}

\section{Summary}

In this study, data collection occurred over the duration of 18 months. The data collected took the form of 25 observations, 20 interviews, teacher journals, and student artifacts. Coding and inductive analysis were used to reveal categories and themes. Triangulation was used to verify these categories and themes. This was done to insure consistency and provide insight into “phenomena observed and/or understanding of real world nuances, including any perceived inconsistencies” (Patton, 2002, p. 556). There were five research questions (RQ) investigated.

RQ1: What kinds of barriers do the teachers encounter when teaching science in elementary school?

This question identified three themes associated with barriers. From the interviews, time management, teacher training, and lack of outdoor resources were identified as barriers to teaching science. From the journals, lack of outdoor resources, time, and accommodations were identified as barriers to teaching. From the observations, lack of outdoor resources, time management, and accommodations were also found as barriers. Through triangulation, time management, lack of outdoor resources, and accommodations emerged in common as barriers to instruction. The member check provided truthfulness to time and accommodations as barriers. In both schools studied, the playgrounds were devoid of trees and green space. This made it 
difficult to do activities with EG, and alternative locations were utilized to do the investigations. Time management is in evidence with Sterling's response in interview one (10/19/10): ... and starting next week or the week after I will teach it to the next class so that gives me the chance to change things and look at the bigger picture but I stay more focused on surviving this time.

RQ2: What impact if any has the use of Elementary GLOBE (EG) had on these barriers? The impact that EG had on barriers that emerged from RQ1 was the easing of time restraints due to integration and availability of hands-on resources. From the interviews, mitigating time due to available resources and accommodations reduced the barriers found in RQ1 (Table 4). From the observations, limited time was mitigated by integration and available accommodations (Table 5). From the journals, time was impacted with ease of integration and available resources for accommodation (Table 6). Triangulation verified that time management; ease of integration, and readily available accommodations impacted the barriers found in RQ1. The member check provided truthfulness to time management as a barrier that was impacted, and also accommodations as a barrier that was impacted. Furthermore, teachers' confidence to teach was a barrier which EG impacted (Table 16).

An additional finding on impact of using EG was going outside to do science activities. The students got excited and were observed skipping, laughing and being engaged with science investigations associated with the lesson. There was a notable enjoyment observed in their exposure to nature while doing science activities in these settings. The teachers' ability to use instruction time was mitigated by the ease of integration and accommodation. Triangulation 
supported this impact. The member check corroborated that EG changed the way that students perceived science and impacted the teachers’ confidence (Table 16).

RQ3: What actions/conditions made Elementary GLOBE difficult for the teachers to use and what factors/conditions made Elementary GLOBE easy for them to use?

Being able to integrate EG with other courses made the curriculum easy to use. This was identified as a theme in the observations (Table 8). The ease of integration was also found in the journals (Table 9). The ease of accommodation was found in observations (Table 8) and the journals (Table 9). The lack of outdoor resources proved to be a barrier to using EG (Table 9). When triangulating the data, ease of integration was confirmed between interviews, observations, journals, and student artifacts. The member check provided trustworthiness to the findings of EG gives teachers’ confidence, making it easier to use.

From classroom observations, hands-on prep time made EG difficult to use. The need of outdoor green space also made it difficult to use. From the journals, outdoor space was identified as a difficult factor for use of EG (Table 9).

RQ4: How has the adoption of Elementary GLOBE impacted the teachers, including their approach to delivery of science instruction?

The adoption of EG impacted teachers' delivery of instruction through the ease of integration, the availability of science resources included with the curriculum, and the motivation to do science instruction outside. Doing science outside engaged and motivated the students which changed the delivery of instruction, so the teachers tried to teach outside whenever the weather permitted. The interview questions, classroom observations, and journal entries provide evidence for ease of integration as a theme (Table 10, Table 11, and Table 12). The student artifacts (Appendices G, L, M, N, O, P, Q, R, S, T, U, and V) show some of the ways EG can be 
integrated with coursework outside of science. Six of the seven teachers' journals stated the benefits of having a curriculum which is easily integrated thereby allowing the teachers to cover more material. Allison's journal entry speaks to the rationale of teaching to show a recognizable positive result of students being engaged and liking science. This has its own impact on delivery by providing positive feedback to the teacher and developing self-efficacy (Bandura, 1997). "We did the measure up lesson. I really liked this lesson and the Willow Creek story. The students had so many 'ah ha' moments - it’s so great to see that when teaching!” (Allison journal, 1/11, p. 5) She added, “... it was great how it tied right in w/ measuring and the students hardly realized it. I like being able to relate what they are doing to the kid's [GLOBE Kids] in the book” (Allison, journal 2/11, p. 11). When teachers observed their students grasping concepts from reading storybooks, they became excited as did the students.

RQ5: How has the adoption of Elementary GLOBE influenced the school's function/capability as a Professional Development School within the WVU PK 20 Collaborative?

The WVU PK20 Collaborative is an institution that promotes improvement in student learning through renewal for university faculty, public school faculty, and administrators (http://benedumcollaborative.wvu.edu/). This is facilitated by strengthening practitioner research within teacher education and the public school. PDS are awarded grants that have an intensiveteacher researcher component. The impact of EG adoption influenced the capability of the PDS by providing more readily available curricula to teach inquiry-based elementary science. Teachers at both schools sent student work home, so EG was recognized by the parents. This is significant because EG is an inquiry-based curriculum and questions learned in science class should be reinforced and receive further investigation at home. This was substantiated in the teacher interviews (Mary, interview two, 10/11/10). This awareness ultimately garnered attention 
and parental involvement with a proposed school garden. Collaboration was in evidence among all the science teachers, six out of six, at the school with six participants. This was explicitly apparent in public display of student artifacts (Appendices L and M).

\section{Conclusions}

The findings of this study show that EG overcomes the insufficient time to teach science encountered by today’s elementary teacher. In addition, the findings fill a void in the elementary science literature by demonstrating the ability to teach inquiry-based science in a time pinched setting and still engage the students in a way that positively influenced their view of science. The findings of this study validate and promote the expanded use of EG to teach inquiry-based science in the lower grades. Given the reduced time for instruction, this is highly significant, as EG includes lessons that are interdisciplinary in scope and designed to easily accommodate special needs populations. Furthermore, the use of EG has positively changed the teachers' attitudes about science instruction and the way their students view science.

Having motivated students pursue activities through self-cognizance should be a goal for educators (Hidi \& Harackiewicz, 2000). With math and language arts being core subjects in elementary school, this study demonstrates that inquiry-based science can be taught successfully in a time starved environment. Further, the use of EG has positively changed the teachers' attitudes about science instruction and the way their students perceive science. With research disproving Piagetian tenets on the metacognition limitations of young children (Keen, 2003), every effort should be begged, borrowed, and stolen to encourage their inquisitiveness and learning science. This study provides evidence for a science curriculum that encourages collaboration and integration in the K- 
4 teaching environment. While it may problematic for adults to understand the causes of Global Climate Change, consider how difficult it must be for children to grasp the issue. Due to the dearth of primary school (K-2) science curricula, EG was developed to encourage teaching inquiry-based pedagogy. This is one way to begin to address the complex interactions occurring in the earth's atmosphere. That is simply teaching students how to ask questions.

EG exposes students to environmental issues, and collaboration with other students globally. Effort is made to draw connections of concepts deepening the literacy component of the GLOBE materials. The materials have been correlated with the National Science Education Standards, National Geography Standards, and the Principles and Standards for School Mathematics. As the teachers progressed through this study, they developed higher competency in their abilities to teach science. This ability manifests in the individual's self-confidence. Bandura (1997) suggested that individuals are more motivated to act if their actions are deemed favorable. He thought that individuals were akin to act if they had favorable outcome result. This study demonstrates favorable outcomes in students work and higher self-esteem demonstrated in student artifacts and collaborative class work. Bass et al. (2009) noted there is a much higher on-task behavior when students are engaged with activities based science. This was witnessed in twenty out of twenty classroom observations of this study. As a serendipitous comparison, the investigator observed three of the participants teach with the district approved textbook and noticed the on-task behavior being less than that with EG. 
The conclusions of this study are extended through a discussion of the implications for practice and recommendations for research.

\section{Implications for Practice}

Based on the findings of this study, which were substantiated through a "member check” with the study participants, the investigator posits several ways to enhance and enrich the K-4 grade science teaching environment. Schools need to adopt inquiry-based interdisciplinary curricula (e.g. EG) because it helps teachers who are time pinched to do more science. Integration with EG mitigates the lack of time for teaching elementary science. In this study, the researcher saw evidence of integrating EG with teaching math, journaling, building vocabulary, making art, learning geography, practicing meteorology, and doing language arts. These observations (Appendix W) demonstrated the ease of integrating EG with the core subjects of elementary school. This integration also mitigates the lack of time for doing science by allowing the teacher to cover more educational standards (GLOBE, 2006). Schools can easily adopt the use of EG as it is available free online at www.globe.gov/elementaryglobe. There are opportunities for teachers to be oriented in using it through inservice programs with qualified trainers located at many universities.

This leads to several implications for practice in instructing elementary science with EG. Teachers need training in the use of inquiry-based science curriculum, and practice using it to gain proficiency. Although EG does not require a science degree to utilize, it requires the instructor to become familiar with the intent of the developers. That intent focuses on learning 
about earth science as the instructor teaches students to read and write. Conducting read-a-longs with the GLOBE Kids storybooks permits students to ask questions and complete learning activities. In this way, the storybooks are designed to further exploration of the science content and process skills. The required materials to implement the activities are inexpensive and readily available. The locations for the storybooks are ecosystems in North America and provide accurate settings for events, such as in the Mystery of the Missing Hummingbird storybook establishing ruby-throated hummingbird (Appendix S) habit in Pennsylvania.

There are teacher's notes and a glossary included in the back of each storybook. The notes provide basic science background information as they help the teacher explain lessons. The glossary information is designed to assist the teacher explain terms found in the story narratives. Teachers are encouraged to read the teacher notes prior to using the materials since they are designed to assist implementing the activities.

Since a lack of green space to implement EG was a finding, urban areas without green space require foresight when intending to use the curriculum. Establishing a garden is one way to adapt for lack of green space as the Brooklyn Botanical Garden does with a community garden in New York City.

EG is an open source, free curriculum available for down load from the internet, www.globe.gov/elementaryglobe, so getting it to be utilized by more elementary schools is not an issue of costs, it is one due to teachers not knowing about it since it is relatively new being available since 2006. Science is not one of the core subjects taught in elementary school, but the findings from this study support the extended use of EG in elementary schools because of the ease of integration with reading and writing, which are core subjects. It should be promoted and 
utilized in more elementary science methods courses in universities and colleges with schools of education.

In this study the one teacher with National Board Certification commented on the need to incorporate EG in science methods classes for the preparation of preservice teachers. Another suggested implication of practice would be creating more outdoor learning laboratories and opportunities for professional development in earth and environmental sciences.

I think it should be definitely a part of the science methods class. Again even if they don't have the GLOBE curriculum in their hands to see how science has taught through them just the way it’s taught gives you a way to think regardless of what textbook or what CSO's you are handed how to handle it (Linda, interview two, 9/29/10).

The burden of preparation for standardized testing conflicts with teachers primary duties of teaching. This needs to be addressed when teaching science and in the preparation of preservice teachers. There is less time for teaching science due to emphasis on the core subjects of language arts and math. These core subjects get assessed through standardized testing with preparation for standardized testing a fixture of the public school landscape. Compliance with No Child Left Behind mandates and state testing such as Westest are given priority over non-core teaching. This preparatory time diminishes the instruction of other courses, especially science (California Council, 2010; Center for Educational Policy, 2008). Elementary GLOBE mitigates the loss of time, as it is easily integrated with other subjects as witnessed in this study. The EG curriculum was integrated with reading, writing, social studies, and math, so this ameliorates the burden on teachers to implement science lessons when knowing they are also practicing core requirements for language arts and math, and in essence still complying for the preparation of 
standardized testing. Through the integration of EG with language arts and math, this study's findings show that teachers can do inquiry-based science through interdisciplinary approaches and still comply with preparation for mandated standardized assessments.

In this study, the findings from observations, interviews, and collected artifacts strongly give evidence for more robust environmental education. Both studied schools have playgrounds devoid of trees and encircled with chain linked fences (Appendices I and K). The playground areas have saw dust lining the ground and are aseptic for play. They are very sterile in appearance. The areas are unnatural in this state, presenting the children with the choices of sitting on playground equipment (e.g. swings, monkey bars, a slide, and a see-saw) or standing.

Louv (2008) wrote, "Parents who wish to raise their children in a climate conducive to modern-or postmodern-creativity do well to expose them to that world, but not at the exclusion of the natural world (p.98).” Children need to feel leaves, look for insects, and be amazed that clouds (Appendix M) have names. EG exposes children to science while integrating math, language arts, and social studies. It offers opportunities for accommodation including the student diversity found in many schools like those in this study.

The neuroscientist, Lise Eliot summarized these thoughts in her book, Pink Brain Blue Brain:

Children need to hold, weigh, move, pour, measure, and explore real objects with mass, texture, and three-dimensional shape: plants, bugs, acorns, rocks, crystals, pennies, blocks, balls, dice, and dominoes, as well as specially designed educational manipulatives like base-ten blocks, fraction pies, and tangrams (Eliot, 2010, p. 165).

The teachers became more competent in their science teaching abilities as they progressed through this study. Bandura (1997) cites this as building self-confidence and 
believed instructors are more motivated if their actions are deemed favorable. This study provides findings of higher teacher self-esteem from favorable results found when instructing students. Appendices (G, L, M, N, O, P, Q, R, S, T, U, and V) show student artifacts produced while students learned science in an engaged and favorable manner. Furthermore, Bass et al. (2009) found that being engaged produced favorable outcomes when teaching science.

This study’s findings suggest that investing time to engage students outside for teaching science incentivized their feelings to like science. The more time outside potentiates the opportunities to do investigations and discuss environmental issues like global climate change. Computer simulations do not address the environment when experiencing it firsthand suffices to create the hands-on tactile context for learning about nature.

This study provides evidence that inquiry-based curriculum impacts the quality of teaching by making it more easily integrated in the classroom, improving teachers' self-efficacy to provide instruction, and changing student perception of science. The self-efficacy of teachers using EG should be studied by using a pre and post survey. The Science Teaching Belief Instrument (STEBI) was developed (Riggs \& Enochs, 1990) to measure self-efficacy in science teaching. STEBI form B has been shown to accurately measure self-efficacy and it might be utilized to investigate teachers' initial use of EG. EG change of teacher self-efficacy warrants additional research after the findings of this study.

\section{Recommendations for Research}

Based on the findings of this study, recommendations for future research are set forth. The target audiences of this research include elementary teachers and students. Due to the emphasis on the core subjects of reading and math, science is often taught with less priority. 
This makes teaching it more difficult because there is less accountability for scores on national assessments since science is not tested. Science takes additional planning to include investigations for instruction. While technology can assuage this problem, the actual hands-on learning requires the teacher to be a facilitator. This can be problematic given the highly structured day found in many elementary schools. If ways can be found to integrate instruction with the core subjects, then research should address exploiting this finding. Integrating subjects gives the teacher more time to cover a broader scope of material. Instruction time is limited and its limitations are not typically self-imposed albeit some teachers rely on textbooks because that meets the minimum requirement to teach science and that can be viewed as self-imposed and self-limiting.

One area of future research should address the students' awareness of the natural environment as it impacts them personally, locally and then globally. Since EG is inquiry-based, future research should address the ability of students to conduct investigations by generating questions. This could be done with assessing pre and post exposure to the meteorology investigation found in EG. It could also be extended through the incorporation of garden based learning, since the playground at Jack and Jill Elementary has been transformed with the addition of raised growing plots (Rye, 2011). The lack of journal entries regarding teaching is another area which should be pursued for future research. Ortlipp (2008) found keeping and using reflective research journals offer insight to the researcher who then can make it available for others. This should be the intent for journal keeping on experiences with EG. The teachers' comments showing their reflections are an invaluable tool when gaining insight into their students’ behavior (Ortlipp, 2008). Unfortunately, some of the participants' journals lacked substance in content and in some cases were done with brevity. How can the researcher persuade 
participating teachers to write entries every two or three days at minimum? In this study, the researcher sent reminders via email and left discrete notes in teacher mailboxes. This was done in a respectful manner and never more than twice each semester. Nonetheless, the compliance to go beyond just the minimal was the result, and produced information deemed light in content and value. One way to encourage regular journaling is to provide a template for the teachers to use as a guide. Additional research needs to be addressed on how to improve compliance with this type of information gathering.

There should be future research on how the focus on reading and math has significantly impacted the teaching of science in grades K-4. There needs a deeper understanding of how this limits teaching elementary science. Is this because science is not assessed in federally mandated testing? This needs the utmost priority because the earlier grades are where student enthusiasm often steers students towards careers in STEM related professions. Furthermore, given that NASA, the University of Colorado, and the U.S. State Department were developers of EG, the study of the policy of teaching about Earth Systems Science has been neglected. This is especially troubling in the present catastrophic conditions being created by Global Climate Change. The contributions of using coal should receive more attention in science classrooms at the elementary level. This should also be addressed at the local, state, and national levels and is ripe for integrating into an elementary curriculum, and has implications in cross cultural research where deforestation affects the habitat of migratory species like the monarch butterfly and such issues as deforestation in the Amazon River Basin and effects on indigenous Indian tribes. The fact that EG is available in the five United Nations languages segue creating lessons encompassing expanding cultural understanding beyond the elementary school. This is a ripe 
area for doing research on what an elementary student can do to become better informed and enhance their understanding of other cultures.

Parents can become better informed from what their children bring home in the way of homework and extension of lessons learned in science class. This has received scant attention but is fertile for research on how this connection can be used to enhance the learning of science and process skills. Parents can be advocates for the learning that their children bring home in the form of furthering curiosity beyond the classroom. There are many science principles that can be piggy backed with simple scaffolding investigations at home. The internet makes this even more readily available, since a student has access to many sources of information to satisfy their yearning to know more and parents can assist with the research as needed.

This study provides evidence that the type of curriculum impacts the quality of teaching by making it more easily integrated in the classroom, improving teacher's self-efficacy to provide instruction, and changing student perception of science. The self-efficacy of teachers using EG should be studied by using a pre and post survey. The Science Teaching Belief Instrument (STEBI) was developed (Riggs \& Enochs, 1990) to measure self-efficacy in science teaching. STEBI form B has been shown to accurately measure self-efficacy and it might be utilized to investigate teachers' initial use of EG. EG change of teacher self-efficacy warrants additional research after the findings of this study. 


\section{REFERENCES}

Ackerson, V. L. (2001). Teaching science when your principal says, “teach language arts.” Science and Children, 38(7), 42-47.

Ainsworth, B., Haskell W.L., Herrmann S.D., Meckes N., Bassett Jr D.R., Tudor-Locke C, \& Greer (2000). The compendium of physical activities tracking guide. Retrieved from Prevention.sph.sc.edu/tools/docs/documents_compendium.pdf.

American Geological Institute (2000). EarthComm: Earth system science in the community. Washington, D.C. American Geological Institute.

Ansberry, K., \& Morgan, E. (2010). Picture Perfect Science Lessons Using Children’s Books to Guide Inquiry ( $2^{\text {nd }}$ ed). Arlington, VA: NSTA Press.

Balog, J. (2009). Time-lapse proof of extreme ice loss. TED Global2009. Filmed Jul2009, Posted Sep 2009.

http://www.ted.com/talks/james_balog_time_lapse_proof_of_extreme_ice_loss.html

Bandura, A. (1997). Self-efficacy: The exercise of control. New York: Freeman.

Barnett, J. \& Hudson, D. (2001) Pedagogical context of knowledge: Toward a fuller understanding of what good science teachers know. Science Education, 85(4), 426-453.

Barstow, D., \& Geary, E., (Eds.) \& TERC (Firm) (2002). Blueprint for change: Report from the national conference on the revolution in earth and space science education, June 21-24, 2001, Snowmass, Colorado.

Bass, J., Contant, T., \& Carin, A. (2009). Teaching science as inquiry (11 $\left.{ }^{\text {th }} \mathrm{ed}\right)$. Boston, MA: Allyn \& Bacon/Pearson. 
Beane, J. (1995) Curriculum integration and the disciplines of knowledge. Phi Delta Kappan, 76 (8), 616-617.

Benedum Collaborative (2011). Retrieved from http://benedumcollaborative.wvu.edu/pds_partnerships

Berlin, D. \& Lee, H. (2005). Integrating science and mathematics in education: Historical analysis. School Science and Mathematics Education, 105(1), 15-24.

Bethel, L. (1982). Tailoring In-service Training in Science to Elementary Teacher’s Needs. Phi Delta Kappan International, 63(6), Feb, 1, p. 416.

Bloom, B.S. (1968). Learning for mastery, UCLA evaluation comment, 1(2), 1.

Bloom, B.S. (1976). Human characteristic and school learning. New York: McGraw-Hill.

Bloom, B.S. (1981). All our children learning: A primer for parents, teachers, and other educators. New York: McGraw Hill.

Blosser, P.E. (1990). Current projects and activities in K-12 science education curriculum development. ERIC/SMEAC Science education digest No. 3 - How do the reforms of the 90S differ from those of the post-SPUTNIK era? ERIC/SMEAC Science education digest, 3. Reproduction service No. ED324 194).

Boyland, J. \& Moyer-Packerham, P. (2008). A review of the literature on mathematics and science teacher quality. Peabody Journal of Education, 83(4), 509-635. doi:10.1080/01619560802414890

Briscoe, C. \& Peters, J. (1997). Teacher collaboration across and within schools: Supporting individual change in elementary science teaching. Science Education, 81(1), 51-65. doi: 10.1002/(SICI)1098-237X(199701)81:1<51::AID-SCE3>3.0.CO;2-0

Brunner, J. (1974). Toward a theory of instruction. Harvard University Press. Cambridge, MA. 
BSCS \& IBM (1989). New designs for elementary school science and health. A Cooperative project between biological sciences curriculum study (BSCS) and International Business Machines (IBM) Dubuque, IA: Kendall/Hunt Publishing Company.

Burlingame, R. (1960). Scientists behind the inventors. Avon Books, New York, NY.

Bybee, Rodger W. \& Nancy M. Landes (1990). Science for life and living. The American Biology Teacher, 52(2) 92-98. Biological Sciences Curriculum Study (BSCS) \& International Business Machines (IBM) (1989). New designs for elementary school science and health. Dubuque, IA: Kendall/Hunt Publishing Company.

Bybee, R., Taylor, J., Gardner, A., Van Scotter, P., Powell, J., Westbrook, A. \& Landes, N. (2006). The BSCS 5E Instructional model: origins, effectiveness and applications. Colorado Springs, CO: Biological Science Curriculum Study.

California Council on Science and Technology (CCST). (2010). The preparation of elementary schoolteachers to teach in California-Challenges and opportunities impacting teaching and learning science. Sacramento: CCST.

Capobianco, B., \& Feldman, A. (2006). Promoting quality for teacher action research for science and technology. (Sacramento: CCST), p. 12: lessons learned from science teachers’ action research. Educational Action Research, 14(4), 497-512.

Carrier, S. (2009). The effects of outdoor science lesson with elementary school students on preservice teacher' self-efficacy. Journal of Elementary Science Teaching, 21(2), 35-48

Center for Champagne Educational Policy (CEP). (2008). Instructional time in elementary school. Curriculum and instruction in the NCLB era. Washington, DC: CEP. 
Chaney, B. (1995). Student outcomes and professional preparation of eight grade teachers in science and mathematics. Unpublished manuscript. Prepared for NSF Grant RED9255255. Rockville, MD: Westat, Inc.

Cochran-Smith, M., \& Lytle, S.L. (1999). Relationships of knowledge and practice: Teacher learning in communities. Review of Educational Research in Education, 24, 249-305.

Colker, L.J., (2002). Teaching and learning about science. Young Children, 57(5) 10-11.

Craig, P. (1978). The heart of a teacher: A heuristic study of the inner world of teaching (Doctoral Dissertation). Retrieved from Boston University, Boston, MA.

Daniels, S., Arnett, D., Eckel, R., Gidding, S., Hayman, L., Kumanyika, S., Robinson, T., Scott, B., Jeor, S., \& Williams, C. (2005). Overweight in children and adolescents pathophysiology, consequences, prevention and treatment. Circulation, 111(15), 19992012.

Darling-Hammond, L., Wei, R., Andree, A., Richardson, N., \& Orpahanos, S. (2009, February). Professional learning in the learning profession: A status report on teacher development in the United States and abroad. Dallas, TX: National Staff Development CouncilSchool Redesign Network at Stanford University. Retrieved from http://www.nsdc.org/news/NSDCstudy2009.pdf

Davis, D., \& Dodd, J. (2002). Qualitative research and the question of rigor. Qualitative Health research, 12(2), 279-289.

Denzin, N. K. (1989). Interpretive interactionism. Newbury Park, CA: Sage.

Dewey, J. (1938). Experience and education. New York, NY: Touchtone.

Edwards, C. (1997). Promoting student inquiry. The Science Teacher, 64: 18-21. 
Eliot, L. (2010). Pink Brain Blue Brain. Houghton Mifflin Harcourt, First Mariner Books, Boston, New York.

Erlandson, D., Harris, E., Skipper, B., \& Allen, S. (1993). Doing naturalistic inquiry: a guide to methods. New Park, CA: Sage Publications.

Ewing, B., Goldfinger, S., Oursler, A., Reed, A., Moore, D., \&Wackernagel, D. (2009). Ecological Footprint Atlas. Global Footprint Network, San Francisco, California, USA.

Fisher, K. (1997). Mind of our own-lessons from thin air program 2. Annenberg CPB. Math and Science Project.

Friend, H. (1985). The effect of science and mathematics integration on selected seventh grade students' attitudes toward and achievement in science, School Science and Mathematics, 85(6), 453-461.

Frykholm, J. \& Glasson, G. (2005). Connecting science and mathematics instructions: pedagogical context knowledge for teachers. School Science and Mathematics, 105(3), $127-135$.

Gallenstein, N. (2005). Engaging young children in science and mathematics. Journal of Elementary Science Education, 17(2), 27-41.

Ginsburg, K. R. (2007). The importance of play in promoting healthy child development and maintaining strong parent child bonds. American Academy of Pediatrics, Committee on Communications and Committee on Psychosocial Aspects of Child and Family Health. Pediatrics, 119(1), 182-191.

Golafshani, N. (2003). Understanding reliability and validity in qualitative research. The Qualitative Report, 8(4), 600. 
Good, R. (1991) Editorial: Research on science-mathematics connections. Journal of Research in Science Teaching, 28 (2) 109. doi: 10.1002/tea.3660280202

Gortmaker, S., Cheung, L., Peterson, K., Chomitz, G., Cradle, J., Dart, H., Fox, M., Bullock, R., Sobol, A., Colditz, G., Field, A. and Laird, N. (1999). Impact of a school-based interdisciplinary intervention on diet and physical activity among urban primary school children. Achieves of Pediatric Medicine, 9(153), 975-983.

Guba, E. (1978). Toward a methodology of naturalistic inquiry in educational evaluation. Monograph \#8. UCLA Center for Study of Evaluation.

Gunning A., \& Mensah, F. (2011). Preservice elementary teachers’ development of self-efficacy and confidence to teach science: A case study. Journal of Science Teacher Education, 22(2), 171-185.

Hachey, A. \& Butler, D. (2009). Science education through gardening and nature-based play. Young Children, 64(6) 42-48.

Harty, H., Kloosterman, P., \& Matkin, J. (1991). Science problem solving approaches in elementary school classrooms. School Science and Mathematics, 91(1), 10-14.

Hawkins. E.F., Stancavage, F.B., \& Dossey, J.A. (1998). School policies and practices affecting instruction in mathematics: Findings from the National Assessment of Educational Progress. Washington, DC: U.S. Department of Education, Office of Educational Research and Improvement. (ERIC Document Reproduction Service No. ED 424116). Henderson, S., Hathaway, L., Gardiner, L., \& Zarlengo, K. (2006). An Early Introduction to Earth System Science through Elementary GLOBE. Journal of Geoscience Education, 54 (3), 210-214. 
Hidi, S., \& Harackiewicz, J. M. (2000). Motivating the Academically Unmotivated: A Critical Issue for the 21st Century. Review of Educational Research, 70(2), 151-179.

High, V., \& Rye, J. (2011). Engaging Within Time Limits: An Integrated Approach for Elementary Science, Manuscript submitted for publication.

Inhelder, B. \& Piaget, J. (1964). The early growth of logic in the child, classification and seriation. London: Routledege \& Kegan Paul.

Jaeger, E. (2007). What every parent, teacher, and community member needs to know about No Child Left Behind, San Jose State University. Retrieved from www.oaklandea.org/front_page_docs/may.../NCLB\%20Jaeger.pdf

Keen, V. (2003). Recapturing the “Disenchanted:” Orienting prospective primary teachers toward problem posing and deeper understanding of the mathematics they will teach. Paper submitted for discussion in ICME-10 Discussion Group DG 18: Current problems and challenges in primary mathematics education. Dept. of Mathematics and Statistics, Miami University, OH. Retrieved from http://www.icmeorganisers.dk/dg18/papers/Keen_ICME.pdf

Kratochvil, D., \& Crawford, J. (1971). Science Curriculum Improvement Study Project, American Institutes for Research in the Behavioral Sciences, Palo Alto, CA.

Lapp, D. (2001). Bridging the gap, Science Link (Newsletter of the National Science Resource Center) 12(1), 2.

Lawson, A. \& Bealer, J. (1984). The acquisition of basic quantitative reasoning skills during adolescence: Learning for development? Journal of Research in Science Teaching, 21 (4), 417-423.

Liberatore, S. (2008) Health wise. The Science Teacher, 75(7), 82-83. 
Lincoln, Y. S. \& Guba, E. G. (1985). Naturalistic inquiry. Beverly Hills, CA: Sage Publications, Inc.

Linder, D. (2008). Famous Trials in American History, Tennessee v John Scopes - The “Monkey” Trial 1925 Retrieved from http://law2.umkc.edu/faculty/projects/ftrials/scopes/scopes.htm

Linn, M. C, Chen, B. \& Thier, H. (1977). Teaching children to control variables: Investigation of free-choice environment. Journal of Research in Science Teaching, 14(3), 249-255. doi: 10.1002/tea.3660140310.

Llewellyn, D. (2002). Inquire within: Implementing inquiry-based science standards. Thousand Oaks, CA: Corwin Press.

Louv, R. (2008). No child left in the woods, saving our children from nature deficit disorder. Chapel Hill: Algonquin Books,

Lubchenco, J. (1998). Entering the century of the environment: A new social contract for science, Science, 279 (5350), 491-497.

McBride, J.W., \& Silverman, F.L. (1991). Integrating elementary/middle school science and mathematics. School Science and Mathematics. 91 (7), 285-292. doi: 10.1111/j.19498594.1991.tb12102.x

McDevitt, T.M., Heikkinen, H.W., Alcorn, J.K., Ambrosio, A.L. \& Gardner, A.L. (1993). Evaluation of the preparation of teachers in science and mathematics: Assessment of preservice teachers' attitudes and beliefs. Science Education, 77(6) 593-610. doi: 10.1002/sce.3730770604

McKibben, B. (1989). The end of nature. New York, NY: Random House. McNeil, J. (1976). Designing curriculum: Self-instructional modules. Boston, MA: Little Brown. 
Micheals, S., Shouse, A., \& Schweingruber, H. (2007). Ready, set, science! Washington, D.C. National Academies Press.

Mitchell, J. (1970). Ladies of the canyon, record, A\&M Studios, Reprise label.

Moustakas, C. (1994). Phenomenological research methods. Thousand Oaks, CA: Sage.

National Council of Teachers of Mathematics. (2000). Principles and standards for school mathematics. Retrieved from http://www.nctm.org/standards/content.aspx?id=16909

NRC (2000). Inquiry and the national science education standards: A guide for teaching and learning, Washington, D.C., National Academy Press.

NRC (1996). National Academy Press 2000, Inquiry and the national science education standards: A guide for teaching and learning, Washington, D.C., National Academy Press (2000).

NGS (1994). The National Geography Standards, Geography for Life, National Council for Geographic Education.

National Survey of Science and Mathematics Education: Status of elementary school science teaching. Horizon Research, Chapel Hill, NC. 2000.

Nedeff, A. (2010). English as a second language Jack and Jill Elementary, We are the world we are the children. Jack \& Jill ESL Program Demographics, Tea at Three Allen Hall WVU April 19, 2011. (Note: Jack and Jill Elementary School is a pseudonym.)

Novak, J. (1997). Mind of Our Own-Lessons from Thin Air Program 2. Annenberg CPB. Math and Science Project. 5:20 time segment

Novak, J. D. \& Musonda, D. (1991). A twelve-year longitudinal study of science concept learning. American Educational Research Journal, 28(1), 117-153. 
Orr, D. (2002). Political economy and the ecology of childhood. In P.H. Kahn \& S.R. Kellert (Eds.) Children and nature: psychological, sociocultural, and evolutionary investigations, Cambridge, MA: Massachusetts Institute of Technology Press.

Ortlipp, M. (2008). Keeping and using reflective journals in the qualitative research process. The Qualitative Report, 13(4), 695-705.

Osborne, J., Simon, S., \& Collins, S. (2003). Attitudes towards science: a review of the literature and its implications. International Journal of Science Education, 25(9), 1049-1079.

Owens, C.V. (1999). Conversational science 101A: Talking it up! Young children, 54(5), 4-9.

Ozer, E.J. (2007). The effects of school gardens on students and schools: Conceptualization and considerations for maximizing healthy development. Healthy education \& behavior, 34 (6), 846-63.

Patton, M. (2002). Qualitative research \& evaluation methods ( $3^{\text {rd }}$ ed). Sage Publications.

Penick, J. \& Bonnstetter, R. (1996). Different goals, different strategies: STS teachers must reflect them. Science/Technology/Society As Reform in Science Education. pp. 163-173.

Perez, D., Fain, S., \& Slater, J. (2004). Pedagogy of place. Peter Lang, New York, NY.

Piaget, J. (1971). Science of education and the psychology of the child. New York NY: The Viking Press.

Piaget. J., \& Inhelder, B. (1956). The child's conception of space. London: Routledge \& Kegan Paul.

Pidgeon, N., Turner, B. \& Blockley, D. (1991). The use of grounded theory for conceptual analysis in knowledge elucidation. International Journal of Man-Machine Studies, 35(2), 151-173.

Pinar, W., Reynolds, W., Slattery, P., \& Taubman, P. (2004). Understanding curriculum. 
New York, NY: Peter Lange.

Polit, D., \& Hungler, B. (1991). Nursing research: Principles and methods. New York, NY: JB Lippincott.

Pretty, J., Angus, C., Bain, M., Barton, J., Gladwell, V., Hine, R., Pilgrim, S., Sandercock, G., \& Sellens, M. (2009). Nature, childhood health and life pathways. Interdisciplinary Centre for Environment and Society (iCES). Occasional Paper 2009-2, University of Essex.

Pretty, J., Brice, S., Brown, J., Clayton, J., Goodman, E., Greer, G., Maskell, M., Oliver, T., \& Tuckerwell, T. (2009). Essex Rural Commission 2009 Report. Essex City Council, Chemsford, UK.

Renner, J. W., Stafford, D. G., Coffia, W.J., Kellogg, D.H., \& Weber, M.C. (1973). An evaluation of the science curriculum improvement study. School science and mathematics, 73(4): 291-318.

Rickinson, M., Dillon, J., Teamey, K., Morris, M., Choi, M., Sanders, D., \& Benefield, P. (2004). A review of research on outdoor learning. Fields Studies Council, Shrewsbury, UK.

Riggs, I. \& Enochs, L. (1990). Towards the development of an efficacy belief instrument for elementary teachers. Science Education. Accepted for publication, March 1990.

Robert Wood Johnson. (2009). Report from wildlife group urges children to play outside. News Digest Retrieved from http://www.rwjf.org/childhoodobesity/digest.jsp?id=10150\&print=true=http\%3A...

Rohrkemper, M. \& Corno, L. (1988). Success and failure on classroom tasks: Adaptive learning and classroom teaching. The Elementary School journal, 88(3), 296-312. 
Rowan, B., Correnti, R., \& Miller, R.J. (2002). What large-scale, survey research tells us about teacher effects on student achievement: Insights from the prospects study of elementary schools. Teachers College Record, 104(8), 1525-1567.

Rubio, A., Barley, Z., \& Jenness, M. (April 1993). Effects of Kit/In-service and Kit Use on teacher's science knowledge, attitudes, and teaching. Paper presented at Research Convocation Kalamazoo, MI.

Rutherford, F. \& Ahlgren, A. (1990). Science for all Americans. New York: Oxford University Press.

Rye, J. (1997). Grape expectations. The Science Teacher, 64(6), 41-46.

Rye, J., O'Hara-Tomkins, N., Eck, R., \& Neal, W. (2008). Promoting youth physical activity and healthy weight through schools. West Virginia Medical Journal, 104(2), 12-15. Retrieved from http://www.wvsma.com/shared/content_objects/media_objects/mediafilepath/2008_mj// mar_apr08mj_web.pdf.

Rye, J. Wilson, S., High, V., \& Hayes, S. (2009). Elementary GLOBE has many reasons to use. WVSTA $25^{\text {th }}$ annual conference, Glade Springs, WV, November 21-24.

Rye, J. (2011). Project Focus: North Elementary school garden-based learning initiative. The Green Scene, 5(9), 1.

Seale, C. (1999). Quality in qualitative research. Qualitative Inquiry, 5(4), 465-478.

Smith, A., C., Wise, M., Anderson, C.A., Krajick, J., \& Coppola, B. (2006). Implications of research on children's learning assessment: Matter and atomic molecular theory. Commissioned paper for the NRC Committee on Test Design for K-12 Science Achievement Workshop, May 6-7, Washington, DC. 
Available: http://www7.nationalacadmies.org/bota/Big\%201deaq\%20Team_\%aMT.pdf [accessed November 2006].

Smith-Sebasto, N., \& Smith, T. (1997). Environmental education in Illinois and Wisconsin: A tale of two states. Journal of Environmental Education, 28(4), 26-36.

Spector, B., Burkett, R., \& Leard, C. (2007). Mitigating resistance to teaching science through inquiry: Studying self. Journal of Science Teacher Education, 18(2), 185-208. doi: 10.1007/s10972-006-9035-2.

Stake, R.E. (1995). The art of case study research. Thousand Oaks, CA: Sage Publications.

Stepans, J., McClung, P., \& Beiswenger, R. (1995). A teacher education program in elementary science that connects content, methods, practicum, and student teaching. Journal of Science Teacher Education, 6 (3), 158-163.

Stevens, C. \& Wenner, G. (1996). Elementary preservice teachers' knowledge and beliefs regarding science and mathematics. School Science and Mathematics, 96(1), 2-9.

Strauss, A. \& Corbin, J. (1990). Basics of qualitative research: Grounded theory procedures and techniques. Newberry Park, CA: Sage Publications, Inc.

Subramanian, A. (2002- Summer). Garden-based learning in basic education: A historical review. Monograph, 1-11.

Teaching Integrated Mathematics and Science (TIMS) Project. Institute for Mathematics and Science Education, University of Illinois at Chicago, 1999. Retrieved from http://www.lsri.uic.edu/projects/tims.asp.

The GLOBE Program (2006). GLOBE teacher's guide. Retrieved from http://archive.globe.gov/tctg.jsp (12 September 2005) Elementary GLOBE Teacher’s Implementation Guide. http://classic.globe.gov/fsl/html/templ.cgi?elemGLOBE\&lang=en 
Their, M. (2002). The New science literacy: Using language skills to help students learn science. Portsmouth, NH: Heinemann.

Vasquez, J. (2005). Bring back elementary science education.

Retrieved from http://www.negystc.org/news.htm.

Vygotsky, L. (1997). Thought and language, Cambridge, MA: MIT Press.

Wenner, G. J. (1993). Relationship between science knowledge levels and beliefs toward science instruction held by preservice elementary teachers. Journal of Science Education and Technology, 2(3), 461-468.

Wideen, M. (1975). Comparison of student outcomes for science-a process approach and traditional science teaching for third, fourth, fifth and sixth grade classes: A product evaluation. Journal of Research in Science Teaching, 12(1), 31-39.

DOI: 10.1002/tea.3660120106.

Wenner, G.J. (1993). Relationship between science knowledge levels and beliefs toward science instruction held by preservice elementary teachers. Journal of Science Education and Technology, 2(3), 461-468.

Wiebe, A. Ecklund, L., \& Hillen, J. (1986) Overhead and underfoot. (Book D). Fresno, CA. AIMS Education Foundation (ERIC Document Reproduction Service No. ED 283 696).

World Wildlife Fund, Global Footprint Network, \& Zoological Society of London (2010). Living Planet Report reveals widening gap between nature’s supply and human demand Retrieved from http://www.footprintnetwork.org/en/index.php/GFN/blog/human_demand_outstripping_n atures_regenerative_capacity_at_an_alarming_rate (p.1). 
Yager, R. (1996). Science/technology/society as reform in science education. State University of New York Press. 


\section{Appendix A - Interview Script}

\section{Appendix A}

\section{Introduction read to interviewees before interview}

Thank you for being willing to be interviewed about the Elementary GLOBE curriculum. I really appreciate the time you are giving. Your effort to assist is completely voluntary. I will be asking you some questions and recording your answers on tape. Is that ok with you?

You can quit anytime you wish. Your participation does not affect your teaching position and you do not have to answer all the questions. Once I transcribe the tape, the tape will be erased, and the transcription will be destroyed after it is analyzed. Your name will not appear on any of the document. While I interview you, I may also write some things down in my book. This is just to remind me of where I am in asking the questions. Is that ok with you? 


\section{Appendix B}

Questions for Interview \#1

(1) What were your thoughts about using Elementary GLOBE in the classroom? (RQ2)

(2) When using the Elementary GLOBE curriculum, how did using the GLOBE kids affect the learning environment in the classroom? (RQ1)

(3) Describe the changes that you observed in your classroom while using Elementary GLOBE? (RQ2)

(4) How could you improve the effectiveness of Elementary GLOBE when teaching about Global Warming and related issues? (RQ1 and RQ2)

(5) How could have improved your students' understanding of environmental issues?

(6) How much teacher training do you think should be required to teach elementary science? (RQ3)

(7) What are the teacher's limitations on getting their students to understand science in elementary school? (RQ1)

(8) Please tell me how your science teaching with Elementary GLOBE has gone since last time we talked? (RQ1)

(9) What are the teacher's limitations on getting their students to understand science in elementary science? (RQ1)

(10) What do you with the student science journals and other student produced artifacts from using Elementary GLOBE? (RQ4) 


\section{Appendix C}

Questions for Interview \#2

1) What were your thoughts about using Elementary GLOBE in the classroom? (RQ2)

2) Please tell me how your science teaching with Elementary GLOBE has gone since last time we talked? (RQ1)

3) When using the Elementary GLOBE curriculum, how did using the GLOBE kids affect the learning environment in the classroom? (RQ1)

4) Describe the changes that you observed in your classroom while using Elementary GLOBE? (RQ2)

5) How could you improve the effectiveness of Elementary GLOBE when teaching about Global Warming and related issues? (RQ1 and RQ2)

6) How could you have improved your students' understanding of environmental issues?

7) How much teacher training do you think should be required to teach elementary science? (RQ3)

8) What are the teacher's limitations on getting their students to understand science in elementary school? (RQ1)If

9) What do you do with the student science journals and other student produced artifacts from using Elementary GLOBE? (RQ4)

10) The Please tell me how your science teaching with Elementary GLOBE has gone since last time we talked? (RQ1)

11) Please tell me how your science teaching with Elementary GLOBE has gone since last time we talked? (RQ1)

12) What is role for the school in promoting science in the elementary class room? (RQ4)

13) How do you deal with barriers of teaching science in elementary school? (RQ1, RQ2)

14) When teaching with Elementary GLOBE, how many ways did you find to integrate the lesson with other courses taught at your school? (RQ4) 


\section{Appendix D}

Questions for interview \#3

(1) When teaching with Elementary GLOBE, how many ways did you find to integrate lesson with other courses taught at your school? (RQ4)

(2) Since using Elementary GLOBE how have been impacted in the classroom? (RQ2)

(3) What is the role for the school in promoting science in the elementary classroom? (RQ4)

(4) What are the teacher's limitations on getting their students to understand science in elementary school? (RQ1)

(5) How could you have improved your students' understanding of environmental issues? (RQ1)

(6) What do you do with the student science journals and other student produced artifacts from using Elementary GLOBE?

(7) Is there anything that you would do differently when teaching science to your students in the future? (RQ3)

(8) When using the Elementary GLOBE curriculum, how did using the GLOBE kids affect the learning environment of your classroom? (RQ1)

(9) Please tell me how your science teaching with Elementary GLOBE has gone since last time we talked? (RQ4)

(10) If we had a school garden, how might that be used as part of and to extend the GLOBE curriculum? 


\section{Appendix E}

\section{Department of Curriculum \& Instruction/Literacy Studies WestVirginiaUniversity.}

College of Human Resources and Education

September 5, 2011

Dear (Name of teacher),

Thank you again for participating in the study "Professional Development School Support of the Elementary GLOBE Curriculum-A Facilitated Adoption of Inquiry Science.” As I finish up the data analysis for this study, it would help me very much to have your "frank" responses as to whether you agree or disagree with the five statements on the attached questionnaire. Please know that your completion of this questionnaire is voluntary, and that you also can choose to complete just some of the questionnaire. Additionally, in any presentation or publication of the findings from this questionnaire, you will remain anonymous (your name will not be associated with any of your responses).

If you choose to complete this questionnaire, please return it in the enclosed postage paid envelope or via email vance.high@gmail.com (you have received this same cover letter and questionnaire in your email). I have sent a copy of the questionnaire to each of your email addresses.

Thank you again for your assistance and time. It has been a pleasure working with each of you.

Best Wishes, Vance High 
Appendix F

\section{Participant Follow-up Questionnaire}

Your "frank" responses will be of great help to me as I finish up with the data analysis phase of the Elementary GLOBE study in which you were a participant. Do you AGREE or DISAGREE (circle one word or the other in questions 1-5) with each statement below? Please provide reasons for why you agree or disagree, and insert extra space (or use back side) as needed. Please email (vance.high@gmail.com) or postal mail in the envelope provided) your responses back to me within one week. Thank you.

(1) Using Elementary GLOBE (EG) changed the way your students experienced science.
AGREE
DISAGREE

Your reason(s):

(2) Using Elementary GLOBE (EG) changed your confidence in your ability to teach science.

AGREE DISAGREE

Your reason(s):

(3) Time management is the major barrier to your teaching of science.
AGREE
DISAGREE

Your reason(s):

(4) Student accommodation is a barrier in your teaching of science?

AGREE DISAGREE

Your reason(s):

(5) You prefer using Elementary GLOBE over the adopted text book curriculum.

AGREE DISAGREE

Your reason(s): 
Appendix G

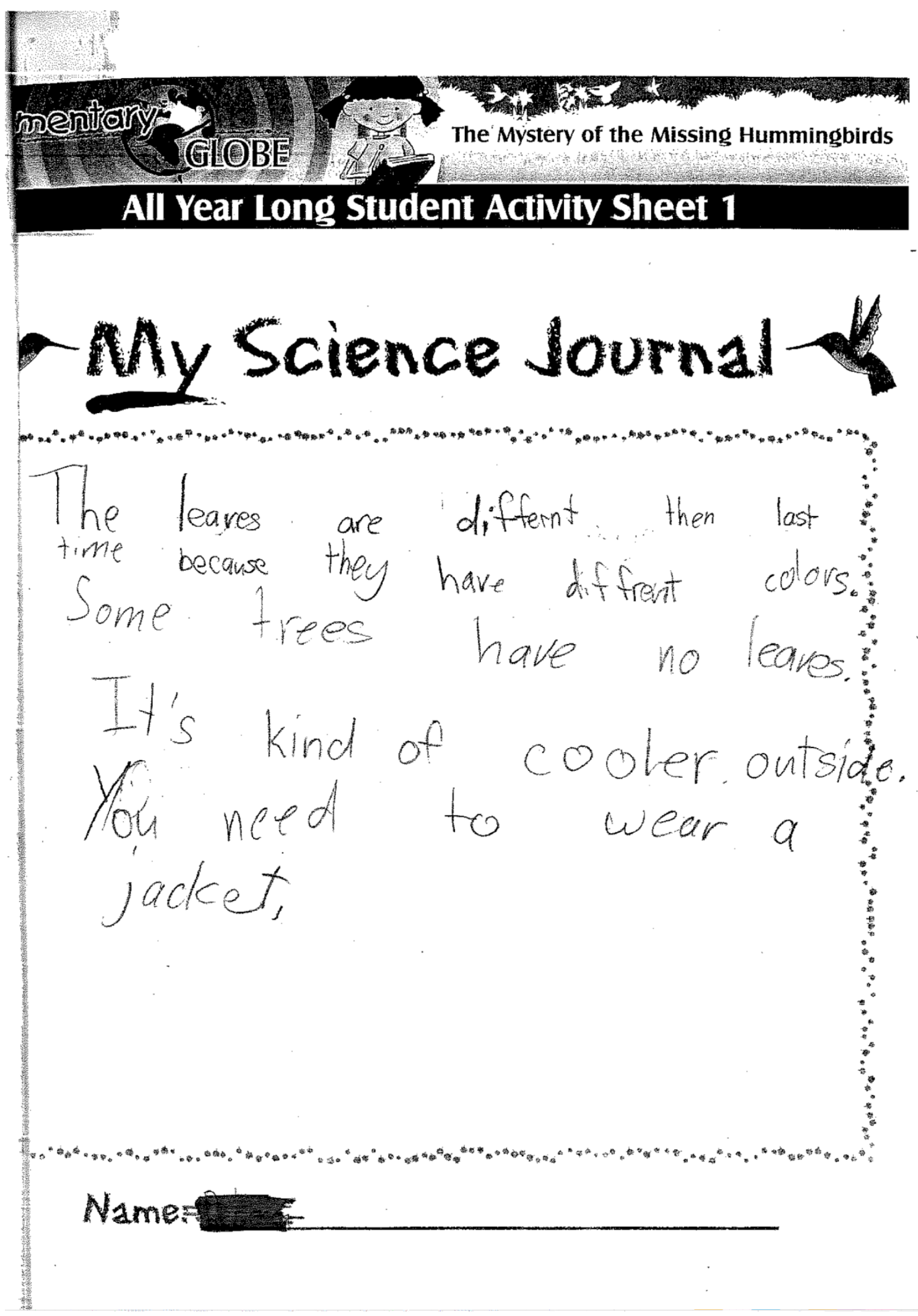




\section{Appendix $\mathrm{H}$}

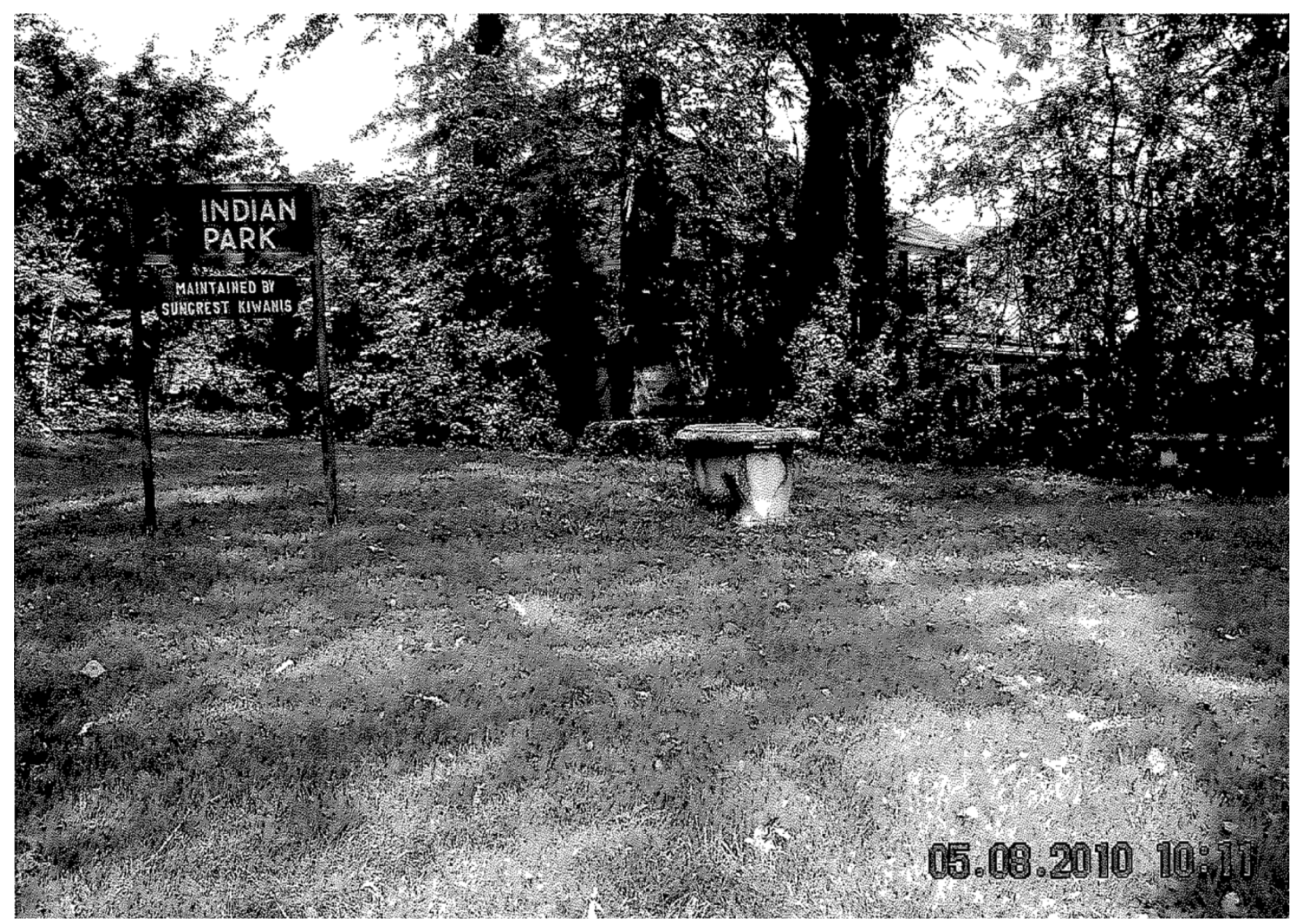


Appendix I

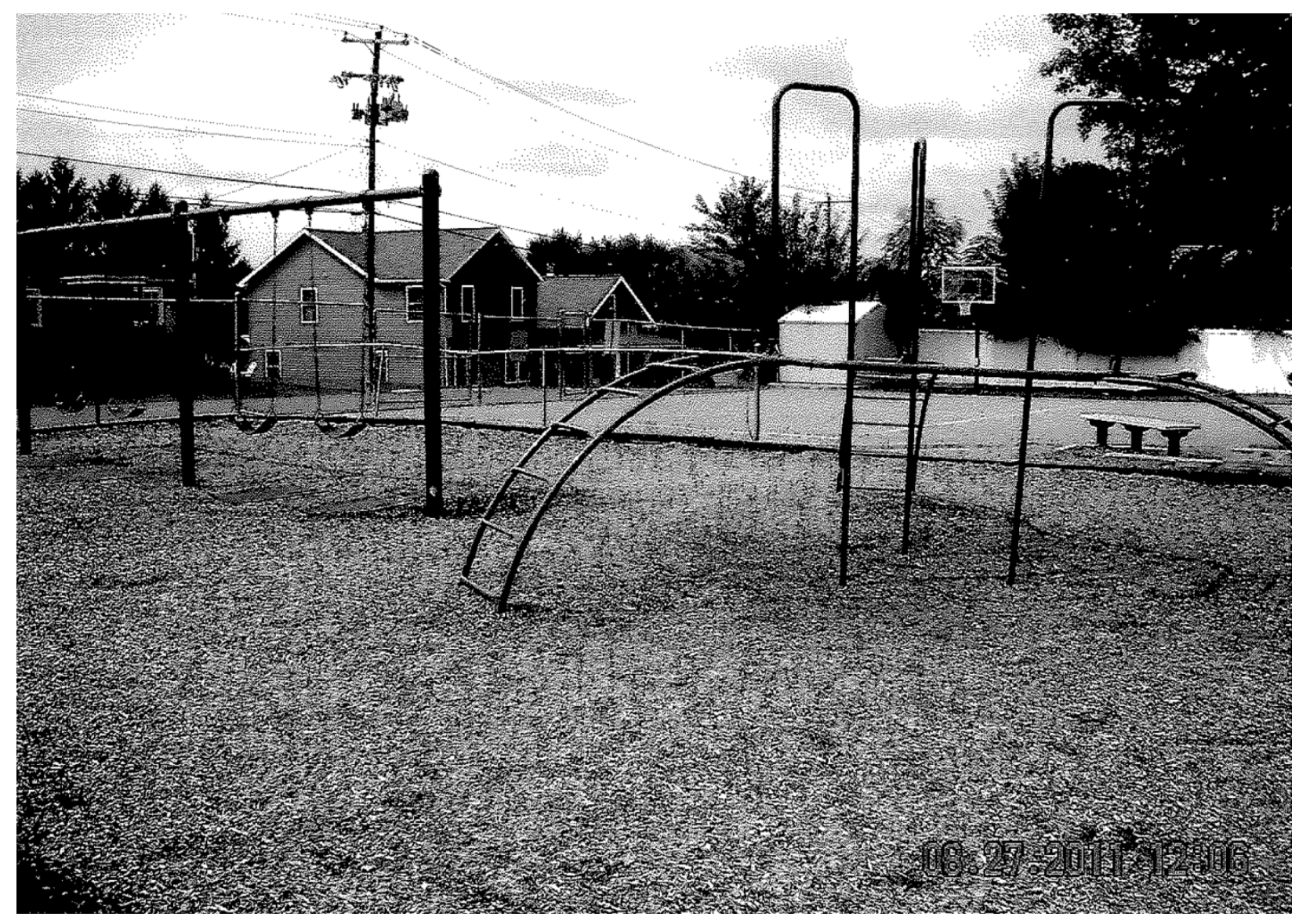




\section{Appendix J}

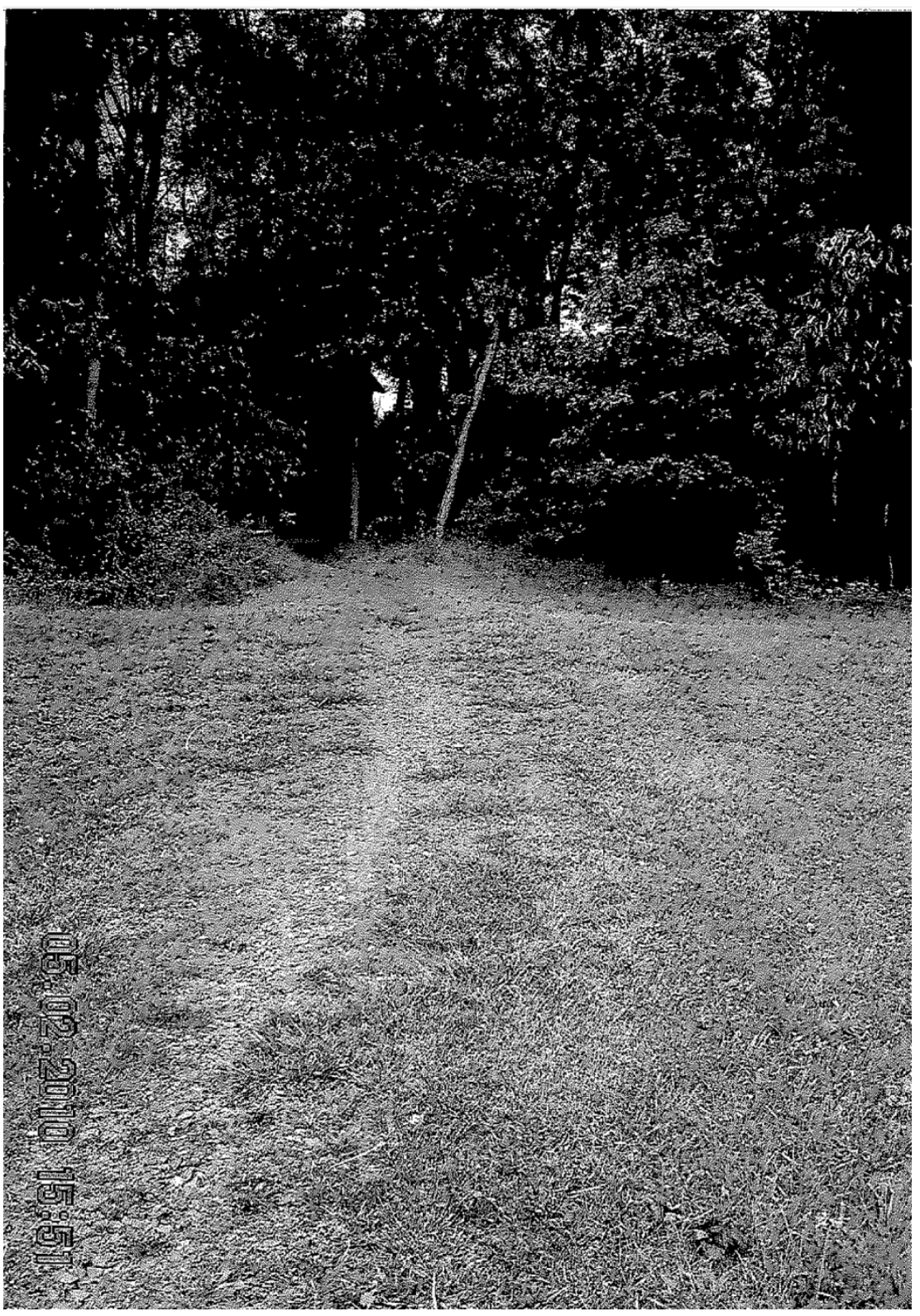


Appendix K

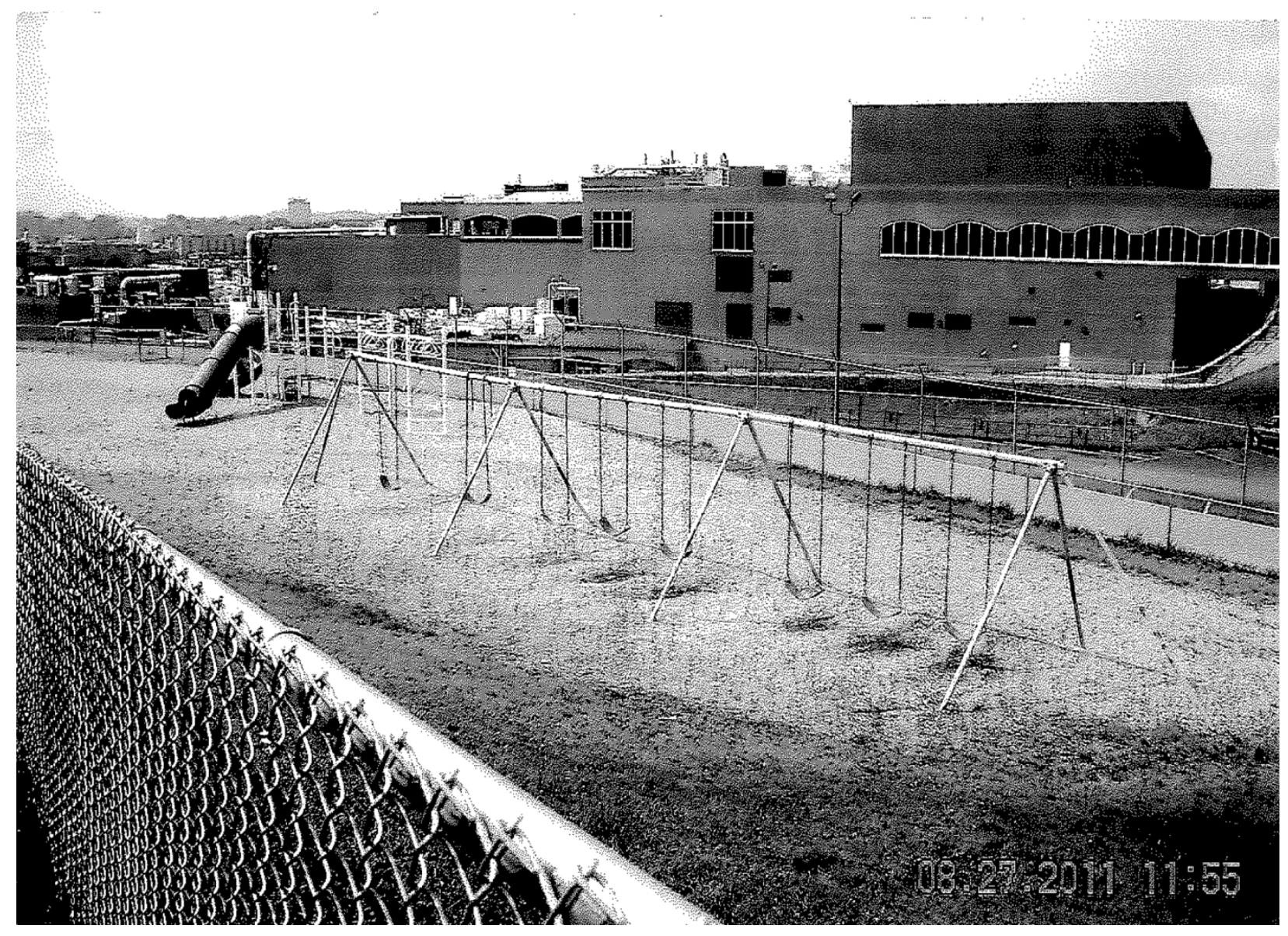


Appendix L

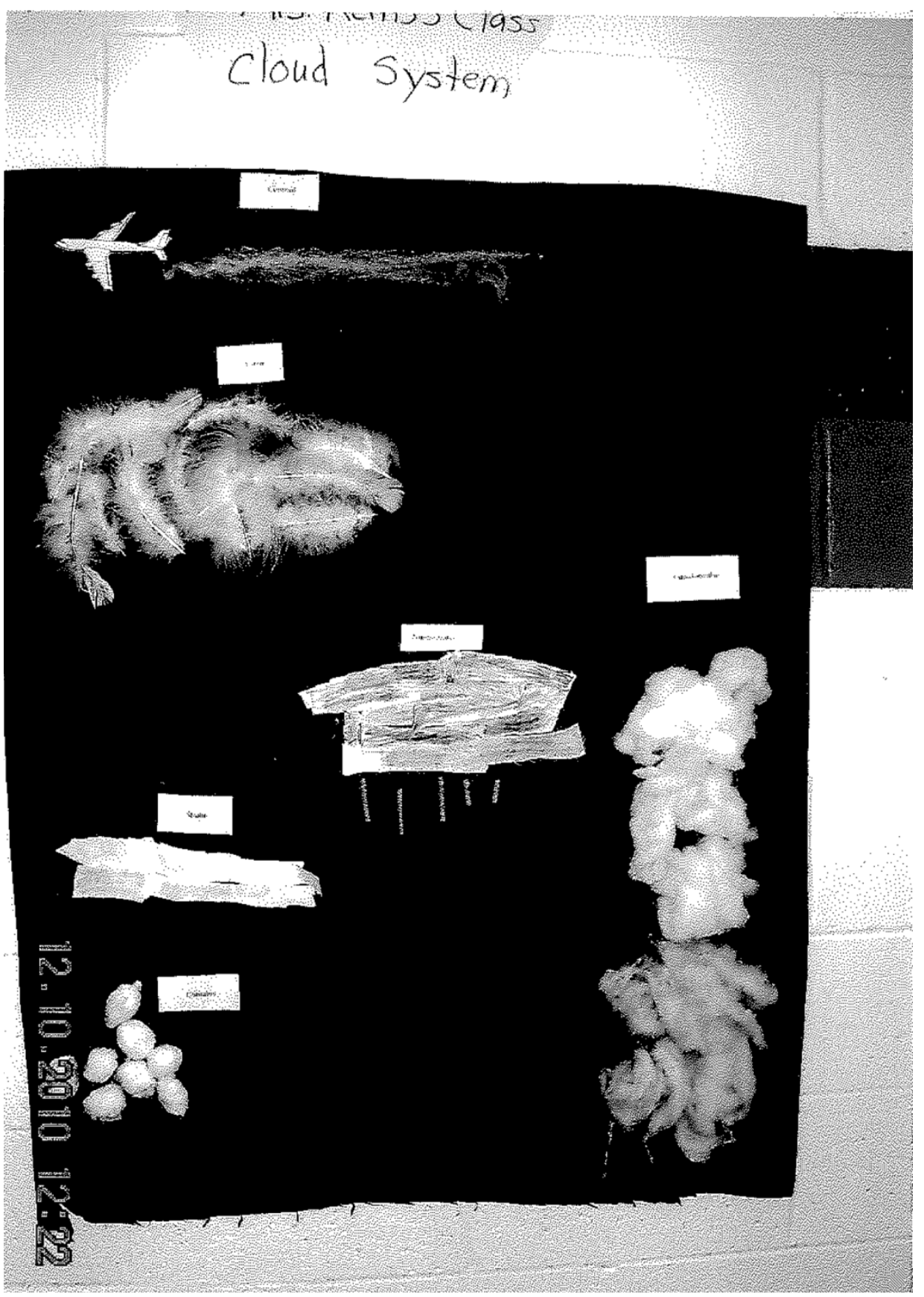


Appendix M

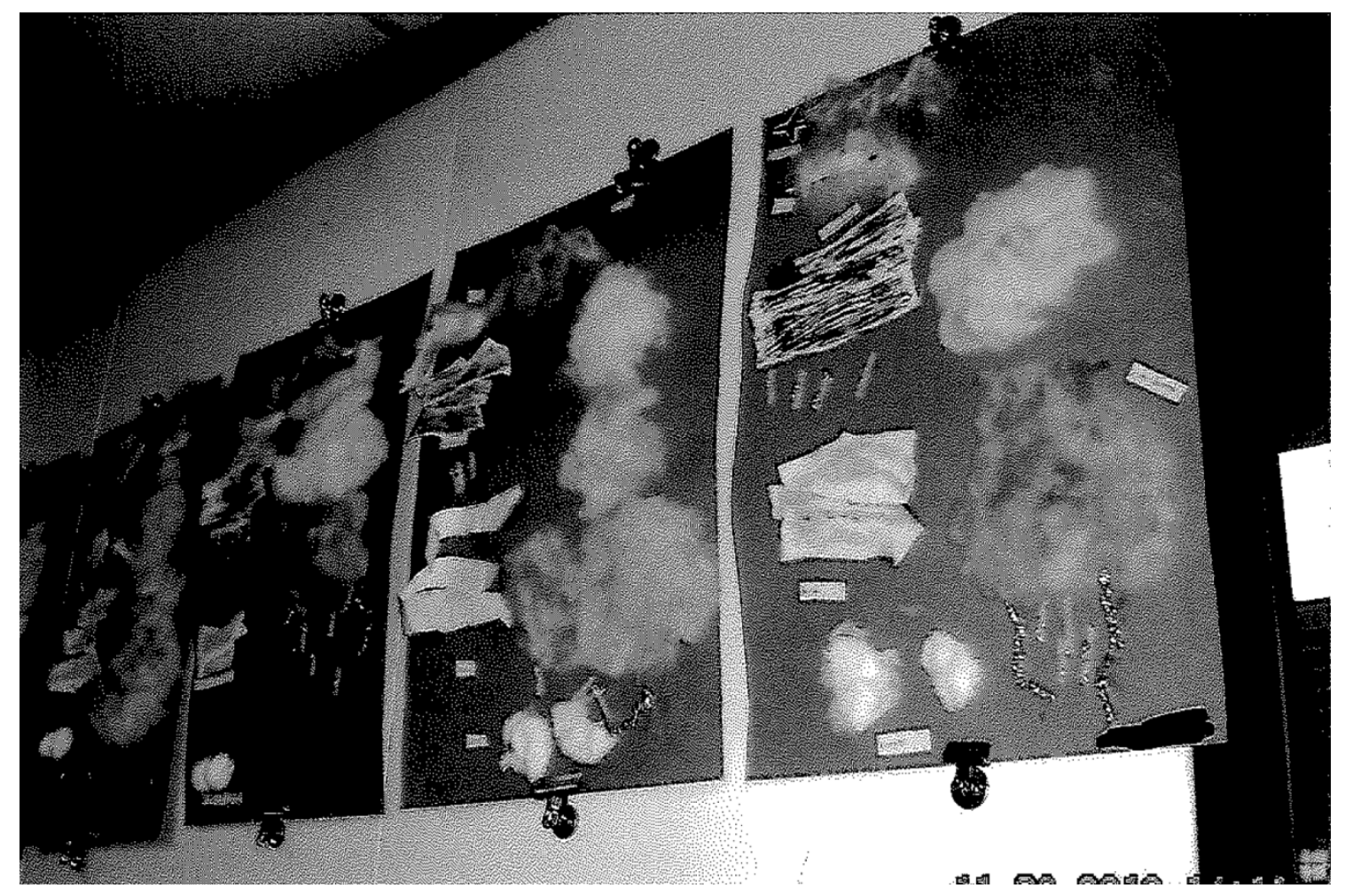


Appendix N

Elementary:

GIOBE

1) -2

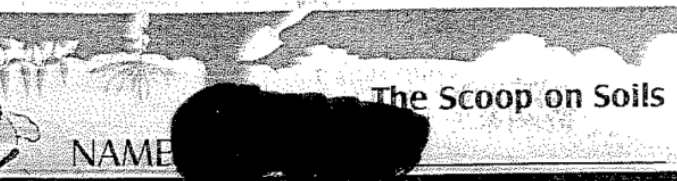

Soll Treasure Hunt Student Activity Sheet 2

Date:

\section{Outdoor Soil Investigation!}

This is where I studied soil outside:

Soil Color

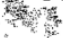
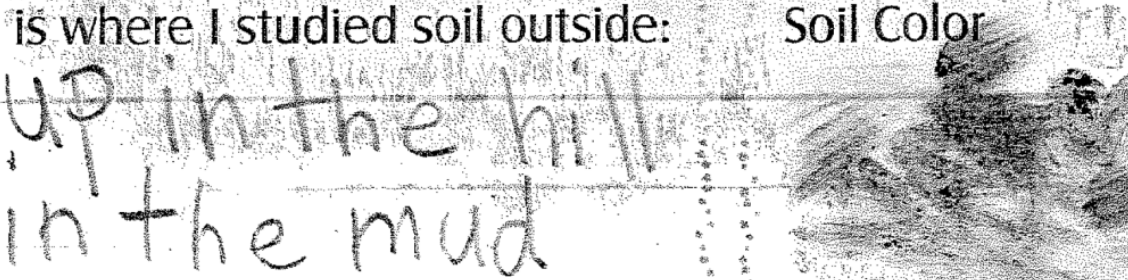

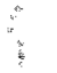

ti

(Rub a little soil above to show color:

These are the things I found in the soil:

grass, antegg, roots, rock

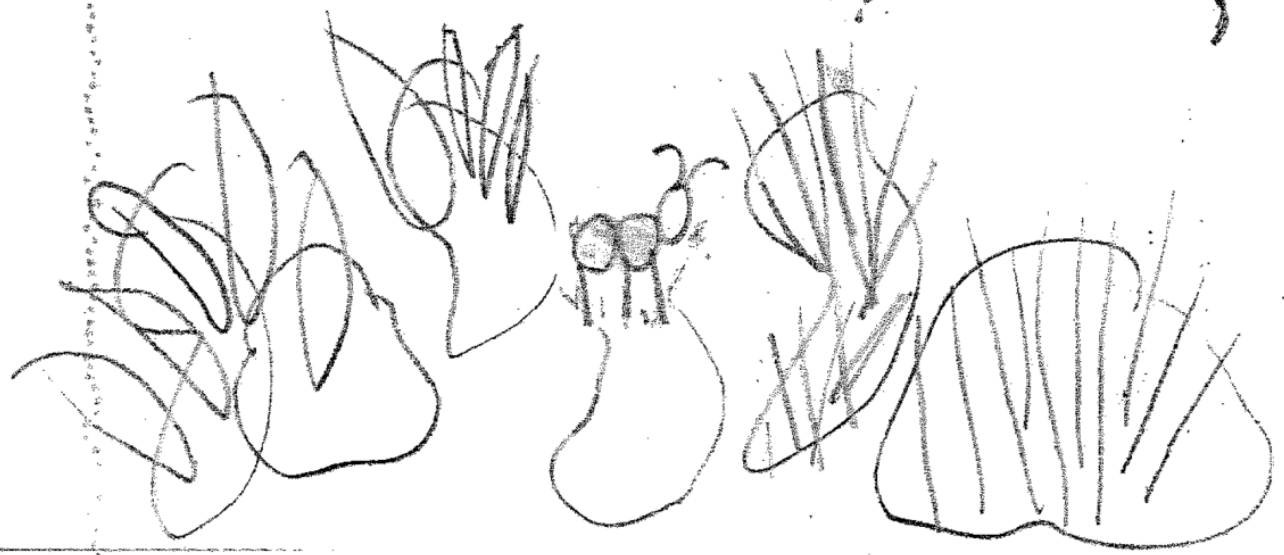


Appendix O

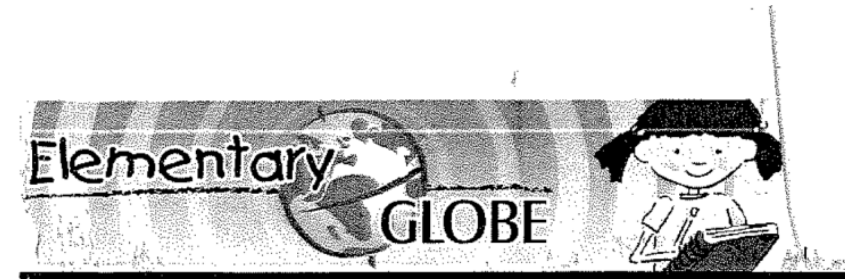

The Colors of the Seasons Student Activity Sheet

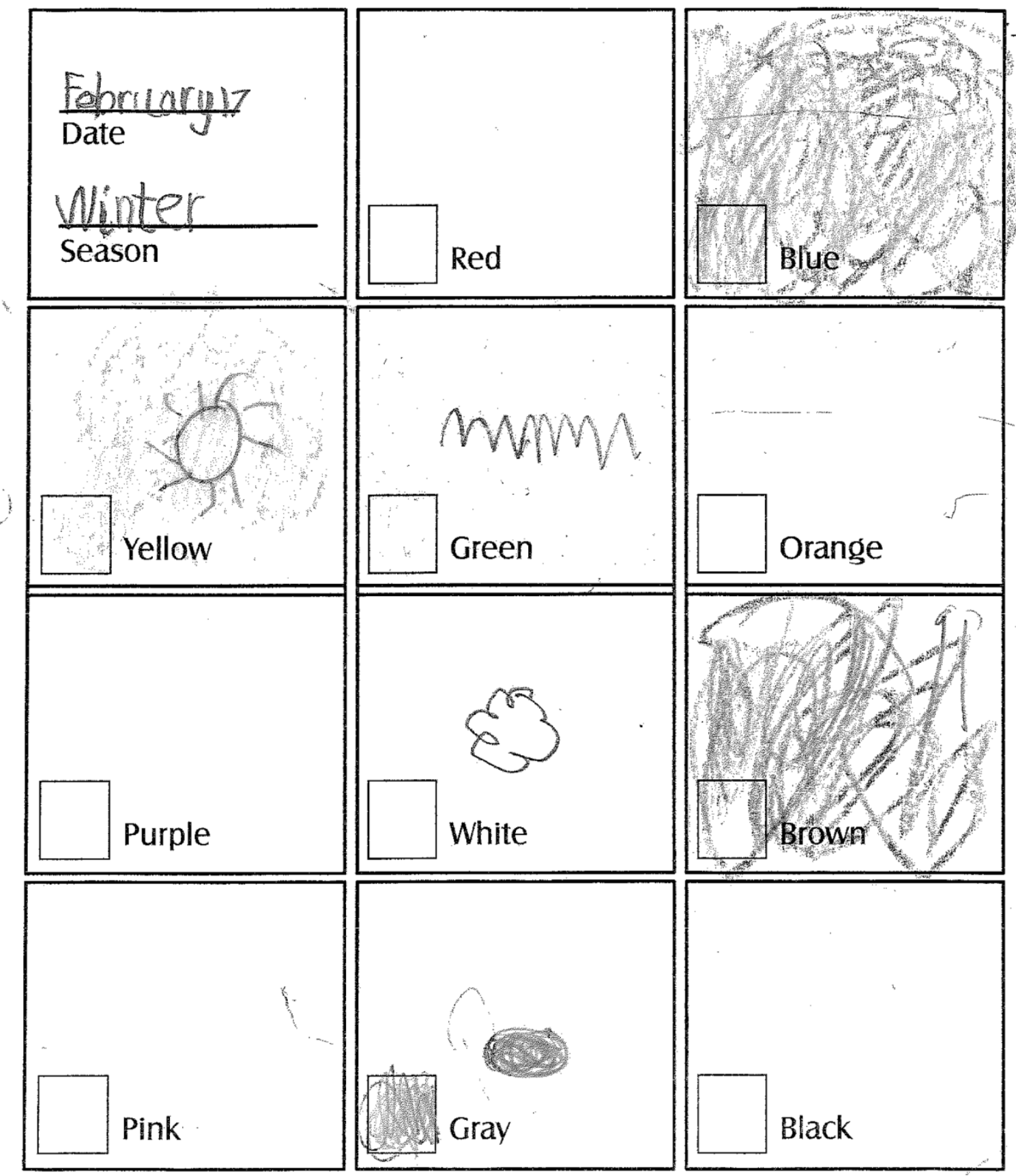

(c) 2006 University Corporation for Atmospheric Research All Rights Reservt 


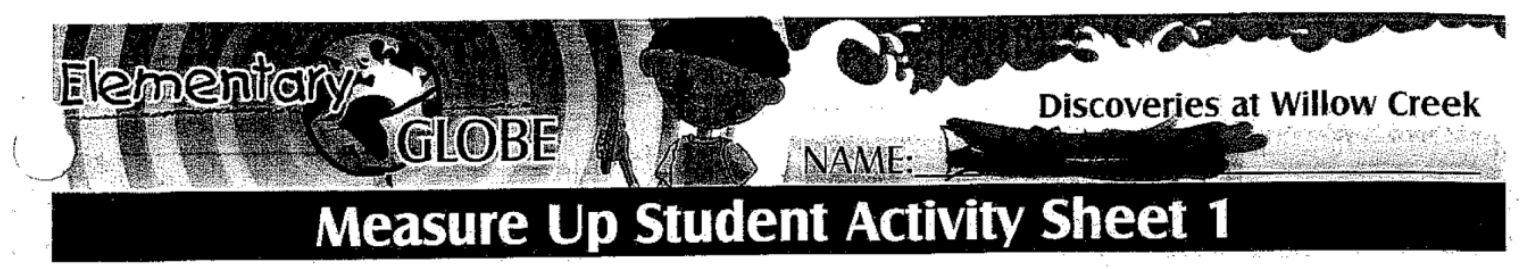

The object I will measure is

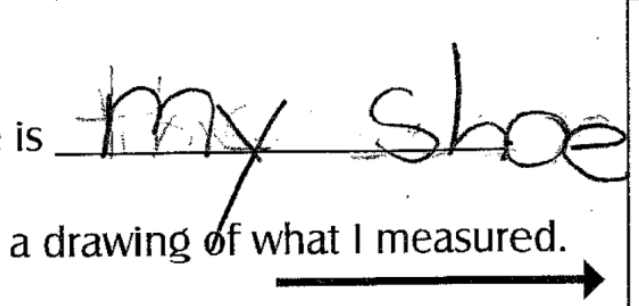

Here's a drawing of what I measured.

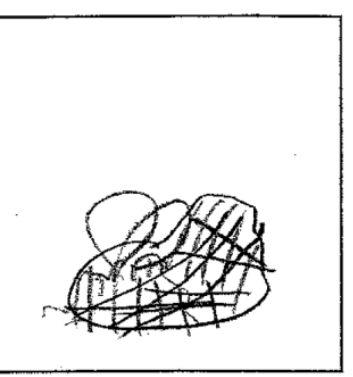

I am using length of my objedt. This is my measurement unit.

Here's a drawing of my measurement unit.
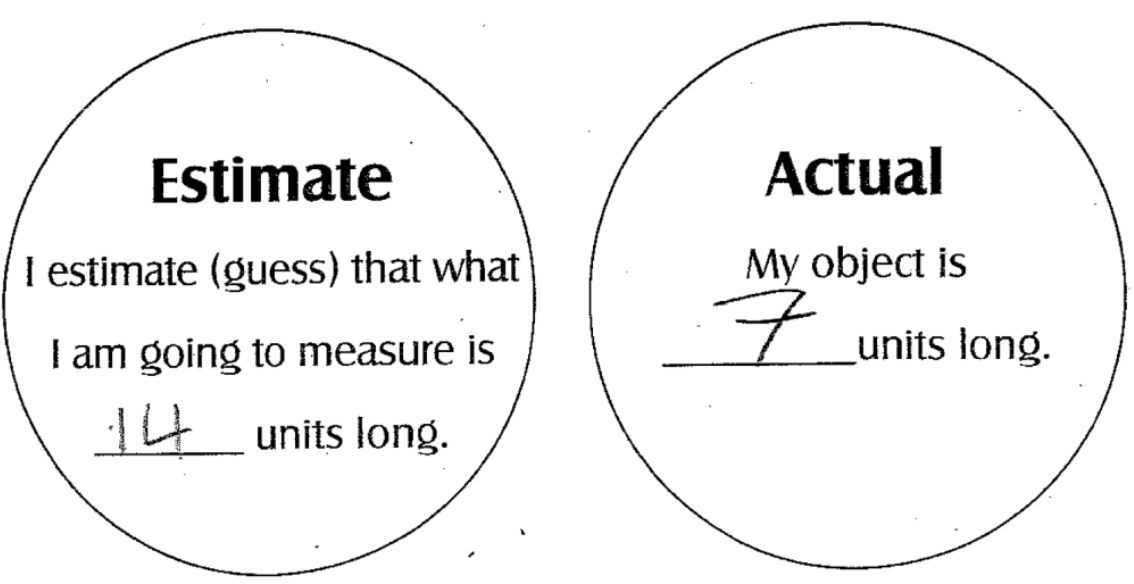

Write a math statement that explains the difference between the estimated and actual length of what you measured.

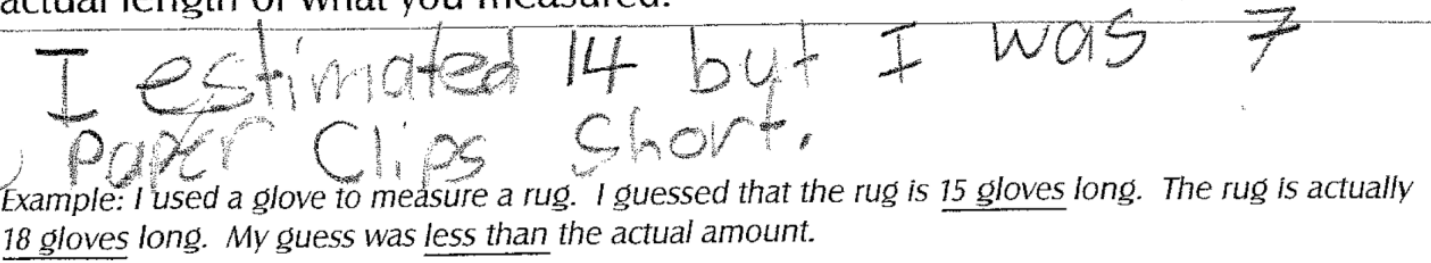




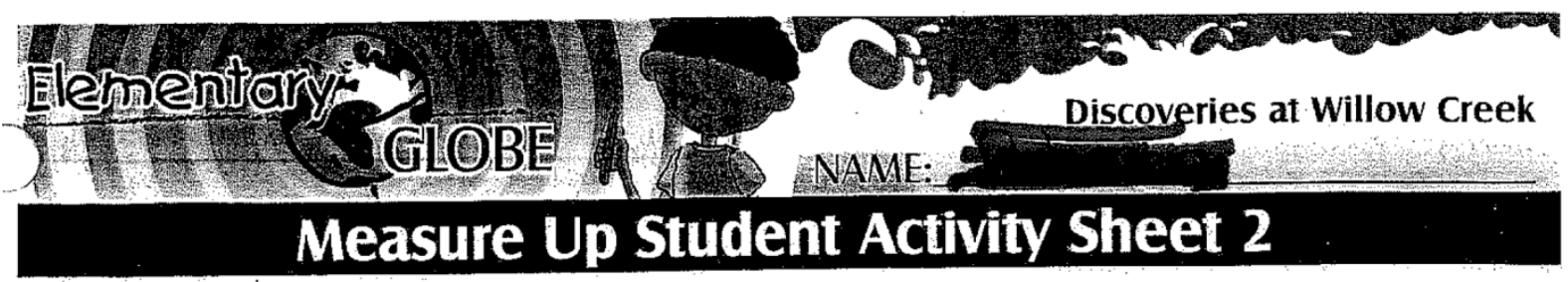

\section{Practice measuring with a ruler}

The object I will measure is a pencil

It was this long: $6 \frac{1}{2}$ inches

\section{How tall is that plant?}

)

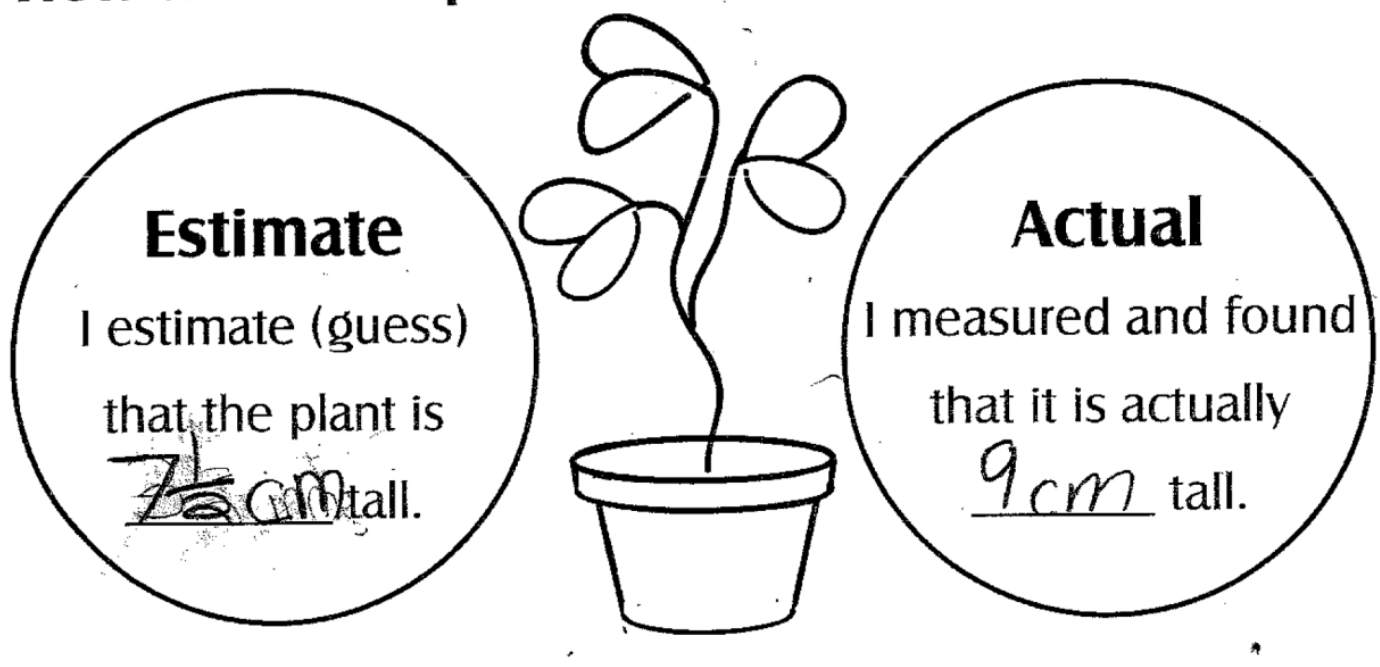

In the space below, write a math statement that explains the difference between your estimate and the actual height.

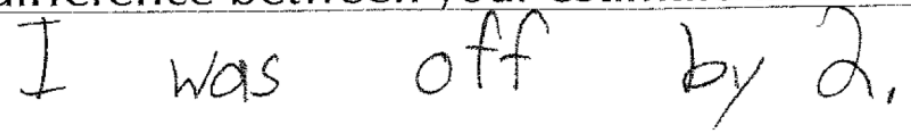


Appendix R

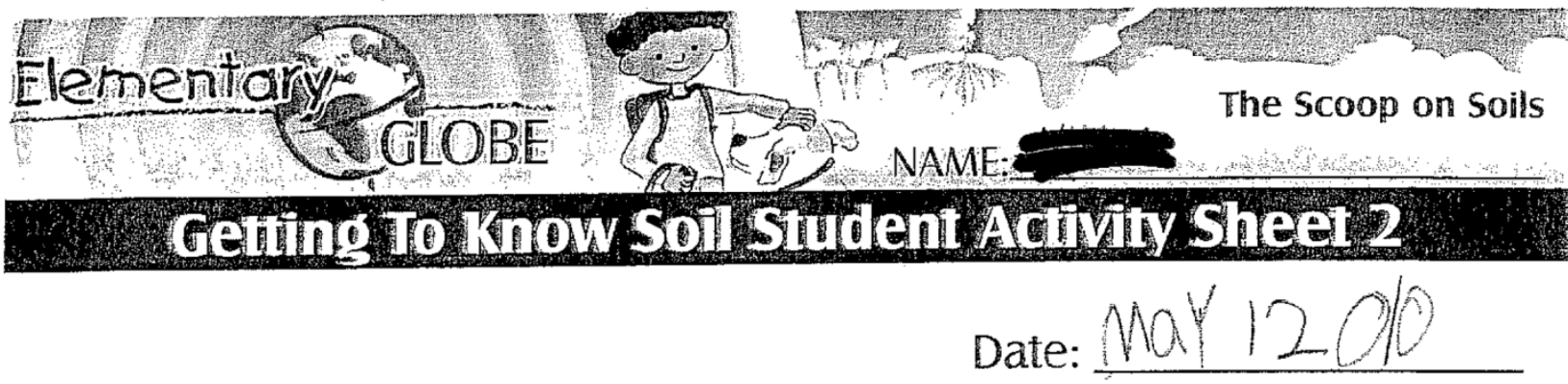

The soil in the jar looked like this after:

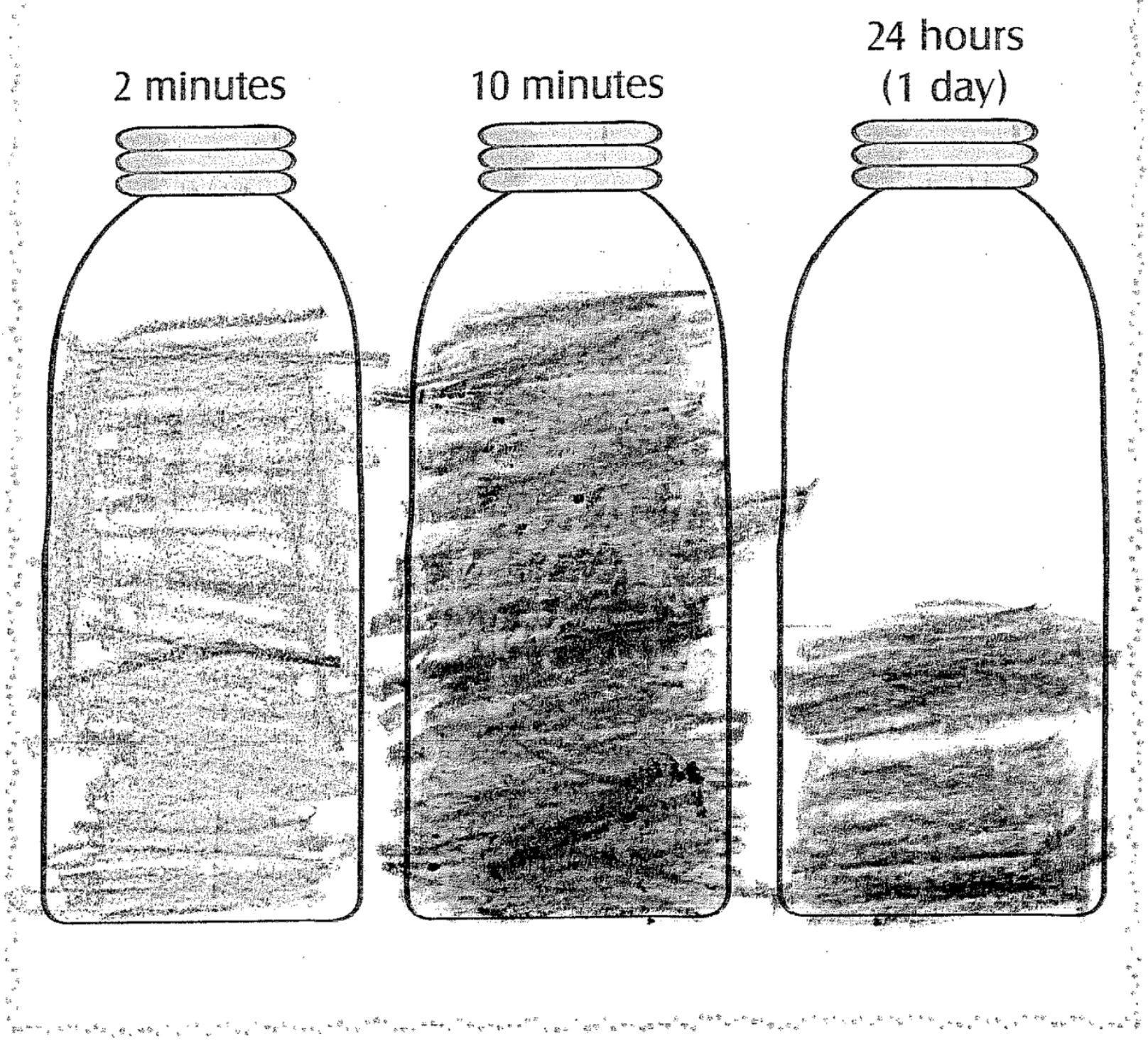


Appendix S

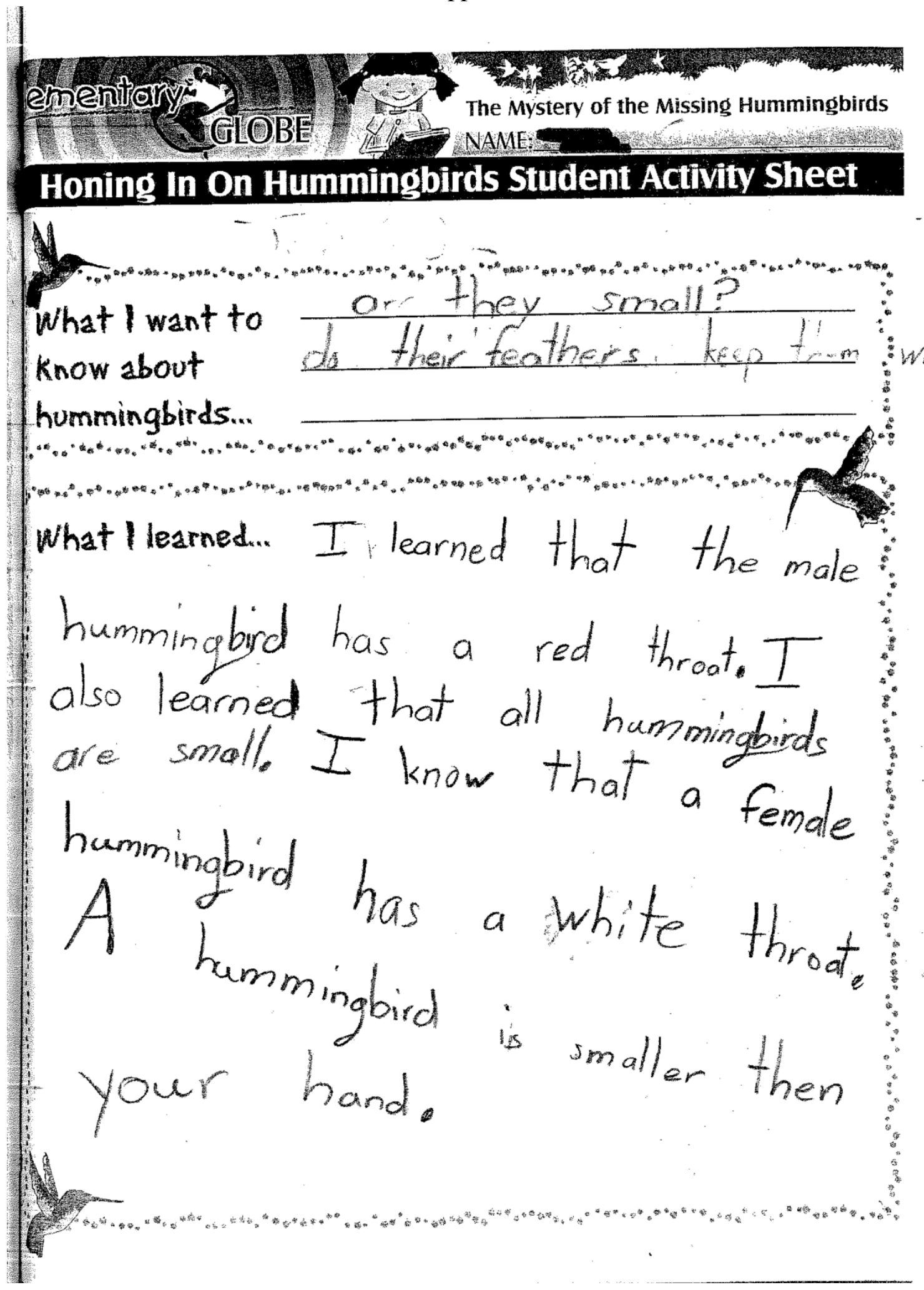


Appendix T
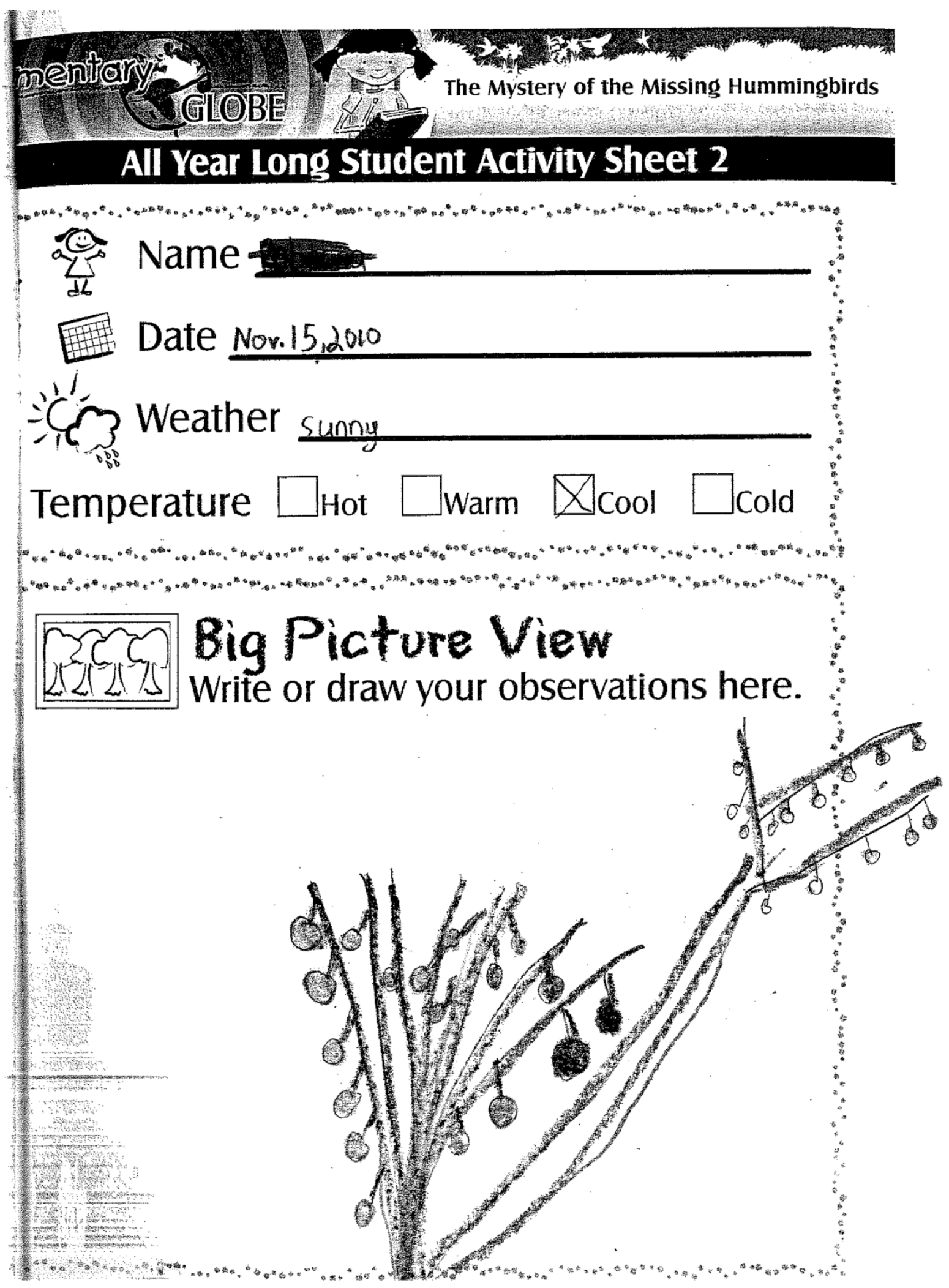
Appendix U

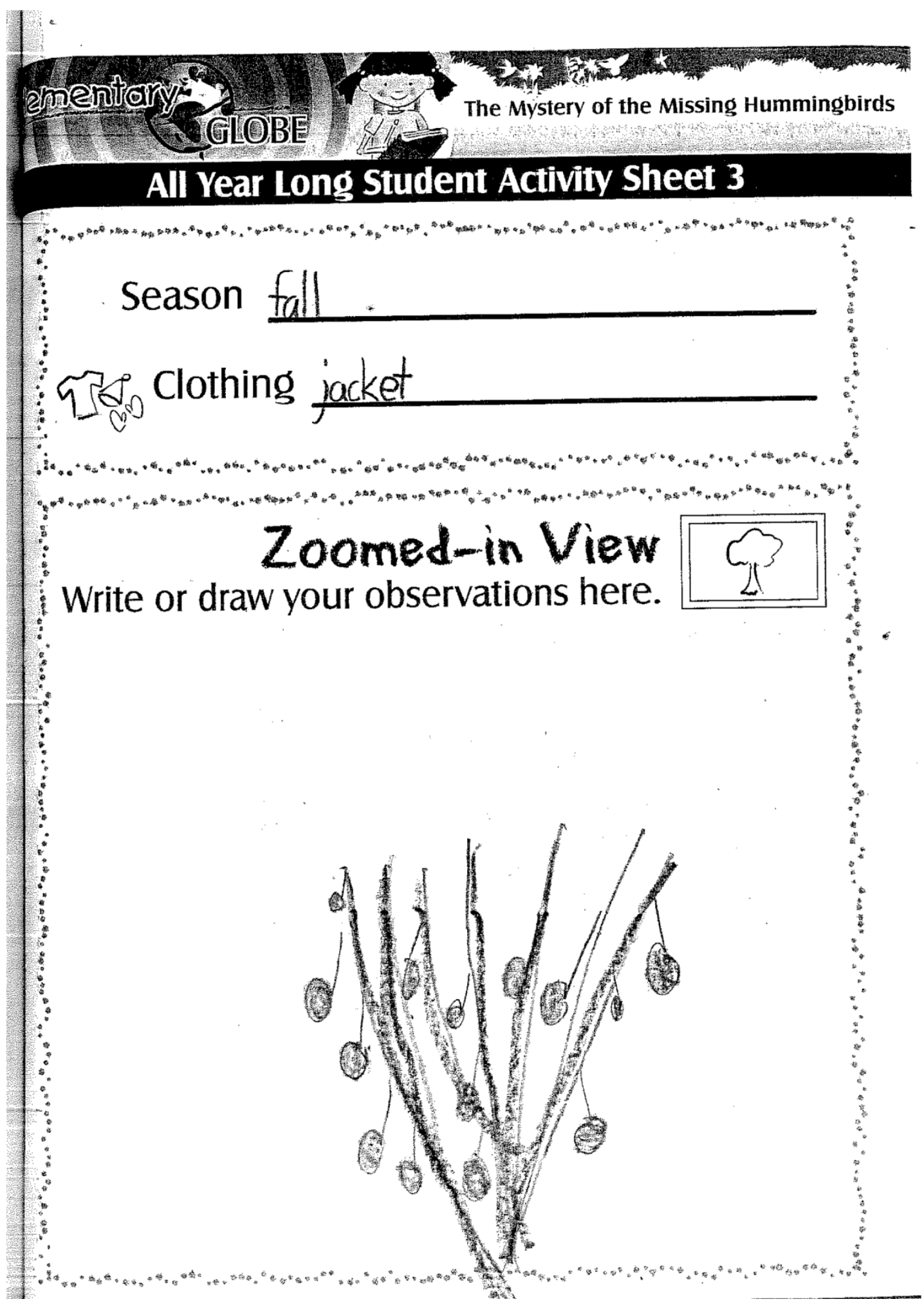


Appendix V

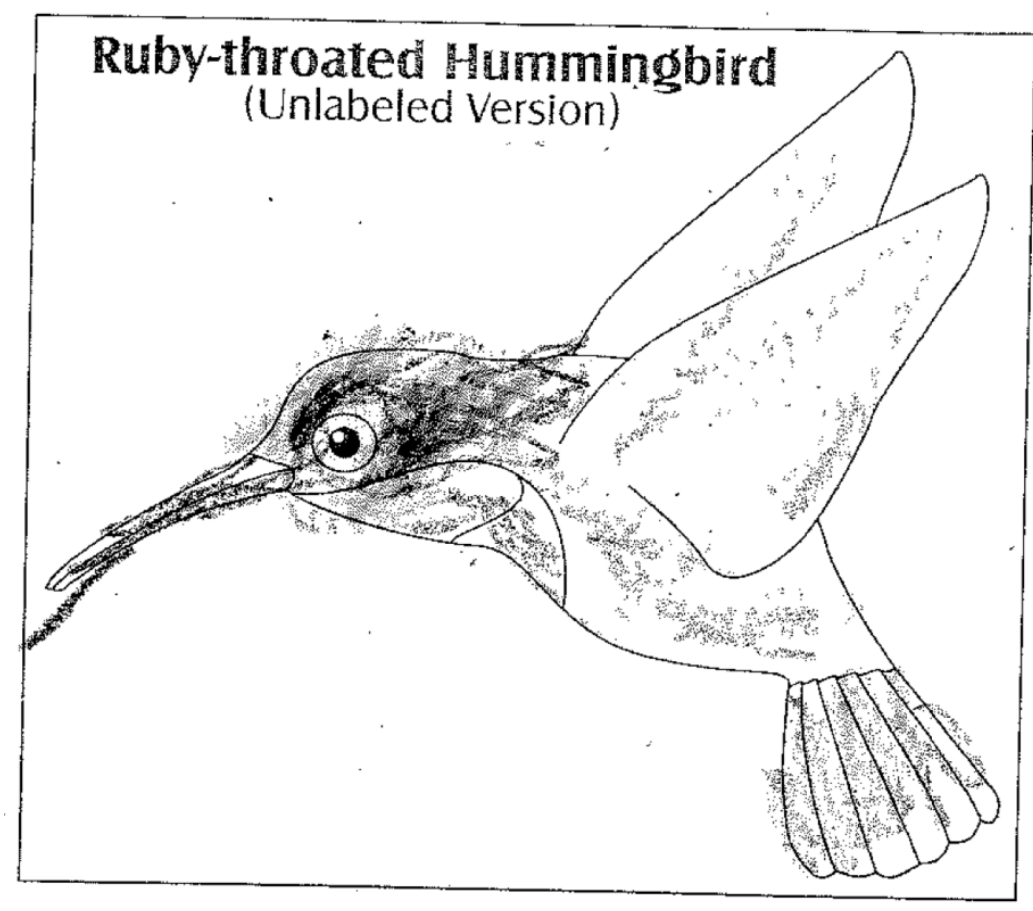




\section{Appendix W (page one of three)}

It is December 15 and I am with Allison at North, second grade. Interview \#2.

You can quit anytime you wish. Your participation does not affect your teaching position and you do not have to answer all the questions. Once I transcribe the tape, the tape will be erased, the transcription will be destroyed after it's been analyzed. Your name will not appear on any of the documents. While I interview you I may also write some things down in my book. This is just to remind me where I am in asking the questions. Is that ok with you?

A: $\quad$ Yes

Q \#1 What were your thoughts and impressions about using elementary GLOBE in the classroom?

A So far I really like it. My kids like it and enjoy the story. The hummingbird, getting to make it and the fact of the exact size but it was really neat.

Q \#2 Please tell me how your science teaching with elementary GLOBE has gone since last time we talked?

A: $\quad$ Great. We have done some more seasonal things outside and did the hummingbird lesson. I think I am getting better at it and learning a little more as I read the materials. The kids seem to be enjoying it.

Q \#3 When using the elementary GLOBE curriculum, how did using the GLOBE Kids affect the learning environment of the classroom?

A: $\quad$ It helped them understand it better and it was nice that it came from other kids like in the story and it was a classroom that kids could relate to it.

Q \#4 Is there anything that you would do differently when teaching science to your students in the future?

A: $\quad$ Yes. I hope to use stuff just like this in the future. Literature that connects to it like that and hands on things that really sticks with them.

Q \#5 How could you have improved your students' understanding of environmental issues?

A: $\quad$ I think getting them involved in things and just doing things hands on and researching things on the computer and seeing that these things are really happening. This is what people are doing. 
(page two of three)

Appendix W

Q \#6. Describe the changes that you observed in your classroom while using elementary GLOBE.

A: $\quad$ They seemed to understand it more where it sticks with them. Not just reading a text and writing it for a test. It is more relating to it and they remember it and store information. I think they pay attention better. It was a long story but it kept their attention.

Researcher Can you think of anything specifically that would indicate or remind you they did remember it longer?

A: Just them talking about it. Like I hear them discussing the hummingbirds and they remember the names of it. I heard them talking about it today. Just a few of them. Then the seasons, any questions that I ask they remember them. Beginning of fall, what it was like.

Q \#7 How could you have improved the effectiveness of elementary GLOBE when teaching about global warming and related issues?

A: Just community projects or maybe a class project.

Q \#8. How much teacher training do you think should be required to teach elementary science?

A: I don't know how much. More than what's offered. Professional development classes to get more ideas. Because we go to all these conferences for reading. I think we should do it with science too.

Q \#9. What are the teacher's limitations on getting their students to understand science in elementary school?

A: $\quad$ It is all textbooks and they don't learn it unless they are out seeing it and doing it. It helps that we can show them on the computer. It would be nice to have things outside where they can do it or even materials for them to plant things. Just too hard just from a textbook. They can't get it. I try to act it out but.

Q \#10. What is the role for the school in promoting science in elementary school?

A: It is up to the teacher what they do. We are basically giving them the textbook. I don't know that the school has a huge role. They just expect us to take out the text and handle it ourselves.

Interviewer: What kinds of things would you like to see the school administer or support? 
A: $\quad$ Like materials? My class created habitats. It was up to me or my students to bring stuff in which a lot of times they don't and I have to buy things. Like planting, we are going to do something with that. Like I will have to buy whatever. If they would just provide me science materials. That would be great. WE would start with a science kit but then you start to run out. We do have some things they do provide.

Q \#11. How do you deal with the barriers of teaching science in elementary school?

A: $\quad$ Try to make it. Doing hands on activities. Another teacher and I made some science lessons with powerpoint which is a little better than reading from the book. The kids enjoyed that learning and doing their own activities.

Q \#12. How important is the relationship of the elementary school in working with a nearby Professional Development School for teaching elementary science?

A: $\quad$ I think it is really important because WVU has a lot of access to things that obviously schools don't in their program. They donated things and I think they help out.

Q \#13 Since using elementary GLOBE how have you been impacted in the classroom?

A: $\quad$ When I see them interested and enjoying something like they do, so far in every activity we have done, that makes me feel good.

Q \#14 What exposure should preservice teachers have to elementary GLOBE before being place for their internships?

A: Well definitely have read it and maybe have someone go over some of the things with them. This is what you do. These are teacher things you should know before you teach it. Obviously someone to go over it with them or just them to read it. But I think it would be good to have them do one of the lessons or set one up.

Q \#15 When teaching elementary GLOBE, how many ways did you find to integrate the lesson with other courses taught at your school?

A: $\quad$ The GLOBE Kids obviously integrates into reading. By putting it up on the white board for them to see then that helps them and they are reading it too even though they don't realize it.

Language arts.

A: $\quad$ Then social studies which is geography with the hummingbirds where they are and where they go.

That is all the questions. Is there anything you want to add?

A: $\quad$ No. Thank you very much. 
(page one of twenty- three)

\author{
Appendix X
}

\title{
Coding for RQ1
}

\section{Category 1}

TIME:

- $\quad$ can with time have (Mary interview one)

- $\quad$ would say time (Alicia interviews one)

- $\quad$ takes a lot of time (Peter interview one)

- $\quad$ time with kids because you only get 30 minutes/day (Mary interview three)

- $\quad$ I think is always resources and time. (Sterling three)

- $\quad$ We have science from 9-9:50 and then to go to specials so any day we are doing a lab it gets stopped and they have to move on and they have to come back and that always interrupts the flow of things so that is another barrier. (Sterling one)

- $\quad$ It is time management for teacher how to balance the science CSOs. (Linda two)

- $\quad$ For a lot of teachers I think it is a time issue. (Linda one)

- $\quad$ Can’t find time with all these pressures on us like reading/ writing. (Alicia two)

- $\quad$ I try to do my best by planning ahead for all eight classes every day and it is kind of overwhelming. (Amy three)

- $\quad$ we are trying to get more science time (Sterling three)

- $\quad$ You have to find time to do all these things and unfortunately science and social studies are being pushed to the back burner instead of being stressed more with our field becoming smaller and smaller because of the technology, actually we need to be stressing science more than what we are instead of limiting it. (Peter one)

- $\quad$ limitations with class time, that is main thing. (Peter third)

- $\quad$ The amount of time you have with each kid it is hard to go in depth with some of the subjects or topics that you really want to. (Mary two)

- $\quad$ I say oh because Elementary Globe is very good for doing that. Time limits and all kinds of things. (Alicia two) 
(page two of twenty- three)

- $\quad$ There is a press for time so skim over the reading and look at the pictures and try to do as much hands on.(Allison one)

\section{Category 2}

\section{TEACHER TRAINING:}

- $\quad$ just because I am trying to find ways to use science and nature in math and reading and writing so they become more knowledgeable... (Alicia interview one)

- $\quad$ our training and background is more hands on (Linda interview two)

- $\quad$ just by willing to ask for help whether it is staff... (Amy two)

- $\quad$ I think it allowed the students to be engaged in a positive learning environment because they are so used to math, writing, reading. When I teach the GLOBE program. Even when I show them the story of the missing hummingbird book they get excited because they know we are doing science so I think it has allowed for a very positive environment. (Alicia two)

- $\quad$ I think based on what the teacher knows and what resources they have available and if they are willing to ask for them and not just say no we don’t have those. (Amy two)

- $\quad$ I think it is based on how well prepared or what the teacher knows to an extent they can expand the kid's lives and let them grow and ask questions and not just following along with whatever the text book says. (Amy three)

- $\quad$ Elementary GLOBE good for doing that (Alicia two)

- $\quad$ so I think the training is to say yes you can do both. (Linda two)

- $\quad$ it'll come with the more often I use it...(Sterling one)

- $\quad$ It is more of an inquiry based format than our texts book is and it goes more in depth to what we already have. (Linda two)

- $\quad$ I though it wonderful because I didn’t have to create a lesson plan. (Amy one)

- $\quad$ instead of just using the text book and things XYZ County wants us to use. (Mary one)

- $\quad$ because it seemed like a lot of materials that I did not necessarily have but after we got the supplies, it ended up being a lot of fun. (Sterling one)

- Well to teach it effectively I don't think you are going to need a lot of training if you are just going to teach straight from the textbook but I think if you are going to do hands on activities that make it relevant to the kids, I think they definitely need at least one 
(page three of twenty- three)

methods class that works on doing activities and having the kids getting comfortable making predictions and things like that so I would say at least one full semester of nothing but a science methods class. (Peter two)

- $\quad$ I was able to present it in a more interesting way than the textbook. (Sterling one)

\section{Category 3}

\section{OUTDOORS:}

- $\quad$ just having what we need out there to teach them because you need to do hands on (Allison interview three)

- $\quad$ We went outside and dug in the soil and looked at what was in the soil after we had done that project. (Mary two)

- $\quad$..lot of things when we were digging, they found a lot of trash and that led to a conversation that kind of went back to the textbook a little bit more but we didn't look at it globally per se as we could have connected it to. (Sterling one)

- $\quad$ We always catch spiders and bugs. I don't want to step on them. We take them outside. (Linda one)

- $\quad$ Going outside first of all they loved going outside and just making them believe they are scientists on a mission to complete an activity and they are in their own world when they are out there. (Alicia one)

- $\quad$ Students are more aware of the outdoors and the weather. (Alicia two)

- $\quad$ I think it has to do with being outside again and then coming back in and transferring into the hands on and you could this in their faces they could see more than just this one type of cloud. (Amy one)

- $\quad$ I think just bringing more to real life with things that we can do outside of the school. Going on nature walks and having accessible like bringing in things. (Amy three)

- $\quad$ I think taking them a little more outside. Just making them more aware of some of the environmental issues. (Peter three)

- $\quad$ Actually I am surprised at how easy it is to take the kids outdoors if you have the right school environment. (Peter three)

- $\quad$ I like doing the outside stuff. If they see it, I need to see things too. (Allison one) 
(page four of twenty- three)

\section{Category 4}

TEXTBOOK DISLIKE (including no curriculum)

- $\quad$ Another teacher and I made some science lessons with PowerPoint which is a little better than reading from the book. (Allison two)

- $\quad$ It gives me another way to get away from just our regular textbook. (Mary two)

- $\quad$..I don't have a science curriculum so this GLOBE curriculum is all I am using. (Alicia one)

- $\quad$ Actually this year I have not used the... (Linda two)

- It seems that they get a lot more out of what I was teaching then if we weren't using it, [and if] I was just using the book or just showed a video or explained it. (Mary two)

- If they are just using the textbook you have certain kids who have trouble with concentrating and paying attention when you are just reading it, they are not really interested but with that they are all very into looking at me, listening to the stories. Really when the activities, they are all doing that, no fiddling around. [sic] (Allison one)

\section{Coding for journals}

\section{Category one}

OUTDOOR RESOURCES (access to green space)

- $\quad$..took the kids outside to observe and draw (Allison journal 10/7/10, p.1)

- $\quad$ The students enjoy being outside and learning in such a way. (Allison journal 10/7/10, p.1)

- We went outside to observe fall now that the leaves have all changed and some trees have no leaves. The students remembered what to do and had a great time working and learning outside (Allison journal, 11/2010, p.3.).

- I I can't wait for it to warm up outside to complete our season's lessons and do some and planting lessons (Allison journal 2/2011, p.11).

- COutside soon for our spring season lesson.” (Allison journal 3/2011, p.7)

- $\quad$ I decided the perfect lesson would be to take students outside for a science lesson (Alicia journal 10/1/10, p.1) 
(page five of twenty- three)

- $\quad$ The walk from the room to back parking lot, fresh air, and new environment was everything they needed. Students were noticing everything...cars in McDonald's Parking lot driving, a roof on a house hidden in trees, bees, signs, tall/short trees. They were very detailed. The pictures are great. It was like they were able to escape and express what they were seeing through their own eyes (Alicia journal 10/7/10, p.1).

- $\quad$...I took the students outside to complete the 'zoomed-in-view'. My kindergartners had a difficult gasping the idea of zoomed in. Some of them understood and only drew one object that the zoomed in on. Students loved going outside (Alicia journal 10/11, p.3).

- $\quad$ After doing this activity/lesson students are more aware of the clouds on daily basis. They have also tied in the weather factor for the clouds (Appendix M), which I think is great. Students enjoyed listening to the story that goes with the activity. These read alouds are engaging and very informative (Amy journal, no date, p.4).”

- $\quad$ To conduct the lesson, we went outside and sat and laid on the ground in a group and discussed what we saw. There was a discussion was a discussion about the diff kinds of clouds (Appendix M), incl. several all contrails (Linda journal 4/10/10, p.3).”

- $\quad$ In the afternoon, we split into pairs and took shovels and a baggie into wood by the school. Kids dug, excited by the prospect of worms and plants and insects they saw in the soil (Linda journal (Linda journal 5/13/10, p.9).”

- $\quad$ Students went outside w/a pencil, paper, board to write on and "binoculars." They sketched in each box as they saw the color. They were surprised at some of the colors they saw that they didn't think they'd see (Linda journal 10/18/10, p.17).”

- $\quad$ The students were so proud of their bags of soil. They were enjoying sharing what they dug up. I've never seen kids so excited about soil (Mary journal 4/29/10, p.3).

- $\quad$ I decided to take my students on a nature walk. I gave each student a plastic bag. The only rule was that their items had to fit in the bag. The students had a blast collecting items. They found rocks, flowers, bugs, cat tails, and turtle (id eastern box turtle by investigator). I thought it would be neat to take the turtle to our class. The students were so proud. We kept it in our class for the day. The students had a chance to write about the items they found and share them with the class (Mary journal no date, p.7).

- $\quad$ I think students enjoy leaving the school grounds and know they must behave for this to continue (Peter journal p.1)

- $\quad$ Students liked outdoors. (Peter journal, p.9) Manipulatives are very important is one observation! Students realized their placement of drawings had changed over time "Some 
(page six of twenty- three)

good questions were asked about what some of the items were and why they didn't see them last time (e.g. honey locust pods) (Peter journal, p.12).”

- $\quad$... students excited about going away from school for activity, Big View (Peter journal, p.14)

- $\quad$... zoomed in view discoveries included cicada exoskeleton, seed pod, feathers (Peter journal, p.14)

- $\quad$ Great day for outdoor science, not quite as hot with few clouds (Peter journal, p.18).

- $\quad$ Both classes this year seemed better prepared and more interested in actually doing the assignments while we're outside (Peter journal, p.18).

- $\quad$ Overall very productive outdoor lesson. Students thrilled that they discovered something on their own (Peter journal, p.20).

- $\quad$ They were SUPER excited to go outside so they were on their best behavior. I had only planned on being out for about 15-20 min. After all...how interesting is digging? Well apparently it is very interesting! They walked all over the hill to dig small and peek at the ground before they settled on where they would take their sample (Sterling journal 5/10/10, p.9).

- $\quad$ Sandy has all of the students with Autism, so I have to approach digging and going outside differently than did with my group. I will have to talk to the autism teacher for suggestions. We have used more streaming videos with Sandy's class than mine. They are more visual learners (Sterling journal 10/10/10, p.29).

- $\quad$ Digging day was very similar to my class. Because it is bit colder, they were slightly disappointed that they did not find as many spiders as my group, but they did find many other critters (Sterling journal 10/10/10, p. 34).

\section{Category two}

TIME

- $\quad$ If and when I do it again, I would like to read half the book one day and the other half another day. It would also give us more time research(Allison journal 12/2010, p. 4).

- $\quad$ I wish that we had more time to do science in school. I think the students really have enjoyed and learned from the GLOBE curriculum. The GLOBE is very easy to adapt and incorporate multi subject areas (Amy journal, no date, p.8). 
(page seven of twenty- three)

- $\quad$ I didn't take enough time in the planning and didn't take into account the developmental issues my kids would have with it. I'll be anxious to teach it again next year w/a different approach (Linda journal 3/8/11, p.21).

- $\quad$ The students really enjoy this but I never really had enough time. I'm always rushed to have all the students come back and don't get to discuss as much as I would like. (Mary journal, p.15, no date)

- $\quad$ Next time we will have bags of supplies pre-made so that each group has all of their materials and we don't waste time passing them out (Sterling journal 11/10/10, p.39)

\section{Category three}

\section{ACCOMMODATION}

- $\quad$ I took 10 students; we had our clipboards, pencil, and 'big picture' journal page. The kids were so quiet and engaged. I was amazed. They went from being wild and disruptive to...eager to learn quiet students (Alicia journal 10/7/10 p.1).

- $\quad$...for SPEDs I’d have a template next time (Amy journal, no date, p.1)

- $\quad$ I wish that we had more time to do science in school. I think the students really have enjoyed and learned from the GLOBE curriculum. The GLOBE is very easy to adapt and incorporate multi subject areas (Amy journal, no date, p.8).

- $\quad$ Good conversations, but recording was difficult - didn’t really have vocabulary to compare, but definitely could see differences in the soil and when the prompted cold articulate. Loved the lesson-very engaged, virtually no discipline problems (Linda journal 5/12/10, p.7).

- $\quad$ This was hard for K students to completely grasp, although they had good bit of drawing on their "B" page and less on the "Z" (Linda journal 9/2/10 p.15).

- $\quad$ Kids really did not connect change in colors to change in season - however, because they had no pre-conceived notion that winter should be "gray." They predicted and found red berries, "purplish" rotting leaves, etc. (Linda journal 10/18/10 p.17).

- $\quad$ I didn't take enough time in the planning and didn't take into account the developmental issues my kids would have with it (Linda journal 3/8/11, p.21).

- $\quad$ It's interesting the boys who are the biggest behavior problems in class were really into outdoor activities. They were actually helping out some of girls who were sort of holding back. Student (LD) had a good day (Peter journal, p.5).

- $\quad$... overall behavior was excellent (Peter journal 9/1/10, p.16) 
(page eight of twenty- three)

- $\quad$ Today I read the Scoop on Soil. I was honestly concerned that it would be to "babyish" for $4^{\text {th }}$ grade but they loved it! It is hard finding something that all 36 will sit and listen to, but it worked out well (Sterling journal 5/10/10 p.3).

- $\quad$ They were SUPER excited to go outside so they were on their best behavior. I had only planned on being out for about 15-20 min. After all...how interesting is digging? Well apparently it is very interesting! They walked all over the hill to dig small and peek at the ground before they settled on where they would take their sample (Sterling journal 5/10/10, p.9).

- $\quad$ Today we used the lab sheet to discuss soil samples. They thought it looked like it should be for little kids but they taught the rubbing part of the paper was interesting. They were surprised to see how many different colors they could see depending where on the hill they took the sample (Sterling journal 5/10/10, p.9).

- $\quad$ The students were able to pick their own partners (special ed students) for digging adventure today. Like last year was surprised at how entertained they were by simply collecting soil samples. They found a variety of bugs and tried to look them up on the internet. I remembered from last year that this would take a whole science period (time) so we will do the worksheet portion next week. I hope I can keep them out of the bugs this time. They are going to have to sit in the room a couple of days before we get to them (Sterling journal 9/10/10, p.23).

- $\quad$ Sandy has all of the students with Autism, so I have to approach digging and going outside differently than did with my group. I will have to talk to the autism teacher for suggestions. We have used more streaming videos with Sandy's class than mine. They are more visual learners (Sterling journal 10/10/10, p.29).

Today, I read Scoop book, not read the whole thing. I tried to use the white board to make sure they could all see and we were having technology issues.

I also wanted to make sure I provided pictures of poison ivy so the kids would stay away. I am also asking for a volunteer (Casey from my home town) to help me during the digging portion in case we run into problems (Sterling journal10/10/10, p.29).

- $\quad$ Mary and I decided it would be fun to collaborate w/ the cloud unit. Because our science times are different we are have (sic) to move our schedules around to make this work.

- $\quad$ Today, I am doing an interactive read aloud w/ cloud book (Sterling journal 11/19/10, p.35).

- $\quad$ Did read aloud. They were a bit overwhelmed w/ the scientific names of the clouds. This was not as well received as the soil aloud (Sterling journal 11/19/10, p.35).

- $\quad$ I personally though it was kind of boring also (Sterling journal 11/9/10, p.35). 
(page nine of twenty- three)

- $\quad$ Today we made cloudscapes (Appendix M) with $1^{\text {st }}$ grade. We made sure to pair my SPED kids with her gifted kids (Sara journal 11/10/10, p. 39).

- $\quad$ It was a bit crowded in the room but a lot of fun. All of the groups did really well! They worked together and were very respectful of each other's space. Next time we will have bags of supplies pre-made so that each group has all of their materials and we don't waste time passing them out (Sara journal 11/10/10, p.39).

- $\quad$ My guys were a little upset they couldn’t keep the model but they were excited to know that they will see them in the hallway (Sterling journal 11/10/10, p.39). 


\section{Closed Coding Used in Margins of Teacher Observations (notes)}

Code: $\mathrm{Ti}$ - time, management of, training

Code: Iq - inquiry, Mystery of the Missing Hummingbirds

Code: $\mathrm{Tt}$ - teacher training, resources, best practice

Code: Eg - engage

Code: Out - outside resources

Code: Int - integrate, journals, reading, art

Code: Fun - surprise, enjoy, excitement, insect discovery

Code: Test - vocabulary, language arts

Code: Hands - hands on, space resources

Code: Acc - accommodate, SPED

Code: OT - on task

\section{Coding for RQ2}

\section{Category 1}

TIME (merged with hands-on and integration impact):

- $\quad$..did not have to create a lesson plan. (Amy one)

- $\quad$ Can’t find time with all these pressures on us like reading/ writing. (Alicia two)

- $\quad$ it'll come with the more often I use it...(Sterling one)

- $\quad$ because it seemed like a lot of materials that I did not necessarily have but after we got the supplies, it ended up being a lot of fun. (Sterling one)

- $\quad$ I think it depends on what you have to use and what your resources are. With Elementary GLOBE you need a little bit of a background but just basic as in going to college classes and learning how to teach the kids and deal with them but if you are thrown a science book I think you need more guidance. (Amy one)

- $\quad$ our training and background is more hands on... (Linda two) 
(page eleven of twenty- three)

\section{Category 2}

\section{TEACHER BEHAVIOR:}

- $\quad$ I think it continues to make me think and planning of how to plan. Big idea at first and then to think inquiry based in all subjects instead of just handing it to them. (Linda interview three)

- We kind of carried it on over to our recess of the other times and they have done that on their own so that's been nice. It hasn't been a science thing. They have moved it across the day, throughout the day. (Sterling one)

- $\quad$ That didn't require them to read and get frustrated which was nice. I was able to present it in a more interesting way than the textbook. (Sterling interview one)

- I I think because it had multi steps to the task so the kids were seated for awhile and they were focused in their classroom and then they were outside and they go to get up and go outside. When we came back in it was hands on so I think because of meeting all the different senses and all the different learning styles it was really beneficial for them and for myself. (Amy one)

- $\quad$ That didn't require them to read and get frustrated which was nice. I was able to present it in a more interesting way than the textbook. (Sterling one)

- $\quad$ That is something more and they actually go out and see what we have and experience especially with the one where they go out and look around and here they have the seasons even all year around and go and say this season the flowers are dead and this season the flowers are blooming. What kind of animals, bugs and insects are around there so it is more hands on and they can physically see it, not just something they are reading in a book. (Mary three)

- $\quad$ our training and background is more hands on... (Linda two)

- $\quad$ it'll come with the more often I use it...(Sterling one)

- $\quad$ It is more of an inquiry based format than our textbook is and it goes more in depth to what we already have. (Linda two)

- $\quad$ I though it wonderful because I didn’t have to create a lesson plan. (Amy one)

- $\quad$ instead of just using the textbook and things XYZ County wants us to use. (Mary one)

- $\quad$ because it seemed like a lot of materials that I did not necessarily have but after we got the supplies, it ended up being a lot of fun. (Sterling one) 
(page twelve of twenty- three)

- $\quad$ I think it depends on what you have to use and what your resources are. With Elementary GLOBE you need a little bit of a background but just basic as in going to college classes and learning how to teach the kids and deal with them but if you are thrown a science book I think you need more guidance. (Amy one)

\section{Category 3}

\section{OUTDOORS:}

- $\quad$ With the GLOBE you need to have an area that you can safely get to be able to do these outdoor observations. (Peter one)

- $\quad$ just having what we need out there to teach them because you need to do hands on (Allison interview three)

- $\quad$ We went outside and dug in the soil and looked at what was in the soil after we had done that project. (Mary two)

- $\quad$.lot of things when we were digging, they found a lot of trash and that led to a conversation that kind of went back to the textbook a little bit more but we didn't look at it globally per say as we could have connected it to. (Sterling one)

- $\quad$ We always catch spiders and bugs. I don't want to step on them. We take them outside. (Linda one)

- $\quad$ Going outside first of all they loved going outside and just making them believe they are scientists on a mission to complete an activity and they are in their own world when they are out there. (Alicia one)

- $\quad$ Students are more aware of the outdoors and the weather. (Alicia two)

- $\quad$ I think it has to do with being outside again and then coming back in and transferring into the hands on and you could this in their faces they could see more than just this one type of cloud. (Amy one)

- $\quad$ I think just bringing more to real life with things that we can do outside of the school. Going on nature walks and having accessible like bringing in things. (Amy three)

- $\quad$ Actually I am surprised at how easy it is to take the kids outdoors if you have the right school environment. (Peter three)

- $\quad$ I like doing the outside stuff. If they see it, I need to see things too. (Allison one) 
(page thirteen of twenty- three)

\section{Category 4}

\section{STUDENT BEHAVIOR:}

- $\quad$ My kids were more engaged and more excited. They couldn't wait until the next day and they would come in and go outside. They couldn't wait until the next day to explore and do the soil. I just think they were really excited to see me. They knew that I talked it up so much they were so excited to do it. (Mary interview one)

- $\quad$ I try to make it as fun as possible so they enjoy it and don’t get turned off on it. I think it is very important for the kids to get science. (Mary one)

- $\quad$ If they are just using the textbook you have certain kids who have trouble with concentrating and paying attention when you are just reading it, they are not really interested but with that they are all very into looking at me, listening to the stories. (Allison one)

- $\quad$ Once we got outside once to do one of the activities, the kids were after it. They wanted to go outside again. I intra mixed the GLOBE program with our regular curriculum so we did a little from our textbook and then we would go outside and do some globe activity and they always wanted to go outside. (Peter one)

- $\quad$ I try to make it as fun as possible so they enjoy it and don't get turned off on it. I think it is very important for the kids to get science. (Mary one)

\section{Category 5}

\section{ACCOMODATION:}

- $\quad$ That didn't require them to read and get frustrated which was nice. I was able to present it in a more interesting way than the textbook. (Sterling interview one)

- $\quad$ I think because it had multi steps to the task so the kids were seated for awhile and they were focused in their classroom and then they were outside and they go to get up and go outside. When we came back in it was hands on so I think because of meeting all the different senses and all the different learning styles it was really beneficial for them and for myself. (Amy one)

- $\quad$ I have the collaborative room so a third of the kids are special needs and learning disabled in reading is a tricky thing so it was nice to have the read aloud even though I didn't do as well as I think I should have. That didn't require them to read and get frustrated which was nice. I was able to present it in a more interesting way than the textbook. (Sterling one) 
(page fourteen of twenty- three)

\section{Category 6}

\section{TEACHER BEHAVIOR:}

- $\quad$ I think it continues to make me think and planning of how to plan. Big idea at first and then to think inquiry based in all subjects instead of just handing it to them. (Linda interview three)

- We kind of carried it on over to our recess of the other times and they have done that on their own so that's been nice. It hasn't been a science thing. They have moved it across the day, throughout the day. (Sterling one)

- $\quad$ That didn't require them to read and get frustrated which was nice. I was able to present it in a more interesting way than the textbook. (Sterling interview one)

- $\quad$ I think because it had multi steps to the task so the kids were seated for awhile and they were focused in their classroom and then they were outside and they go to get up and go outside. When we came back in it was hands on so I think because of meeting all the different senses and all the different learning styles it was really beneficial for them and for myself. (Amy one)

- $\quad$ That didn't require them to read and get frustrated which was nice. I was able to present it in a more interesting way than the textbook. (Sterling one)

- $\quad$ That is something more and they actually go out and see what we have and experience especially with the one where they go out and look around and here they have the seasons even all year around and go and say this season the flowers are dead and this season the flowers are blooming. What kind of animals, bugs and insects are around there so it is more hands on and they can physically see it, not just something they are reading in a book. (Mary three)

- $\quad$ our training and background is more hands on... (Linda two)

- $\quad$ it'll come with the more often I use it...(Sterling one)

- $\quad$ It is more of an inquiry based format than our textbook is and it goes more in depth to what we already have. (Linda two)

- $\quad$ I though it wonderful because I didn’t have to create a lesson plan. (Amy one)

- $\quad$ instead of just using the textbook and things XYZ County wants us to use. (Mary one)

- $\quad$ because it seemed like a lot of materials that I did not necessarily have but after we got the supplies, it ended up being a lot of fun. (Sterling one) 
(page fifteen of twenty- three)

- $\quad$ I think it depends on what you have to use and what your resources are. With Elementary GLOBE you need a little bit of a background but just basic as in going to college classes and learning how to teach the kids and deal with them but if you are thrown a science book I think you need more guidance. (Amy one)

\section{Coding for RQ3}

\section{Category 1}

TIME MANAGEMENT (difficult):

- $\quad$ I try to do my best by planning ahead for all eight classes every day and it is kind of overwhelming. (Amy interview three)

- $\quad$ Just make sure they clearly understand. I think I rushed a lot or I feel I need to rush a lot. (Mary interview three)

- $\quad$ we only have one class (Mary interview one)

- $\quad$ Unfortunately I see it being stressed less and less because of the testing we are doing now or the accountability. (Peter interview one)

\section{Category 2}

\section{TEACHER TRAINING (difficult):}

- $\quad$ Professional development classes to get more ideas. Because we go to all these conferences for reading. I think we should do it with science too. (Allison interview two)

- $\quad$ More than what's offered. Professional development classes to get more ideas. (Allison interview two)

- $\quad$ Well to teach it effectively I don't think you are going to need a lot of training if you are just going to teach straight from the textbook but I think if you are going to do hands on activities that make it relevant to the kids, I think they definitely need at least one methods class that works on doing activities and having the kids getting comfortable making predictions and things like that so I would say at least one full semester of nothing but a science methods class. (Peter interview two)

- Just knowing what is going on environmentally. I think planning ahead. (Amy interview three) 
(page sixteen of twenty- three)

- $\quad$ think I rushed (Mary interview three)

- $\quad$ You know we only have to have one class. I think for some teachers it doesn't matter because they don't teach science but I am a science teacher so I wouldn't have minded having another class on science just to get more ideas and get a better way of teaching it besides just using the curriculum they give us. (Mary interview one)

\section{Category 3}

TEACHER TRAINING (easy):

- $\quad$.. so with the GLOBE we can [go] outside and find the soil samples or we can go outside and look at the clouds that are doing whatever and it is nice because I do not have the materials and it is intimidating but they are easier to access from GLOBE then they are the specific ones the book has. (Sterling interview one)

- $\quad$ It is easy to do but right now I don't think that GLOBE can be your whole curriculum. There are so many other CSO's and things that aren't covered in there so I think GLOBE should definitely be included in that semester of methods but I don't think that by itself would suffice for training. (Peter interview two)

- $\quad$ I really think if they have a good mentor teacher in their school, I think the one semester of the science methods class for most students is enough to get them started because even with all the bookwork and the classroom you are just going to get there by doing it. I don't know if more classroom prep would make that much difference but I do know there are a lot of veteran teachers who do not like to do the hands on activities in science because as one of them told me once it doesn't always work. Actually you learn why it doesn't work and you try to figure out why and explain to the children that experiments are done many times not just once before they come up with a theory or a rule. (Peter interview one) (note: Jack and Jill Elementary has an effective mentor team for science teachers)

\section{Category 4}

Dislike book/current curriculum (easy)

- $\quad$ I wouldn't have minded having another class on science just to get more ideas and get a better way of teaching it besides just using the curriculum they give us. (Mary interview one) 
(page seventeen of twenty- three)

\section{Category 5}

Teaching behavior

- $\quad$ I am really glad we have GLOBE as a second source. (Mary interview one)

- $\quad$ I think that class taught me more about science then I learned through any other class at WVU. It was very hands on and me that is the most effective way to teach. (Alicia one)

- $\quad$ I think that not as much training but these types of materials in teacher's hands. These types of materials in a teacher's hands I think are affective. (Linda one)

- $\quad$ Maybe it is more a willingness to let go of the textbook. Instead of textbooks and work sheets make it more hands on. (Linda two)

- $\quad$ I hope to use stuff just like this in the future. Literature that connects to it like that and hands on things that really sticks with them. (Allison two)

- $\quad$ My plan because I really like the Elementary GLOBE because it has hands on it gives me ideas of things to do so it is easier for them to learn...(Allison three)

- $\quad$ I think just not take things for granted since they are just eight years old. Just be able to explain more thoroughly step by step and not assuming everyone can get it right away and taking more time through it. (Amy two)

- Just knowing what is going on environmentally. (Amy three)

- $\quad$ Explain things more to them. Realize that they don't already know, don't assume that they know more then what they do and take the time to explain. (Mary two)

- $\quad$ I need to know more. Like this year is the first year we done this and I feel it was more trial and error and we are winging it and I don't know what to expect. With the clouds particularly if we did it over time instead of having set weeks to do it that would have been easier because we really struggled getting outside because it rained I think that full week. I think that is how it changes, just be more prepared (Sterling three)

- $\quad$ I think it's given me a better format to plan my own lessons and have them more inquiry and hands on based. (Linda two)

- $\quad$ The change probably for me is that not giving away why you are doing what you are doing until they get their hands on it and figure it out as opposed to telling them at the start. (Linda three)

- $\quad$ Again I would focus on inquiry based and discovery based learning. (Linda three) 
(page eighteen of twenty- three)

\section{Coding for RQ4}

\section{Category one}

INTEGRATION (ease)

- $\quad$ Obviously integrating the writing in the journal. Along with that come the English and the grammar because you have to have capitals and periods in their writing. Even in their reading because they are listening to the story. The seasons you can tie that into our reading story which was about fall. (Allison one)

- $\quad$ The GLOBE kids obviously integrate into reading. By putting it up on the white board for them to see then that helps them and they are reading it too even though they don't realize it. Then, social studies which is geography with the hummingbirds where they are, and where they go. (Allison two)

- $\quad$ Then social studies which is geography with the hummingbirds where they are and where they go. (Allison three)

- $\quad$ I think it is easy to integrate into all of the subject areas with it. (Amy two)

- $\quad$ I think it was easy to integrate it because it opened for a variety of other classes with adding the math in it and adding the write so I think it was very easy to take one of the lessons and then integrate it throughout the day or throughout the unit actually with other classes too. (Amy three)

- $\quad$ For example I used the science journal as their journal writing for the day so they day we do science or a couple days later or something that week instead of their normal journal page I am able to use the journals from the GLOBE program (Alicia two)

- $\quad$ We integrated it with writing because when they finished a GLOBE lesson we would then follow up with the journal writing about their observations so we integrated it with writing and I would say use math as well talking about seasons and how many sunny days and how many cloudy days we had so math and writing. (Alicia three)

- $\quad$ The project that I used I could use it for reading because you have a story. Definitely science you could use it with math, even social studies because it is geographic different areas. You could use it definitely across the curriculum. (Mary one)

- $\quad$ The GLOBE curriculum worked well with our guided reading and literary stations. We actually found some books that went along with this cloud and weather unit. We didn't do the entire GLOBE unit lesson so we kind of mixed and matched it with our guided reading and literacy stations. (Sterling three) 
(page nineteen of twenty- three)

- $\quad$ I mentioned that earlier, already in just the last week we discussed this integration with language arts. In just that first lesson with the big picture and zoomed in view and then in relation to social studies as well so it certainly ties in, especially in language arts and then in math as well. We didn't get into a lot of that in the first module yet but we certainly will with measurements. (Linda two)

- $\quad$ We integrated it throughout the curriculum just that language of what the big picture and close up view meant and how to use it other than the obvious math and science we related it across the fields. (Linda three)

- $\quad$ It was very easy to integrate. Several of our leading stories have come up and they would be wait we did this in science or in math. A lot of times I would intentionally put math problems with our globe program. (Peter one)

- $\quad$ It can tie in with mostly anything. We will be reading a story and the kids will mention something they did with GLOBE and that is the same type of activity we did. Hummingbird comes up and they mention oh yes that was in GLOBE. They don't actually mention GLOBE but does say we did that in science. The measurement, comparing temperatures and things like that. Social Studies and mainly comes into current events. We talk about current events every morning and it is a good time there also. (Peter three)

\section{Category two}

\section{PARENT CONNECTON}

- $\quad$ I sent home a couple activities but most of them they keep in their science journals. It makes it nice because when we go to do a science lesson and they look back at what they have done they can reflect on that. (Alicia three)

- Just display them and we hang them up and they get to take them home and show their parents. (Amy three)

- $\quad$.. after we have done all the lessons that we planned to do, I send it home with them. (Allison three)

- $\quad$ The soil project, I have taken pictures of them digging and that sort of thing and I make copies of the photos for them so they can take them home. They get to take everything home at the end. (Mary three)

- $\quad$ Most of the things go home with the kids. I send home a weekly newsletter to the parents so the materials that go home I explain so the newsletter that go home with them on Friday explains what we have done so that helps the parents see a connection. I think it is important for kids to take those home. (Linda one) 
(page twenty of twenty- three)

- $\quad$ The journals we started this year from the beginning so it will be something they will use all year and then take home at the end of the year. What I plan to do because their drawings are so elementary, I plan to write an accompanying letter to the parents explaining what we had down throughout the year and what some of those pictures and drawings were to mean. (Linda three)

- $\quad$ I think the opportunity is there to make a really nice holistic science opportunity. I did not do that as much this year as I would like to do next year. I think the opportunity is there. The kids got a big kick of getting it all back together and got to take it home.( Peter one)

- $\quad$.. when we finish our last outdoor observation with GLOBE we bind them it all together and send them home so their parents can see what they have done. And it reinforces to the parents how important it is. (Peter three)

\section{Category three}

\section{COLLABORATION}

- $\quad$ I think it is really good to collaborate with other teachers. I am open for suggestions and learning about what they are doing whether it is science, math, reading or writing or social studies so I try to learn from them. (Alicia one)

- $\quad$ I have a couple teachers that I go to daily. Linda and Debbie is another one. (Alicia one)

- $\quad$ We displayed them in the hallways so the other kids could see them. I know at the first grade they were excited to do the projects and our guys upstairs being the mentors the other kids were able to see what we had done with the first grade and wanted to participate in that also. (Sterling three)

- $\quad$ Have a science committee or a little group who is going to meet every so often and share ideas of what they are doing. (Amy one)

- $\quad$ Something we talk about a lot. (Allison three)

- $\quad$ I have also talked to some second grade teachers about how they are implementing GLOBE. I haven't really talked to any teachers who aren't implementing Elementary GLOBE and are doing science in their room so as far as kindergarten goes. The GLOBE program is awesome to promote science. (Alicia two)

- $\quad$..a lot of other teachers here are as well so it encourages me to teach GLOBE and teach science because of the importance of it at North. (Alicia three) 
(page twenty-one of twenty-three)

- $\quad$ They are very supportive. They love having outsiders come in and help with that. They are supportive of the work we are doing. (Mary two)

- $\quad$ They are working more and more with WVU trying to get, of course we had the GLOBE now and I believe they are trying to get a garden started so they are trying to do as much as they can possible in helping us to integrate it. (Mary three)

- $\quad$ We are trying to align the curriculum a little bit closer using the same vocabulary across the grade levels so it is not like starting over every single time we do something. (Sterling one)

\section{Coding for RQ5}

\section{Category one}

OUTDOOR RESOURCE (includes garden)

- $\quad$ Oh well that would be great. We haven't got into the soil ones yet because it is not nice out but my class will be a part of that and hopefully we will have jobs. I have already thought of the hummingbird. I want to have a hummingbird feeder out there so they could see that. (Allison interview three 3/10/11)

- $\quad$ That is something more and they actually go out and see what we have and experience especially with the one where they go out and look around and here they have the seasons even all year around and go and say this season the flowers are dead and this season the flowers are blooming. What kind of animals, bugs and insects are around there so it is more hands on and they can physically see it, not just something they are reading in a book. (Mary interview three 11/17/10)

- $\quad$ The school garden would be nice with the soil's one because they could see what was going on where. The garden would get them outside more because they really enjoy that and we don't have any place here where they can really get their hands dirty or do anything. A lot of things are off limits. It would be nice to get them outside and give them ownership on their playground. (Sterling interview three 12/21/10)

- $\quad$ Lessons would be easily integrated from science from the GLOBE curriculum which is working and helping the environment knowing where the food is coming from that we are eating and then doing writing lessons, math activities with it and I think it would be easy to integrate all of the components, reading components and everything with the science then and I think kids don't understand because everything is really easy for us to get food and it comes from the store... (Amy interview three 3/31/11) 
(page twenty-two of twenty-three)

- $\quad$ Hopefully the attraction of birds and certainly a discussion about what I said earlier they don't see outside of what affects them but to see that dry weather affects the garden. You could certainly talk about acid rain is an issue here but you could talk about that sort of thing changes. When you talk about why something doesn't grow I think they can relate. (Linda interview three 12/16/10)

- If I could walk outside and have a garden here at North that would be amazing and the kids would appreciate it as well. Maybe some of them haven't ever been exposed to a garden and plants before as kindergarteners at home. Some of them might not even know how to plant a seed so I think that would be wonderful. (Alicia interview three 3/8/11)

- $\quad$..we want to set it up to be used with the soil unit so we can have different types of soil divided off and let different grades take care of different sections of the garden so we could use that with the soil section of the GLOBE curriculum so we do have a garden but it is very bad disrepair right now. (Peter interview three 12/3/10)

\section{Category two}

\section{PST TEACHING TRAINING WITH EG}

- $\quad$ Obviously someone to go over it with them or just them to read it. But I think it would be good to have them do one of the lessons or set one up. (Allison second interview $12 / 15 / 10)$

- $\quad$ I think they should have to go through the whole curriculum at the elementary level and do it hands one first. (Amy interview two 3/31/11)

- $\quad$ It be an advantage for them to have that exposure because maybe the teacher they are working with doesn't use GLOBE then they could get them started on it...(Alicia interview two 12/2/10)

- $\quad$ I would say a semester would be fine because now the schools here are using it. (Mary interview two 10/11/10)

- $\quad$ I think it should be definitely a part of the science methods class. Again even if they don't have the GLOBE curriculum in their hands to see how science has taught through them just the way it's taught gives you a way to think regardless of what textbook or what CSO's you are handed how to handle it. (Linda, 9/29/10)

- $\quad$ The more exposure the better but I think they should at least go through one of the lessons and actually practice teaches it including the reading of the story and doing the outdoor activities. (Peter interview three 8/5/11) 
(page twenty-three of twenty-three)

\section{Category three}

\section{EG PROMTES COLLABORATION}

- $\quad$ It would be nice to get them outside and give them ownership on their playground. (Sterling interview three 12/21/10)

- $\quad$ I am thinking of our last meeting. We were sitting at a table. I think there were six teachers there and that is not just full time teachers. Some of our reading interventionists. One of our academic coaches who was a teacher her last year. (Amy interview two $3 / 31 / 11)$

- $\quad$ For me it is the support and want to be handed the materials but the exposure to what the students are being taught. For me I think a part of it is the motivation and the excitement that the two provide. The support to say yes you are doing the right thing or here is some additional materials or the opportunity to pair with the pre service teachers and their willingness, their kind of untarnished view of sure we can try this. (Linda interview two 9/29/10) 


\section{Appendix Y}

\section{Initial Codes and Categories for Classroom Observations}

Environment (En): need to have area to do outdoor observations safely, lying outside to look up to draw clouds

Reading (Re): EG allows practice, scoop on soil, mystery of missing hummingbird, Willow Creek extensions

Time (Ti): $\quad$ pressed for time, time of activity paramount in training, have lab stations in all parts of room with accommodation, unscheduled assembly bumps science class; time for lunch used as break

Behavior (Be): engaged when hands on; high ontask behavior, students monitor other students task to get work done; class hums

Training (Tr): teachers need prep time and practice w/ EG, makes distinction between hibernate and migrate; when given hummingbird feeders not used properly, best practice

Outside (Ou): barriers are getting outside, hard finding places to take students, garden an option, we are going out changes student behavior; zoomed in view/big pix view, colors of season worksheet; tie in with fun; clouds have names story

Accommodate (Acc): use EG because have story; writing in journal; mentoring with more capable student; boy found rock IEP (autistic), different languages, nonreaders, 6 IRP in room; learning to students culture shift; diversity an issue with non Americans, SPED

Resources limited $(\mathbf{R l})$ : $\quad$ teachers need resources for science or provide themselves like cloud lab for EG; crayons science kits; need hummingbird feeder

Hands (Ho): playing with soil, examining w/ hand lens, do a better job than last year, little split open dandelion to draw; rubbing soil on paper; you can do this experiment at home; comparing size of hummingbird cut outs, science journals; difference between standard and non standard measurement; MOMH story cut outs; cloudscape investigation

Inquiry (Inq): inquiry observed in teacher practice, what will you find? How will soil look outside? This is a helicopter seed, see? Learning how to use open ended questions; how will your jar be different in 10 minutes; difference between male and female hummingbirds; teacher directs from seat not copying board; send question home with student; what do they eat; anyone want to make a prediction; do all hummingbirds have red necks; is it cold in Cost Rico contrast with PA; Willow Creek story used for questioning in $3^{\text {rd }}$ grade

Engage (Eg): coloring hummingbirds, cloudscapes, students on floor on newspapers examining soil, students amazed there was life in bag of soil after several days; boy found mag glass 
could burn holes; measurement non standard/standard; colors of season reading worksheet; mystery of missing hummingbird story cut outs; cloudscape investigation

Fun (Fun): $\quad$ skipping to dig, patty cake with soil samples, I love science, outside, student -fun having science outside; colors of seasons liked

Integration (Int): Willow Creek story, hummingbird story, parental support boy brings book on hummingbirds, math measure 